Issued by Sandia National Laboratories, operated for the United States Department of Energy by Sandia Corporation.

NOTICE: This report was prepared as an account of work sponsored by an agency of the United States Government. Neither the United States Government, nor any agency thereof, nor any of their employees, nor any of their contractors, subcontractors, or their employees, make any warranty, express or implied, or assume any legal liability or responsibility for the accuracy, completeness, or usefulness of any information, apparatus, product, or process disclosed, or represent that its use would not infringe privately owned rights. Reference herein to any specific commercial product, process, or service by trade name, trademark, manufacturer, or otherwise, does not necessarily constitute or imply its endorsement, recommendation, or favoring by the United States Government, any agency thereof, or any of their contractors or subcontractors. The views and opinions expressed herein do not necessarily state or reflect those of the United States Government, any agency thereof, or any of their contractors.

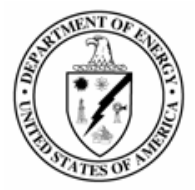


SAND2001-2100

Unlimited Release

Printed July 2001

\title{
Solar Power Tower Design Basis Document Revision 0
}

\author{
Prepared by Alexis B. Zavoico \\ Nexant \\ San Francisco, CA 94104
}

\begin{abstract}
This report contains the design basis for a generic molten-salt solar power tower. A solar power tower uses a field of tracking mirrors (heliostats) that redirect sunlight on to a centrally located receiver mounted on top a tower, which absorbs the concentrated sunlight. Molten nitrate salt, pumped from a tank at ground level, absorbs the sunlight, heating it up to $565^{\circ} \mathrm{C}$. The heated salt flows back to ground level into another tank where it is stored, then pumped through a steam generator to produce steam and make electricity. This report establishes a set of criteria upon which the next generation of solar power towers will be designed. The report contains detailed criteria for each of the major systems: Collector System, Receiver System, Thermal Storage System, Steam Generator System, Master Control System, and Electric Heat Tracing System. The Electric Power Generation System and Balance of Plant discussions are limited to interface requirements. This design basis builds on the extensive experience gained from the Solar Two project and includes potential design innovations that will improve reliability and lower technical risk. This design basis document is a living document and contains several areas that require trade-studies and design analysis to fully complete the design basis. Project- and site-specific conditions and requirements will also resolve open To Be Determined issues.
\end{abstract}


Design Basis Document 


\section{Contents}

\section{Design Standards, Material Properties, System Functional Descriptions, General}

Design Requirements, and Design Data ...................................................................13

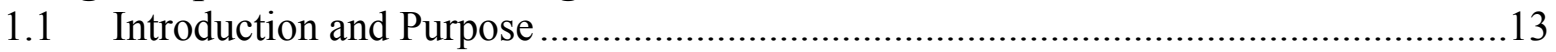

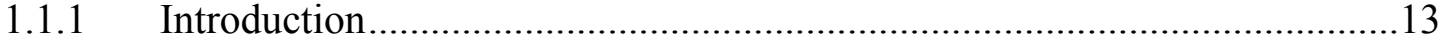

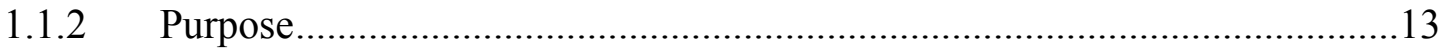

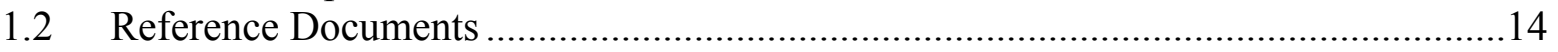

1.2.1 Design Codes and Standards................................................................. 14

1.3 Solar Power Tower Plant Functional Descriptions .............................................15

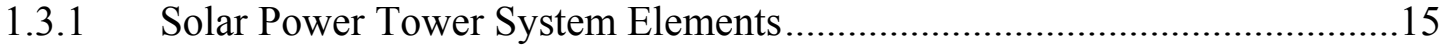

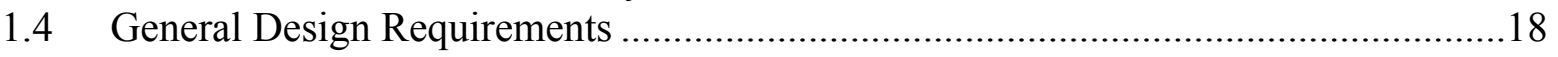

1.4.1 Solar Power Tower Plant Sizing Criteria............................................... 18

1.4.2 American Society of Mechanical Engineers Boiler and Pressure Vessel

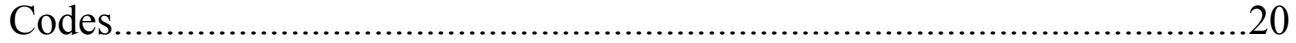

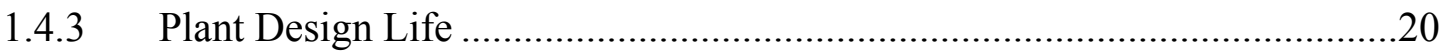

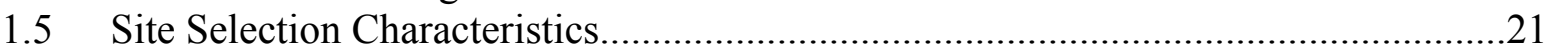

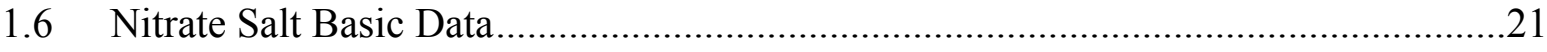

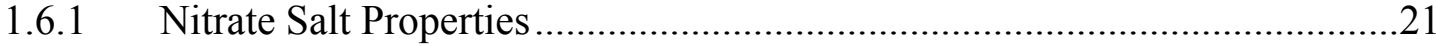

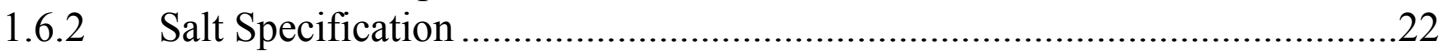

1.6.3 Fluid Nitrate Salt Property Formulas .....................................................23

1.6.4 Solid Salt Properties...........................................................................23

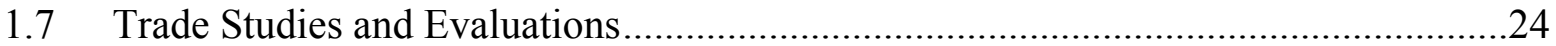

2. Operating States and Transitions ......................................................................................25

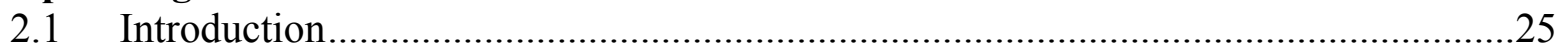

2.2 State and Transition Definitions - Energy Collection Section ..................................25

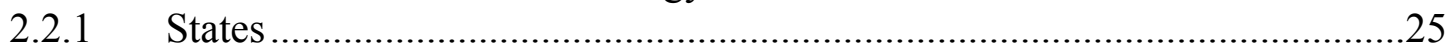

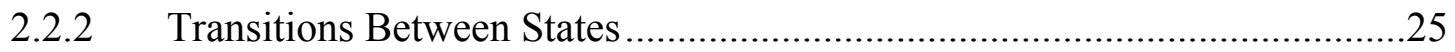

2.3 State and Transition Definitions - Energy Conversion Section ................................28

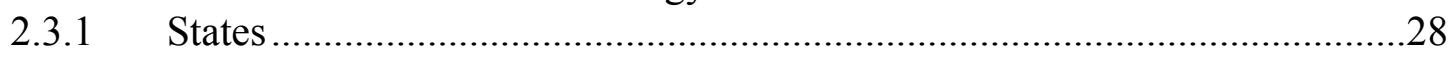

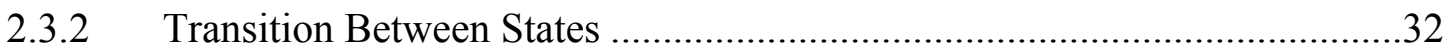

3. System Descriptions, Scope of Study, and Design Bases..............................................35

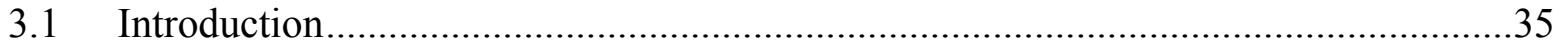

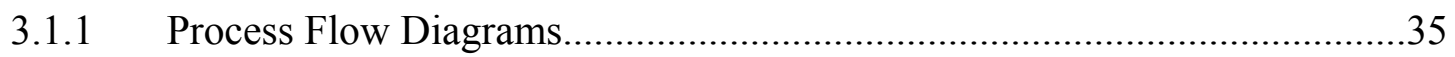

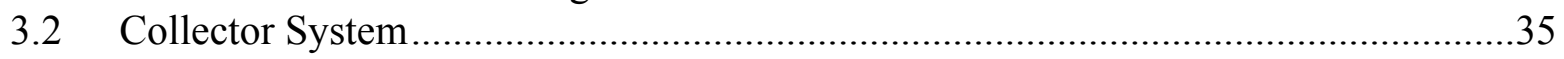

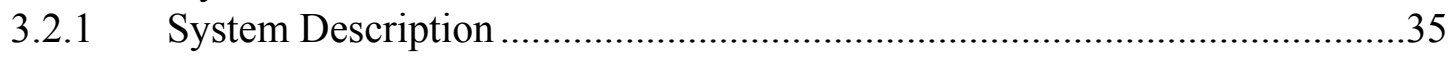

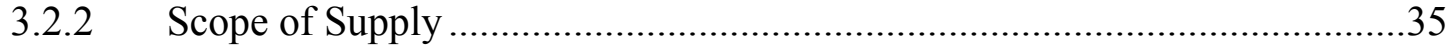

3.2.3 Field Communication Link Design Basis ..................................................55

3.2.4 Emergency Heliostat Defocus Design Basis ...........................................55

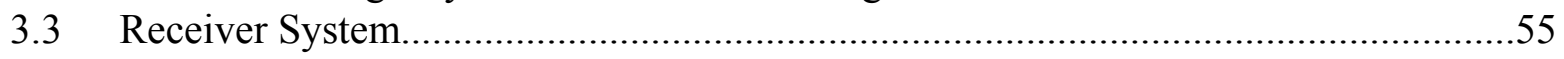

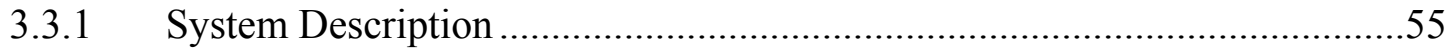

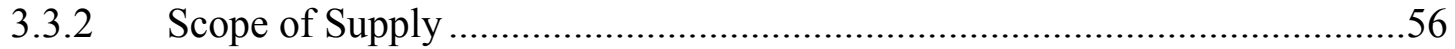

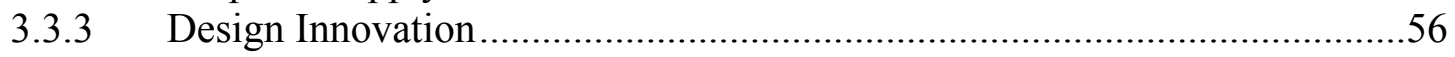

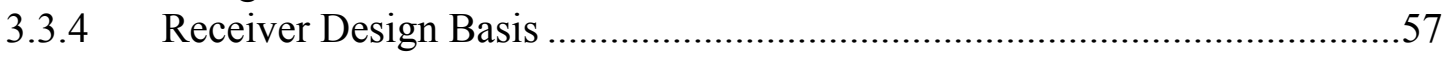

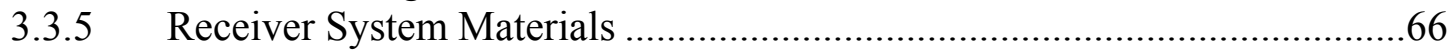


3.3.6 Receiver Inlet Vessel Design Basis .........................................................67

3.3.7 Receiver Outlet Vessel Design Basis.............................................................68

3.3.8 Receiver Circulation Pump Design Basis .....................................................69

3.3.9 Receiver Control System .........................................................................

3.3.10 Typical Sequence of Operations …………………......................................

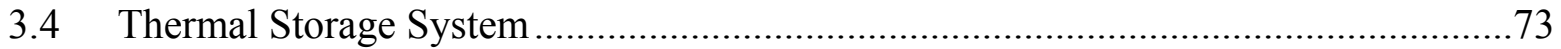

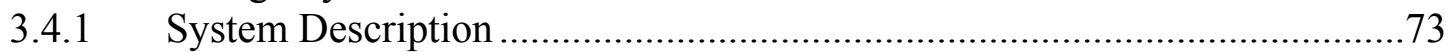

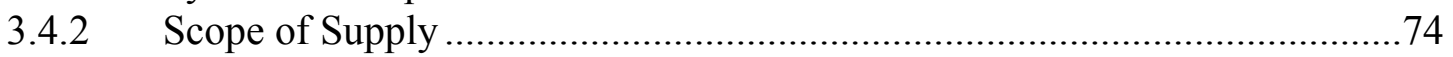

3.4.3 Thermal Storage System Design Basis ..........................................................75

3.4.4 Design Temperatures, Heating Rates, and Tank Thermal Cycles .................80

3.4.5 Thermal Storage System Tank Materials......................................................83

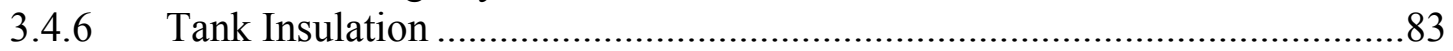

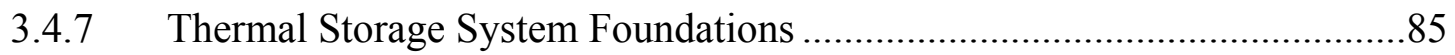

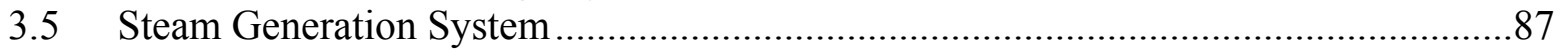

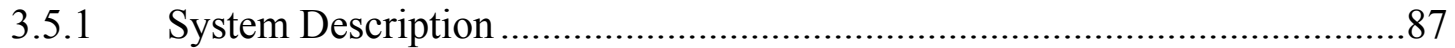

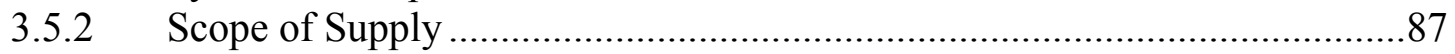

3.5.3 Steam Generation System Design Basis ........................................................8

3.5.4 Steam Generation System Shell and Tube Heat Exchanger Design

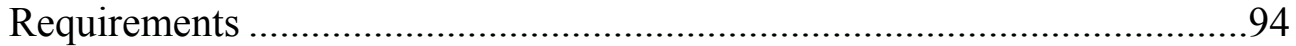

3.5.5 Steam Drum Design Requirements..............................................................95

3.5.6 Steam Generation System Circulation Pump and Steam Generation System Attemperation Pump Design Requirements .....................................96

3.5.7 Steam Generation System Preheater Feedwater Pump(s) and Steam Generation System Evaporator Feedwater Pump(s) Design Basis ................97

3.5.8 Steam Generation System Material Selection ................................................99

3.5.9 Steam Generation System Fill Process ……………...................................... 101

3.5.10 Steam Generation System Sequence of Operation ......................................102

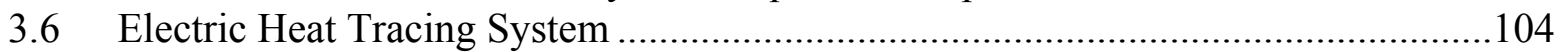

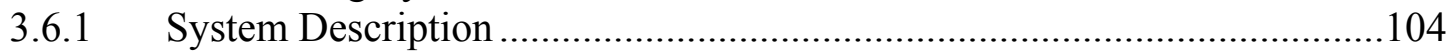

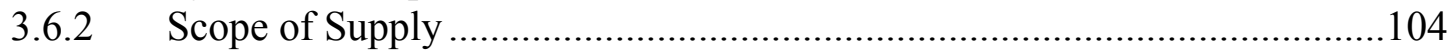

3.6.3 Electric Heat Tracing System Design Basis ...............................................105

3.6.4 Equipment Thermal Conditioning and Freeze Protection ..........................109

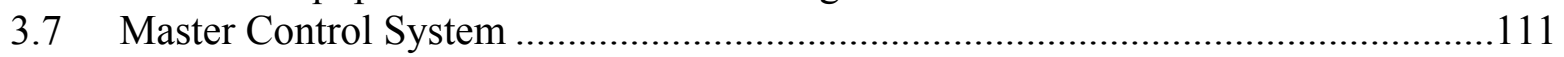

3.7.1 System Description ..............................................................................111

3.7.2 Preliminary System Block Diagram ………….........................................112

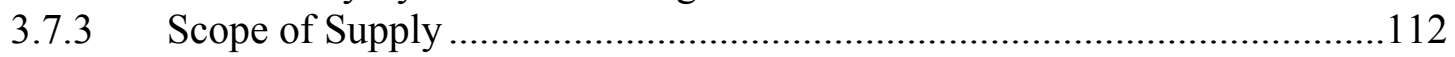

3.7.4 General Distributed Control System Design and Functional

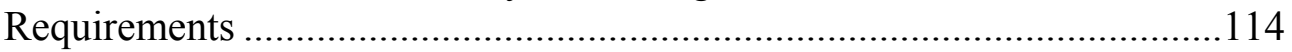

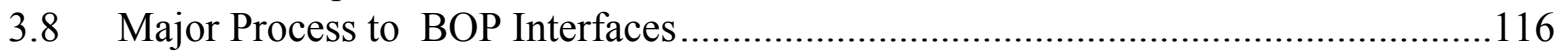

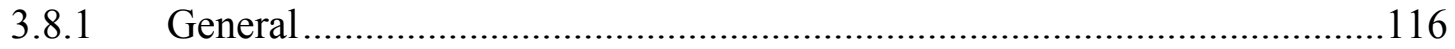

3.8.2 Balance of Plant to Collector System Interface Requirements....................116

3.8.3 Balance of Plant to Receiver System Interface Requirements ....................116

3.8.4 Balance of Plant to Thermal Storage System Interface Requirements .......117

3.8.5 Balance of Plant to Steam Generation System Interface Requirements .....118

3.8.6 Balance of Plant to Electric Heat Tracing System Interface

Requirements ..........................................................................................118 
3.8.7 Balance of Plant to Master Control System Interface Requirements .........118

3.8.8 Balance of Plant to Electric Power Generation System Interface

Requirements

4. General Layout, Materials, and Processes .......................................................................120

$4.1 \quad$ Plant Layout .....................................................................................................120

4.1.1 Layout for Access and Egress - Personnel Safety.....................................120

4.1.2 Maintenance Access ...........................................................................120

4.2 Mechanical and Electrical Equipment Maintenance Automation ..............................121

4.2.1 Solar Power Tower Mechanical and Electrical Equipment .........................121

4.2.2 Component Failure Diagnostics..............................................................121

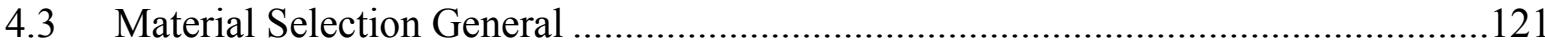

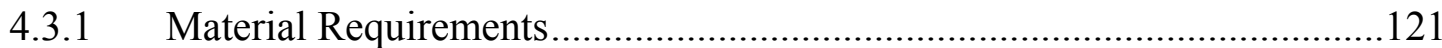

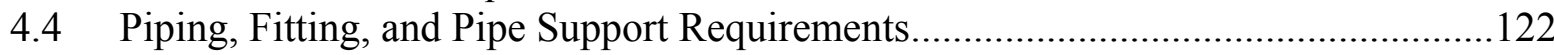

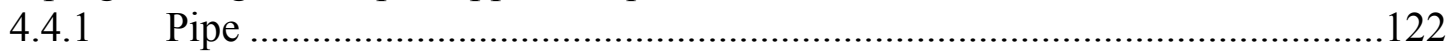

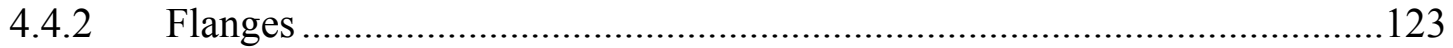

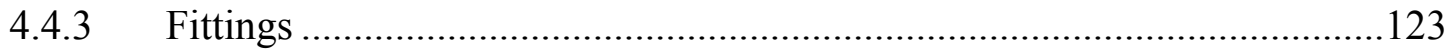

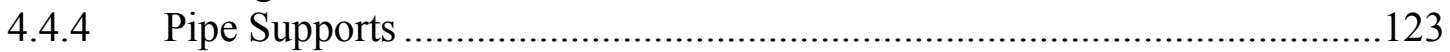

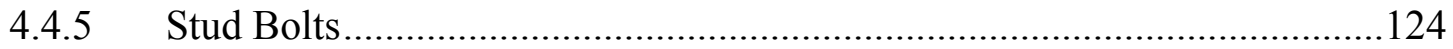

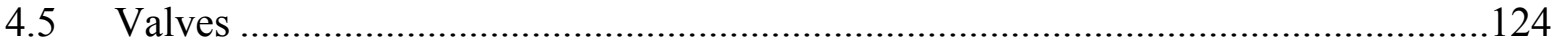

4.5.1 Gate Valves and Globe Valves ............................................................124

4.5.2 Bonnet Gaskets and Split Body Gaskets.....................................................125

4.5.3 Extended Bonnet Valves..........................................................................125

4.6 Solar Power Tower and Nitrate Salt Service Instrumentation...................................125

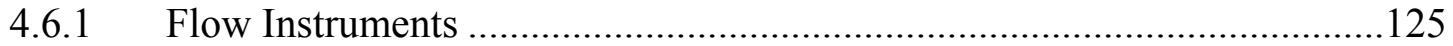

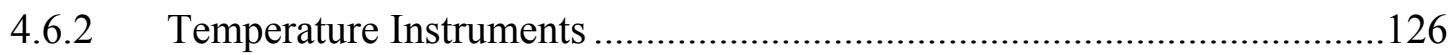

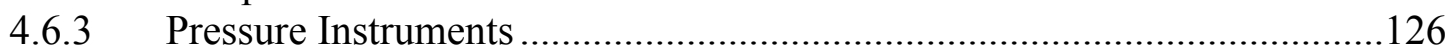

4.6.4 Direct Normal Insolation, Total Insolation, and RS Flux Instrumentation 127

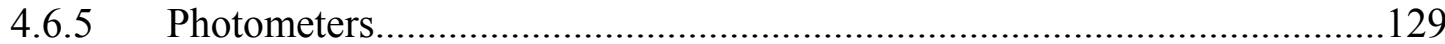

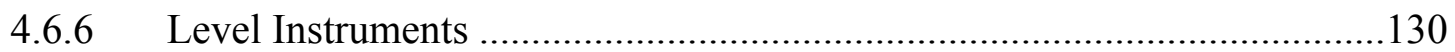

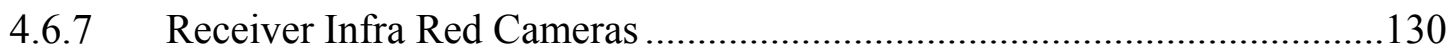

$4.7 \quad$ Electrical Component Requirements ……………….............................................131

4.7.1 General Layout Issues............................................................................131

4.7.2 Cable and Raceway Materials..............................................................132

4.7.3 Enclosures, Junction Boxes, Panels, Cabinets, Motors, and Motor

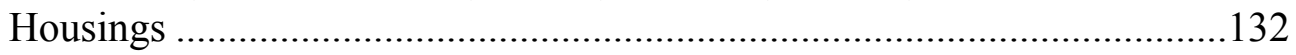

4.7.4 Power System Reliability...................................................................133

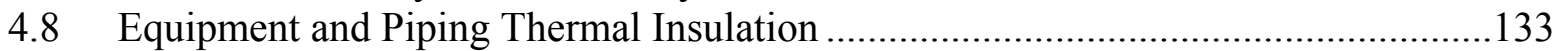

4.8.1 Economic Insulation Thickness ...........................................................133

4.8.2 General Insulation System Design.............................................................133

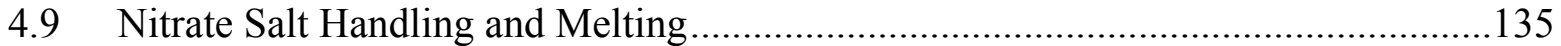

4.9.1 Nitrate Salt Handling and Melting Equipment ...........................................135

4.9.2 Off-Gassing NOX ............................................................................... 136

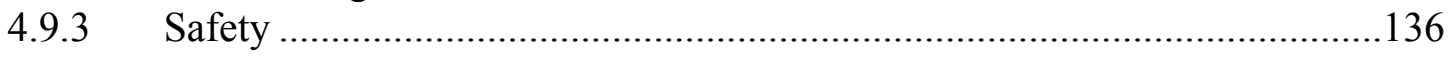

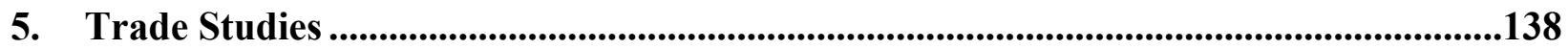

5.1 Elimination of the Receiver Inlet Vessel .............................................................138 


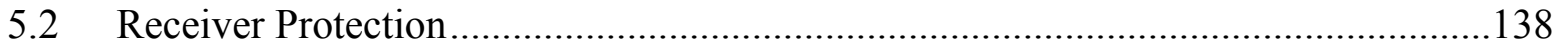

5.2.1 Primary Objective .............................................................................138

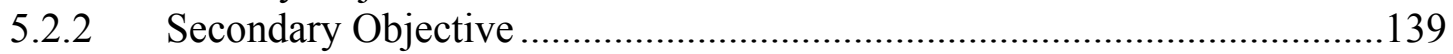

5.2.3 Receiver Protection Requirement Basis ..................................................139

5.2.4 Protection System Reliability …………………….....................................139

5.2.5 Receiver Protection Options ................................................................139

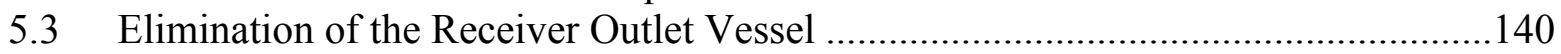

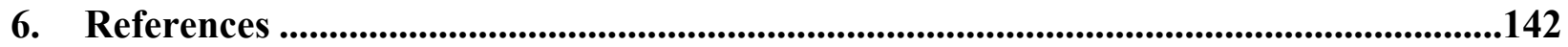

\section{Figures}

Figure 2-1. Energy Collection Section: Operating States and Transitions................................27

Figure 2-2. Energy Conversion Section: Operating States and Transitions...............................31

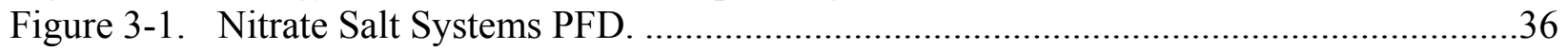

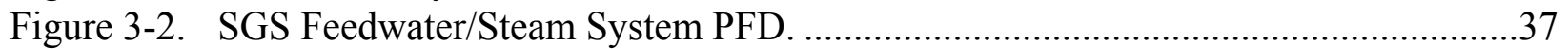

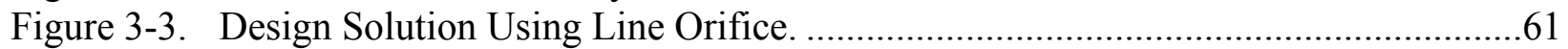

Figure 3-4. Conceptual Sectional View of Oven Box Assembly ................................................62

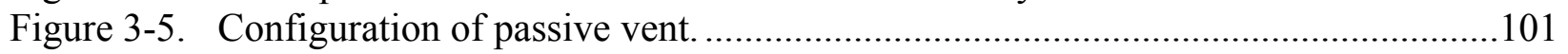

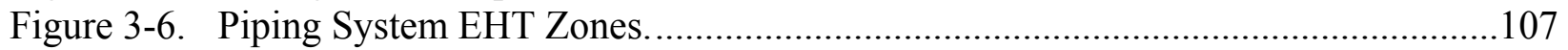

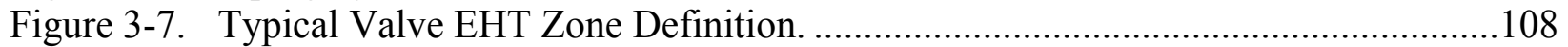

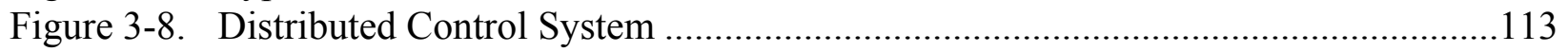

Figure 4-1. Typical Installation of Pressure Transducer ..........................................................128

\section{Tables}

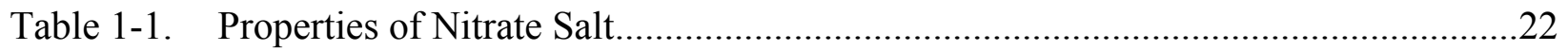

Table 2-1. Plant States; Equipment and System Status...........................................................26

Table 2-2. Plant States: Equipment and System Status...........................................................29

Table 3-1. Wind Definitions for Heliostat Structural Design. ...................................................40

Table 3-2. Typical Error Stack-Ups for Tracking and Beam Quality in Calm Winds................42

Table 3-3. Typical Error Stack-Ups for Tracking and for Beam Quality in Windy

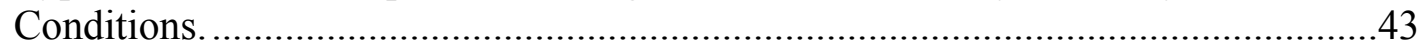

Table 3-4. Receiver Maximum Design Temperatures ................................................................65

Table 3-5. Receiver Materials Specification .............................................................................6

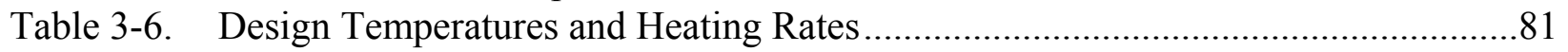

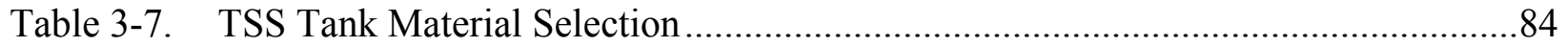

Table 3-8. Nominal Full Load SGS Equipment Design Temperature and Pressure

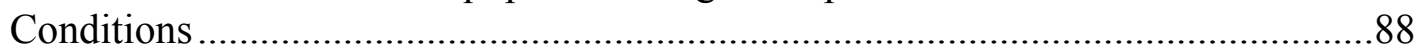

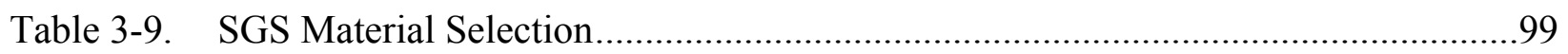

Table 4-1. Material Requirements for Piping in Nitrate Salt Service and Structural Steel 


\section{Acronyms/Abbreviations}

\begin{tabular}{|c|c|}
\hline ADAS & Administrative and Data Analysis System \\
\hline API & American Petroleum Institute \\
\hline ASME & American Society of Mechanical Engineers \\
\hline ASTM & American Society for Testing and Materials \\
\hline bar & Bars, pressure \\
\hline BCS & beam characterization system \\
\hline BOP & Balance of Plant \\
\hline BTU & British Thermal Unit \\
\hline $\mathrm{CPU}$ & Central Processing Unit \\
\hline CS & Collector System \\
\hline D & diameter $(\mathrm{ft})$ \\
\hline DAPS & Dynamic Aim Processing System \\
\hline DCS & Distributed Control system \\
\hline EHT & electric heat tracing \\
\hline EHTS & Electric Heat Tracing System \\
\hline EPGS & Electric Power Generation System \\
\hline $\mathrm{f}$ & friction factor (dimensionless) \\
\hline $\mathrm{ft}$ & feet \\
\hline $\mathrm{ft} / \mathrm{s}$ & feet per second \\
\hline g & gravitational constant $\left(\mathrm{ft} / \mathrm{sec}^{2}\right)$ \\
\hline $\mathrm{HAC}$ & heliostat array controller \\
\hline $\mathrm{HC}$ & heliostat controller \\
\hline $\mathrm{h}_{1}$ & head loss (feet) \\
\hline HLL & high liquid level \\
\hline HMI & Human Machine Interface \\
\hline hr & hour \\
\hline $\mathrm{I} / \mathrm{O}$ & input/output \\
\hline in & inch \\
\hline IR & infrared \\
\hline $\mathrm{KNO}_{3}$ & potassium nitrate \\
\hline $\mathrm{kPa}$ & Pascals x 1000, Pressure \\
\hline $\mathrm{kW} / \mathrm{m}^{2}$ & kilowatts per square meter \\
\hline $\mathrm{kWh}$ & kilowatt hours \\
\hline $\mathrm{L}$ & length (ft) \\
\hline $1 b_{m}$ & pound mass \\
\hline LLL & low liquid level \\
\hline $\mathrm{m}$ & meter \\
\hline $\mathrm{m} / \mathrm{s}$ & meters per second \\
\hline MCMS & Material Control and Maintenance System \\
\hline MCS & Master Control System \\
\hline MI & Mineral Insulated (Magnesium Oxide) \\
\hline MIS & Management Information System \\
\hline $\mathrm{mm}$ & millimeter \\
\hline $\mathrm{mph}$ & miles per hour \\
\hline
\end{tabular}




\begin{tabular}{|c|c|}
\hline mrad & milliradian \\
\hline $\mathrm{MW} / \mathrm{m} 2$ & megawatts per square meter \\
\hline $\mathrm{MW}_{\mathrm{e}}$ & megawatt - electric \\
\hline MWh & megawatt hour \\
\hline $\mathrm{MW}_{\mathrm{t}}$ & megawatt - thermal \\
\hline $\mathrm{N}$ & number of moles of gas $(\mathrm{N}=\mathrm{M}$ (molecular Weight)/mass \\
\hline N/A & Not Applicable \\
\hline $\mathrm{NaK}$ & sodium potassium \\
\hline $\mathrm{NaNO}_{3}$ & sodium nitrate \\
\hline $\mathrm{NC}$ & normally closed \\
\hline NDE & nondestructive examination \\
\hline NEC & National Electric Code \\
\hline NEMA & National Electric Manufacturers Association \\
\hline NFPA & National Fire Protection Association \\
\hline NLL & normal liquid level \\
\hline NO & normally open \\
\hline NOX & nitrous oxides \\
\hline${ }^{\circ} \mathrm{C}$ & temperature - degrees centigrade \\
\hline${ }^{\circ} \mathrm{F}$ & temperature - degrees Fahrenheit \\
\hline${ }^{\circ} \mathrm{F} / \mathrm{hr}$ & ${ }^{\circ} \mathrm{F} /$ hour, temperature rate of change \\
\hline $\mathrm{p}$ & pressure (pounds per square inch) \\
\hline $\mathrm{Pa}$ & Pascal, pressure \\
\hline PCN & personal computer network \\
\hline PFD & process flow diagram \\
\hline PLC & programmable logic controller \\
\hline psia & pressure, pounds per square inch - absolute \\
\hline psig & pressure, pounds per square inch - gauge \\
\hline PSV & pressure safety valve \\
\hline $\mathrm{R}$ & universal gas constant $8.3144 \mathrm{Joule} / \mathrm{mol}^{\circ} \mathrm{K}\left(1.987 \mathrm{Btu} / \mathrm{lb} \mathrm{mol}{ }^{\circ} \mathrm{R}\right)$ \\
\hline RS & receiver system \\
\hline RTJ & ring type joint, flanged fitting \\
\hline SAPS & Static Aim Processing System \\
\hline SAPS & static aim point \\
\hline $\mathrm{sec}$ & second \\
\hline SGS & steam generation system \\
\hline SNL & Sandia National Laboratories \\
\hline SPT & solar power tower \\
\hline $\mathrm{T}$ & $\begin{array}{l}\text { temperature (degrees Fahrenheit }\left({ }^{\circ} \mathrm{F}\right) \text {, Centigrade }\left({ }^{\circ} \mathrm{C}\right) \text {, Kelvin }\left({ }^{\circ} \mathrm{K}\right) \text {, or } \\
\text { Rankine }\left({ }^{\circ} \mathrm{R}\right)\end{array}$ \\
\hline TBD & To Be Determined (Design Issue) \\
\hline TEMA & Tubular Exchanger Manufacturers Association \\
\hline TSS & thermal storage system \\
\hline UPS & uninterruptible power supply \\
\hline $\mathrm{V}$ & volt \\
\hline $\mathrm{V}$ & volume \\
\hline $\mathrm{V}$ & velocity $(\mathrm{ft} / \mathrm{sec})$ \\
\hline
\end{tabular}


VSD

Variable Speed Drive 
Design Basis Document 


\section{Design Standards, Material Properties, System Functional Descriptions, General Design Requirements, and Design Data}

\subsection{Introduction and Purpose}

\subsubsection{Introduction}

The next generation Solar Power Tower (SPT) will build upon the experience gained from designing, constructing, and operating the $10 \mathrm{MW}_{\mathrm{e}}$ Solar Two central receiver project at Daggett, California. The design basis will draw in a large part from:

- A Bechtel Solar Two report entitled "Topical Report on the Lessons Learned, Project History, and Operating Experience, Solar Two, Daggett, California - Revision 1, dated 5 Nov 1999."

- A Bechtel Solar Two criteria document entitled "Design Basis Document for the Solar Two Project, Daggett, California - Revision 2, dated 25 Feb 1994.”

Potential design innovations are also discussed. These are recommended innovations to Solar Two baseline that will improve the overall system reliability and lower risk; however, additional preliminary design and analysis will have to be completed before these implemented. Trade Studies and concept design analyses will be completed and, based upon recommendation, will be incorporated into a revised baseline.

\subsubsection{Purpose}

The purpose of this document is to establish a set of criteria upon which the next generation SPT project will be designed. The SPT Design Basis Document (DBD) will be generic in nature and not for a specific plant rating. The DBD will focus on the following Solar SPT elements:

- Collector System (CS)

- Receiver System (RS)

- Steam Generation System (SGS)

- Thermal Storage System (TSS)

- Master Control System (MCS)

- Electric Heat Tracing System (EHTS)

- Electric Power Generation System(EPGS)*

- BOP*

* EPGS, BOP, and their related subsystems discussions will be limited to interface requirements. The EPGS uses conventional turbine-generator hardware and technology that is not unique to SPT technology. There are many turbine-generator systems available. The appropriate EPGS will be selected based upon SPT system thermal performance. BOP systems will also be discussed as interface requirements and, if necessary, in greater detail when the BOP subsystem is unique to the SPT system e.g., heliostat emergency power. 


\subsection{Reference Documents}

\subsubsection{Design Codes and Standards}

Reference codes and standards are keyed to the United States of America (USA) market. Should an SPT facility be constructed outside the USA, an equivalency matrix will have to be prepared to reflect the specific requirements for the host country.

\section{No. Designation}

ASME

ASME

ASME

ASME

ASME

ASME

ASTM

ASTM

ASTM

ASTM

ASTM

ASTM

ASTM

ASTM

ASTM

ASTM

ASTM

ASTM

ASTM

ASTM

ASTM

ASTM

\section{Title}

B31.1, Power Piping

Section I, Rules for the Construction of Power Boilers

Section III, Division 1, Subsection NH, Class 1 Components in Elevated Temperature Service

Section V, Non Destructive Examination

Section VIII, Division 1, Rules for the Construction of Pressure Vessels Section VIII, Division 2, Alternative Rules for the Construction of Pressure Vessels

A105, Specification for Forgings, Carbon Steel, for Piping Components A181, Specification for Forgings, Carbon Steel for General Service A182, Specification for Forged or Rolled Alloy-Steel Pipe Flanges, Forged Fittings, and Valves and Parts for High-Temperature Service A192, Specification for Seamless Carbon Steel Boiler Tubes for HighPressure Service

A193, Specification for Alloy-Steel and Stainless Steel Bolting Materials for High-Temperature Service

A194, Specification for Carbon and Alloy Steel Nuts for Bolts for HighPressure and High-Temperature Service

A213, Specification for Seamless Ferritic and Austenitic Alloy-Steel Boiler, Superheater, and Heat Exchanger Tubing A216, Specification for steel Castings, Carbon, Suitable for Fusion Welding, for High-Temperature Service A240, Specification for Heat-Resisting Chromium and Chromium-Nickel Stainless Steel Plate, Sheet, and Strip for Pressure Vessels A249, Specification for Welded Austenitic Steel Boiler, Superheater, Heat Exchanger, and Condenser Tubes A312, Specification for Seamless and Welded Austenitic Stainless Steel Pipe A325, Specification for Structural Steel Bolts, Steel, Heat Treated, 120/125 ksi Minimum Tensile Strength A351, Specification for Castings Austenitic Austenitic-Ferritic (Duplex) for Pressure-Containing Parts A36, Specification for Carbon Structural Steel A387, Specification for Pressure Vessel Plates, Alloy Steel, ChromiumMolybdenum A403, Specification for Wrought Austenitic Stainless Steel Piping Fittings 

ASTM
A500, Specification for Cold-Formed Welded and Seamless Carbon Steel Structural Tubing in Rounds and Shapes
ASTM
A506, Specification for Steel, Sheet and Strip, Alloy, Hot-Rolled and
Cold-Rolled, Regular Quality and Structural Quality
ASTM
A516, Specification for Pressure Vessel Plates, Carbon Steel, for Moder-
ASTM ate- and Lower-Temperature Service
ASTM
A53, Specification for Pipe, Steel, Black and Hot-Dipped, Zinc-Coated
Welded and Seamless
NEC
A556, Specification for Seamless Cold-Drawn Carbon Steel Feedwater
NEMA
Heater Tubes
NFPA
National Electric Code
National Electrical Manufactures Association
National Electric Code (NEC), National Fire Protection Association (NFPA)
TEMA Tubular Exchanger Manufacturers Association, 8th Edition TEMA Stan-
UBC dards Uniform Building Code

\subsection{Solar Power Tower Plant Functional Descriptions}

\subsubsection{Solar Power Tower System Elements}

The following are the major SPT system elements.

\subsubsection{Collector System}

The collector system (CS) contains the collector field and heliostats that redirect and focuses sunlight on the receiver. The major system elements are two-axis tracking mirrors (heliostats), heliostat controllers (HCs), a heliostat array controller (HAC), and a communications link between the HCs and the HAC. The number of heliostats will vary for a particular receiver thermal duty and a specific heliostat design.

- The heliostat and HC consist of a foundation, pedestal, drive, support structure, mirrors, drive units, control sensors, $\mathrm{HC}$ and firmware/software, and associated heliostat wiring for power, control, and grounding.

- The HAC resident in the control center maintains master control over the entire CS and includes the Beam Characterization System (BCS), static aim processing system, and Dynamic Aim Processing System (DAPS) software. The operator interface and interaction will be through the Distributed Control System (DCS).

- BCS consists of BCS target, cameras, and automatic software resident on the HAC.

- The communication link should be a redundant network (copper path or fiber) between the $\mathrm{HAC}$ and the HCs 


\subsubsection{Receiver System}

The RS converts the redirected solar flux into thermal energy. The receiver is a cylindrical tube wall heat exchanger that heats molten nitrate salt from $290^{\circ} \mathrm{C}\left(550^{\circ} \mathrm{F}\right)$ to $565^{\circ} \mathrm{C}\left(1050^{\circ} \mathrm{F}\right)$ and includes the associated piping, valves and controls, and unique RS control system software interface requirements. The control system software resides in the MCS. The system components of the RS are: the receiver, receiver pumps, receiver inlet vessel, and outlet vessel.

The RS is installed on top of a tower structure. The tower structure is a BOP subsystem. The interfaces between the RS and the tower will be discussed.

The cold salt pump is installed on a structure on top of the thermal storage system (TSS) cold tank. The structural support frame is a BOP subsystem.

\subsubsection{Thermal Storage System}

The TSS stores high temperature nitrate salt $565^{\circ} \mathrm{C}\left(1050^{\circ} \mathrm{F}\right)$ from the receiver for use by the steam generator, and stores low temperature nitrate salt $290^{\circ} \mathrm{C}\left(550^{\circ} \mathrm{F}\right)$ from the steam generator for use by the receiver. The TSS system components are the: cold nitrate salt tank; hot nitrate salt tank; pressure relief valves (over- and under-pressure relief); tank foundations; nitrate salt inventory; tank immersion heaters; and tank insulation system.

\subsubsection{Steam Generation System}

The Steam Generation System (SGS) uses thermal energy from the hot nitrate salt to produce superheated steam at the conditions required by the turbine-generator and auxiliary steam systems. The SGS system components are: shell and tube exchangers including superheater, reheater, evaporator, preheater, and startup feedwater heater; a steam drum; steam drum mixer; steam generator evaporator feedwater pump; and steam generator preheater feedwater circulation pump. A hot nitrate salt delivery system consists of the SGS circulation pump and SGS attemperation pump.

The SGS circulation pump is installed on a structure on top of the hot salt tank and the SGS attemperation pump is installed on a structure on top of the cold salt tank. The structural support frames are BOP subsystems.

\subsubsection{Master Control System}

The MCS controls and monitors all SPT process functions for all system equipment through all states and transitions in response to operator commands. The MCS is comprised of the following major subsystems: a DCS, HAC, and ADAS. MCS functions tie all plant systems together into a common database encompassing the CS, RS, TSS, SGS, electric heat tracing system (EHTS), EPGS, and BOP.

The DCS consists of the Human Machine Interface (HMI) - operator consoles, redundant Personal Computer Network (PCN) servers, network server, redundant Programmable Logic Con 
trollers (PLCs), PLC remote input/output (I/O) devices and cabinets, data historian and network communications, peripherals, and software

The HAC consists of redundant HAC Processors (PCs), data historian, BCS hardware and software, DAPS hardware and software, Static Aim Processing System (SAPS) software, special instruments, associated network ties, and peripherals. The HAC controls and monitors the CS and individual HCs. The HAC HMI interface is through the DCS. HCs are not part of the HAC.

The Administrative and Data Analysis Systems (ADAS) are linked to the DCS and HAC with read-only access and consist of the Management Information System (MIS), Material Control and Maintenance Systems (MCMS), and SPT administrative systems, peripherals, and software. ADAS will not be defined in the Design Basis Document other than its interfaces with the DCS and HAC.

\subsubsection{Electric Heat Tracing System}

The EHTS provides nitrate salt freeze protection to all process equipment and components; thermal conditioning of all process equipment and components for plant startup; and protects equipment from extreme thermal gradients and excessive thermal stresses. The EHTS encompasses all STP equipment, component thermal conditioning, and nitrate salt freeze protection systems. The EHTS consists of the following components:

- All electric heat tracing (EHT) circuits/zones,

- Installation hardware-cold leads, termination kits,

- Temperature elements either thermocouples or resistant temperature detectors (RTDs),

- Temperature signal conditioning instrumentation and transmitters, and

- Power conditioning equipment including a solid state contactors.

EHTS system control will be through the PLCs and the DCS. The EHTS is a process critical system and is an integral part of the MCS. EHT is required on equipment, piping, instruments, valves, vents, drains, pressure relief valves, tank immersion heaters, and RS ovens.

Thermal Insulation. Thermal Insulation is part of the system on which it is installed. However, the design and installation details are an integral part of the EHTS and must be developed as part of an integrated system design package.

\subsubsection{Electric Power Generation System}

The Electric Power Generation System (EPGS) converts the energy in the main steam into electric power for delivery to the electric grid. The EPGS consists of the turbine-generator, deaerator, condenser, condensate system, feedwater system, circulating water system including the cooling tower, water sampling system, turbine lubrication oil system, and associated pumps and rotating equipment. 


\subsubsection{Balance of Plant}

The Balance of Plant (BOP) supports all other plant systems and includes:

- Switch yard/main power distribution system including main power transformers and secondary power transformers

- Emergency and uninterruptible power supply (UPS) system

- RS tower cranes providing RS receiver panel access, RS and SGS pump access, SGS exchanger tube bundle access

- Fire protection and detection systems

- Plant security system

- Compressed air system

- Potable water system

- Cooling water system

- Service water system

- Nitrogen supply system

- Water treatment system

- Deionized water system

- Sanitary waste and industrial waste systems

- Oil/water separator

The BOP includes the power distribution system feeding the individual process system Motor Control Centers (MCCs), grounding, lightning protection, lighting with associated raceway, conduit, and wire. The MCCs and associated power distribution supplying equipment, instruments, and components are part of the system element and are not BOP.

The BOP includes all site civil (grading, drainage, fencing), buildings, receiver tower structure, and bridging structures over the TSS. The BCS target is included in the BOP.

\subsection{General Design Requirements}

\subsubsection{Solar Power Tower Plant Sizing Criteria}

SPT plant sizing criteria are discussed below. This is an iterative design process lead by the project integrator with support from the collector field technical specialists, receiver engineer/ designer, and the turbine-generator manufacturer.

- Establish the required net annualized $\mathrm{MWh}_{\text {electric }}$ delivered to power grid.

- Establish the annual direct normal insolation $\mathrm{MWh}_{\text {thermal }} / \mathrm{m}^{2}$ available to the plant based upon insolation models for the area (Climatic factors that affect the annual solar radiation, e.g., dust, haze, wind outages, weather, etc.) should be taken into account, if available.)

- Determine collector field/mirror area $\left(\mathrm{m}^{2}\right)$ required based upon annualized power delivered to grid, the annual solar radiation, annual collector field efficiency, annual receiver efficiency, and annual net turbine cycle efficiency. 
$1-$ The annual collector field efficiency (\%) adjusts annual direct normal insolation to the collector field for heliostat losses as a function of time, the sum of cosine factors, shading losses, blocking losses, heliostat cleanliness, losses, etc. This efficiency is developed by the collector field designer.

- The annual receiver efficiency (\%) adjusts annual receiver output (MWh) as a function of time considering varying receiver loads (startup and shut down cycles) and the sum of conduction, convection, and radiation losses. This efficiency is developed by the receiver designer.

- The annual net turbine cycle efficiency (\%) adjusts the turbine output (MWe) as a function of time for partial loads (startup and shut down cycles), etc. This efficiency is developed by the turbine manufacturer and the plant operations models.

- Determine the maximum daily insolation $\left(\mathrm{MWh} / \mathrm{m}^{2}\right)$ for the "best day," summer solstice.

- Determine the maximum amount of solar energy collected (MWh) for the "best day" from the maximum daily insolation, mirror area, collector field efficiency, and daily receiver efficiency.

- Determine the daily collector field efficiency (\%) for the "best day" e.g., cosine factor, shading losses, and blocking losses.

- The daily receiver efficiency (\%) is similar to the annual receiver efficiency but adjust the receiver output (MWt) for partial loads considering conduction, convection, and radiation losses. This efficiency is developed by the receiver designer.

- Establish the hours per day (hrs) that the plant is expected to deliver energy to the grid.

- Determine the gross amount of energy delivered to the SGS (MW) from the maximum amount of energy collected and the hours of operation.

- Establish turbine size based upon gross amount of energy delivered to the SGS times the turbine efficiency $(\%)$.

- Establish a target SPT annual plant availability (\%) based upon the annual direct normal insolation $\mathrm{MWh}_{\text {thermal }} / \mathrm{m}^{2}$ that could produce power with a corresponding theoretical maximum power generated and compare this value to a target theoretical annual SPT operation by reducing the maximum as a function of time considering:

- Time for planned maintenance outages that impact power generation

- Time that insolation levels are below the minimum to allow the heliostats to track the receiver

- Time durations for RS warm-up

- Time durations for SGS/EPGS startup/warm-up

A target SPT annual plant availability of $90 \%$ should be a design objective. 
- TSS Sizing

- Minimum storage capacity for daytime operation. The steam generator and turbine generator are sized to accept the peak thermal output from the receiver with a nominal storage capacity of one hour provided to simplify the daily turbine startup.

- Storage Capacity for $24 \mathrm{hr}$ /day operation. A storage capacity of 12 to 16 hours allows continuous turbine operation at full load on the "best day."

- $\quad$ RS Sizing $\left(\mathrm{MW}_{\mathrm{t}}\right)$

- Establish the peak reflected power from the collector field at noon of the "best day."

- Estimate receiver spillage losses, reflection losses, and heat losses due to convection, conduction, and radiation.

- Receiver rating $\left(\mathrm{MW}_{\mathrm{t}}\right)$ is the reflected power from the collector field minus the sum of the receiver losses.

\subsubsection{American Society of Mechanical Engineers Boiler and Pressure Vessel Codes}

It is recommended that:

- Salt piping systems and steam piping systems be designed and manufactured to American Society of Mechanical Engineers (ASME) B31.1.

- All pressure vessels and heat exchangers in salt service be designed and manufactured to ASME Section VIII with the exception of the receiver.

- National, state, and local jurisdictional authorities may have special requirements that could override this recommendation. For example, ASME Section I was required for Solar Two SGS Exchangers by the State of California-any steam generator, regardless whether it was fired or unfired.

- Solar Two Receiver design and manufacturing requirements were driven by metallurgy and operating temperatures. These resulted in application of ASME Section I and Code Case N47. Refer to page 57, line 17 for a discussion on Code Case N 47.

\subsubsection{Plant Design Life}

Plant and equipment will be designed for a 30-year design life. 


\subsection{Site Selection Characteristics}

Site selection characteristics for an SPT are similar to any industrial facility, but for an SPT facility, the following apply:

- Annual mean direct beam solar insolation ranging from 5.6 to $7.5 \mathrm{kWh} / \mathrm{m}^{2} /$ day.

- Site altitude and weather conditions both macro- and micro-level should not have high incidences of atmospheric water, smoke, fogs, haze, and airborne particulates (dust, tilled farm land, evaporation pond residues, etc). Periodic rain and snow assist in keeping the heliostats clean.

- Not subject the high winds or wind amplification due to terrain features.

- Land area sufficient to site the SPT, heliostat field, and provide a clear safety zone for heliostat and plant operations e.g., glint, cooling tower fog.

- Water availability requirements are the same as any power plant with an additional requirement for deionized water for heliostat washing.

- Close proximity to power grid tie-in point.

- Not in the vicinity of local airports, particularly airport low-altitude approach paths.

- Relatively low seismic risk.

- While not critical, isolated away from major inhabited areas, but close enough for construction and operations labor pool.

\subsection{Nitrate Salt Basic Data}

\subsubsection{Nitrate Salt Properties}

\subsubsection{Nitrate Salt-General}

The nitrate salt is a mixture of $60 \%$ by weight sodium nitrate $\left(\mathrm{NaNO}_{3}\right)$ and $40 \%$ by weight potassium nitrate $\left(\mathrm{KNO}_{3}\right)$. It is stable in air and has a low vapor pressure.

\subsubsection{Phase Change Nitrate Salt Properties}

- Melted salt can be used over a temperature range of $260^{\circ} \mathrm{C}\left(500^{\circ} \mathrm{F}\right)$ to approximately $621^{\circ} \mathrm{C}$ $\left(1150^{\circ} \mathrm{F}\right)$.

- As temperature decreases, it solidifies at $221^{\circ} \mathrm{C}\left(430^{\circ} \mathrm{F}\right)$ and starts to crystallize at $238^{\circ} \mathrm{C}$ $\left(460^{\circ} \mathrm{F}\right)$. 
1 - Isotropic compressibility (NaNO3) at the melting point: $2 \times 10^{-10}\left(\mathrm{~m}^{2} / \mathrm{N}\right)$

- Heat of fusion (based on the average of heat of fusion of each component): $\mathrm{h}_{\mathrm{sl}}=161 \mathrm{~kJ} / \mathrm{kg}$

- Change in density upon melting: $\Delta \mathrm{V} / \mathrm{V}_{\text {solid }}=4.6 \% \Rightarrow \mathrm{V}_{\text {liquid }}=1.046 \mathrm{~V}_{\text {solid }}$

\subsubsection{Thermal and Fluid Properties}

Table 1-1. Properties of Nitrate Salt

\begin{tabular}{ccccc}
\hline \hline $\begin{array}{c}\text { Temperature } \\
\text { Fahrenheit }\end{array}$ & $\begin{array}{c}\text { Density } \\
\mathbf{l}_{\mathbf{m}} / \mathbf{f t}^{3}\end{array}$ & $\begin{array}{c}\text { Specific Heat } \\
\text { Btu/lb } \mathbf{m} F\end{array}$ & $\begin{array}{c}\text { Absolute Vis- } \\
\text { cosity } \\
\mathbf{l}_{\mathbf{m}} / \mathbf{f t}-\mathbf{h r}\end{array}$ & $\begin{array}{c}\text { Thermal Con- } \\
\text { ductivity } \\
\text { Btu/hr-ft-F }\end{array}$ \\
\hline 500 & 120.10 & 0.356 & 10.5058 & 0.284557 \\
$\mathbf{5 5 0}$ & $\mathbf{1 1 8 . 9 8}$ & $\mathbf{0 . 3 5 8}$ & $\mathbf{8 . 6 0 7 3}$ & $\mathbf{0 . 2 8 7 6 9 2}$ \\
600 & 117.87 & 0.359 & 7.0853 & 0.290827 \\
650 & 116.76 & 0.360 & 5.8940 & 0.293962 \\
700 & 115.65 & 0.361 & 4.9873 & 0.297097 \\
750 & 114.54 & 0.362 & 4.3196 & 0.300232 \\
800 & 113.43 & 0.363 & 3.8450 & 0.303367 \\
850 & 112.32 & 0.364 & 3.5175 & 0.306502 \\
900 & 111.21 & 0.366 & 3.2913 & 0.309637 \\
950 & 110.10 & 0.367 & 3.1206 & 0.312771 \\
1,000 & 108.99 & 0.368 & 2.9596 & 0.315906 \\
$\mathbf{1 , 0 5 0}$ & $\mathbf{1 0 7 . 8 8}$ & $\mathbf{0 . 3 6 9}$ & $\mathbf{2 . 7 6 2 3}$ & $\mathbf{0 . 3 1 9 0 4 1}$ \\
1,100 & 106.77 & 0.370 & 2.4830 & 0.322176 \\
\hline \hline
\end{tabular}

Note: Bold type denotes design points for the nitrate salt systems

\subsubsection{Salt Specification}

Industrial grade salt with a nominal composition of $60 \%$ by weight $\mathrm{NaNO}_{3}$ and $40 \%$ by weight $\mathrm{KNO}_{3}$ should be specified. The composition could vary from this $60 / 40$ requirement but property tables and relationships must be developed in order for process design to commence. Therefore, it is recommended that the $60 / 40$ composition be used as the design basis unless there are other issues driving the requirement. A minimum nitrate salt concentration will be specified as $98 \%$ by weight with the following requirements:

- Maximum chloride ion concentration from all sources will be $0.6 \%$ by weight

Maximum contamination from all sources will be: 
- Nitrite: $\leq 1.00 \%$ by weight

- Carbonate: $\leq 0.10 \%$ by weight

- Sulfate: $\leq 0.75 \%$ by weight

- Hydroxyl alkalinity: $\leq 0.20 \%$ by weight

- Perchlorate: $\leq 0.25 \%$ by weight

- Magnesium: $\leq 0.05 \%$ by weight

7 Specification will include requirement for detailed chemical analysis and notification to the proj-

8 ect for any contaminants not listed above that exceed a concentration of $0.04 \%$ by weight.

\subsubsection{Fluid Nitrate Salt Property Formulas}

Fluid nitrate salt property formulas as a function of temperature between 300 to $600^{\circ} \mathrm{C}(570$ to $1110^{\circ} \mathrm{F}$ ) are as follows:

Density as a function of temperature:

$\rho\left(\mathrm{lb}_{\mathrm{m}} / \mathrm{ft}^{3}\right)=131.2-0.02221 \times \mathrm{T}\left({ }^{\circ} \mathrm{F}\right)$

$\rho\left(\mathrm{kg} / \mathrm{m}^{3}\right)=2090-0.636 \times \mathrm{T}\left({ }^{\circ} \mathrm{C}\right)$

Specific heat as a function of temperature:

$\mathrm{c}_{\mathrm{p}}\left(\mathrm{Btu} / \mathrm{lb}_{\mathrm{m}}-\mathrm{F}\right)=0.345+\left(2.28 \times 10^{-5}\right) * \mathrm{~T}\left({ }^{\circ} \mathrm{F}\right)$

$\mathrm{c}_{\mathrm{p}}\left(\mathrm{J} / \mathrm{kg}-{ }^{\circ} \mathrm{C}\right)=1443+0.172 \times \mathrm{T}\left({ }^{\circ} \mathrm{C}\right)$

Absolute viscosity as a function of temperature:

$\mu(\mathrm{lbm} / \mathrm{ft}-\mathrm{hr})=60.28440-0.17236 \times \mathrm{T}\left({ }^{\circ} \mathrm{F}\right)+\left(1.76176 \times 10^{-4}\right) \times\left(\mathrm{T}\left({ }^{\circ} \mathrm{F}\right)\right)^{2}-\left(6.11408 \times 10^{-8}\right) \times$ $\left(\mathrm{T}\left({ }^{\circ} \mathrm{F}\right)\right)^{3}$

$\mu(\mathrm{mPa}-\mathrm{sec})=22.714-0.120 \times \mathrm{T}\left({ }^{\circ} \mathrm{C}\right)+2.281 \times 10^{-4} \times\left(\mathrm{T}\left({ }^{\circ} \mathrm{C}\right)\right)^{2}-1.474 \times 10^{-7} \times\left(\mathrm{T}\left({ }^{\circ} \mathrm{C}\right)\right)^{3}$

Thermal conductivity as a function of temperature:

$\mathrm{k}\left(\mathrm{Btu} / \mathrm{hr}-\mathrm{ft}-{ }^{\circ} \mathrm{F}\right)=0.253208+6.26984 \times 10^{-5} \times \mathrm{T}\left({ }^{\circ} \mathrm{F}\right)$

$\mathrm{k}\left(\mathrm{W} / \mathrm{m}-{ }^{\circ} \mathrm{C}\right)=0.443+1.9 \times 10^{-4} \times \mathrm{T}\left({ }^{\circ} \mathrm{C}\right)$

\subsubsection{Solid Salt Properties}

Solid salt properties are as follows:

Density, $\rho$ $\mathrm{NaNO}_{3}: \quad 2260 \mathrm{~kg} / \mathrm{m}^{3}$ at ambient temperature $\mathrm{KNO}_{3}$ : $\quad 2190 \mathrm{~kg} / \mathrm{m}^{3}$ at ambient temperature

Heat Capacitance $\mathrm{c}_{\mathrm{p}}$ $\mathrm{NaNO}_{3} \quad 37.0 \mathrm{cal} /{ }^{\circ} \mathrm{C}-\mathrm{mol}=1820 \mathrm{~J} / \mathrm{kg}-{ }^{\circ} \mathrm{C}$ near the melting point 
$\mathrm{KNO}_{3}$
Thermal Conductivity

\subsection{Trade Studies and Evaluations}

5 There were elements of the Solar Two design that, while the technical solution worked, the sys-

6 tems were problematic. Based upon Solar Two "Lessons Learned," follow-on evaluations and

7 trades studies are required to completely resolve the issue. Major trade studies will be discussed

8 in Section 5.0. 


\section{2. Operating States and Transitions}

\subsection{Introduction}

For the purposes of the states and transitions, the SPT can be divided into the following sections: (1) energy collection section, consisting of the CS and the RS; and (2) energy conversion section, consisting of the steam generator system and the EPGS.

\subsection{State and Transition Definitions - Energy Collection Section}

\subsubsection{States}

The energy collection section operates in one of the following five states (Refer to Table 2-1 and Figure 2-1):

- Long Term Hold/Overnight Hold. The heliostats are in the stow position, the receiver is drained, and the electric heat trace circuits are inactive.

- $\quad$ Standby. The heliostats are focused on the standby aim points, and the receiver pump is in operation. Salt is flowing in the riser, the receiver bypass line, and the downcomer.

- $\quad$ Preheat. The receiver electric heat trace circuits are active, the preheat heliostats are focused on the receiver, and the receiver pump is in operation. Salt is flowing in the riser, the receiver bypass line, and the downcomer.

- Normal Operation. All of the available heliostats are focused on the receiver, the receiver flow rate is controlled to achieve an outlet temperature of $565^{\circ} \mathrm{C}\left(1,050^{\circ} \mathrm{F}\right)$, and the electric heat trace circuits are de-energized at normal operation temperature set points.

- Cloud Standby. All of the available heliostats are focused on the receiver, the receiver flow rate is controlled to achieve an outlet temperature of $510^{\circ} \mathrm{C}\left(950^{\circ} \mathrm{F}\right)$ under theoretical clear sky conditions, and the electric heat trace circuits are de-energized at the normal operation temperature set points.

\subsubsection{Transitions Between States}

The nine transitions between the states are as follows:

- $\quad$ Long Term Hold to Standby. The operator moves the heliostats from the stow positions to tracking the standby aim points. The temperatures of the riser, the receiver bypass line, and the downcomer are raised to $260^{\circ} \mathrm{C}\left(500^{\circ} \mathrm{F}\right)$. The receiver pump is started, and a flow is established in the riser, the bypass line, and the downcomer. 
Table 2-1. Plant States; Equipment and System Status

\begin{tabular}{|c|c|c|c|c|c|c|c|c|c|c|c|}
\hline \multirow{2}{*}{$\begin{array}{l}\text { Receiver } \\
\text { System, } \\
\text { Collector } \\
\text { Field \& } \\
\text { Thermal } \\
\text { Storage }\end{array}$} & \multirow[b]{2}{*}{$\begin{array}{l}\text { Collector } \\
\text { Field }\end{array}$} & \multicolumn{3}{|c|}{ Receiver } & \multirow[b]{2}{*}{$\begin{array}{c}\text { Riser \& } \\
\text { Downcomer }\end{array}$} & \multirow[b]{2}{*}{$\begin{array}{l}\text { Receiver } \\
\text { Pump }\end{array}$} & \multicolumn{2}{|c|}{ Thermal Storage } & \multirow[b]{2}{*}{$\begin{array}{l}\text { Downcomer } \\
\text { Flow }\end{array}$} & \multicolumn{2}{|c|}{ Thermal Conditioning } \\
\hline & & $\begin{array}{l}\text { Inlet Ves- } \\
\text { sel }\end{array}$ & Panels & $\begin{array}{l}\text { Outlet } \\
\text { Vessel }\end{array}$ & & & Cold Tank & Hot Tank & & $\begin{array}{l}\text { Immersion } \\
\text { Heaters }\end{array}$ & $\begin{array}{l}\text { Electric Heat } \\
\text { Tracing }\end{array}$ \\
\hline $\begin{array}{l}\text { Long Term } \\
\text { Hold / Over- } \\
\text { night }\end{array}$ & $\begin{array}{l}\text { Heliostats } \\
\text { Stowed }\end{array}$ & Empty & Empty & Empty & Empty & Off & $\begin{array}{l}\text { Filled Max } \\
\text { Level }\end{array}$ & Heel Level & None & $\begin{array}{l}\text { Tank Systems } \\
\text { Energized with } \\
\text { controllers at } \\
\text { Long Term } \\
\text { Hold tempera- } \\
\text { ture set points }\end{array}$ & $\begin{array}{l}\text { Salt wetted Sys- } \\
\text { tems Activated, } \\
\text { Most Systems } \\
\text { Inactive }\end{array}$ \\
\hline Standby & $\begin{array}{l}\text { Heliostats } \\
\text { Tracking } \\
\text { Standby } \\
\text { Imaginary } \\
\text { Aim Points }\end{array}$ & $\begin{array}{l}\text { Level } \\
\text { Control } \\
\text { Operating } \\
\text { at Partial } \\
\text { Pressure }\end{array}$ & Empty & Empty & $\begin{array}{l}\text { Filled with } \\
\text { flow through } \\
\text { Crossover }\end{array}$ & $\begin{array}{l}\text { Re- } \\
\text { circulation }\end{array}$ & $\begin{array}{l}\text { Level Con- } \\
\text { trol- Level } \\
\text { Variable }\end{array}$ & $\begin{array}{l}\text { Level } \\
\text { Control- } \\
\text { Level } \\
\text { Variable }\end{array}$ & $\begin{array}{l}\text { Flow routed } \\
\text { to Cold Tank }\end{array}$ & $\begin{array}{l}\text { De-energized } \\
\text { with controllers } \\
\text { at Normal Op- } \\
\text { eration tem- } \\
\text { perature set } \\
\text { points }\end{array}$ & $\begin{array}{l}\text { Salt wetted Sys- } \\
\text { tems Activated, } \\
\text { Flowing systems } \\
\text { standby }\end{array}$ \\
\hline Preheat & $\begin{array}{l}\text { Heliostats } \\
\text { assigned to } \\
\text { preheat } \\
\text { focused on } \\
\text { the receiver }\end{array}$ & $\begin{array}{l}\text { Level } \\
\text { Control } \\
\text { Operating } \\
\text { at partial } \\
\text { Pressure }\end{array}$ & Empty & Empty & $\begin{array}{l}\text { Filled with } \\
\text { flow through } \\
\text { Crossover }\end{array}$ & $\begin{array}{l}\mathrm{Re}- \\
\text { circulation }\end{array}$ & $\begin{array}{l}\text { Level Con- } \\
\text { trol- Level } \\
\text { Variable }\end{array}$ & $\begin{array}{l}\text { Level } \\
\text { Control- } \\
\text { Level } \\
\text { Variable }\end{array}$ & $\begin{array}{l}\text { Flow routed } \\
\text { to Cold Tank }\end{array}$ & $\begin{array}{l}\text { De-energized } \\
\text { with controllers } \\
\text { at Normal Op- } \\
\text { eration tem- } \\
\text { perature set } \\
\text { points }\end{array}$ & $\begin{array}{l}\text { Receiver EHT } \\
\text { and Ovens Active }\end{array}$ \\
\hline $\begin{array}{l}\text { Normal Op- } \\
\text { eration }\end{array}$ & $\begin{array}{l}\text { Heliostats } \\
\text { Tracking } \\
\text { Receiver } \\
\text { Aim Points }\end{array}$ & $\begin{array}{l}\text { Pressure } \\
\text { Control } \\
\text { Design } \\
\text { Flow }\end{array}$ & $\begin{array}{l}\text { Filled and } \\
\text { Design } \\
\text { Flow Es- } \\
\text { tablished }\end{array}$ & $\begin{array}{l}\text { Filled Un- } \\
\text { der Level } \\
\text { Control }\end{array}$ & $\begin{array}{l}\text { Filled and } \\
\text { Design Flow }\end{array}$ & On & $\begin{array}{l}\text { Level Con- } \\
\text { trol - Draw- } \\
\text { down to } \\
\text { Heel Level }\end{array}$ & $\begin{array}{l}\text { Level } \\
\text { Control- } \\
\text { Filling to } \\
\text { Max Level }\end{array}$ & $\begin{array}{l}\text { Flow routed } \\
\text { to Hot Tank }\end{array}$ & $\begin{array}{l}\text { De-energized } \\
\text { with controllers } \\
\text { at Normal Op- } \\
\text { eration tem- } \\
\text { perature set } \\
\text { points }\end{array}$ & $\begin{array}{l}\text { Salt wetted Sys- } \\
\text { tems Activated, } \\
\text { Flowing systems } \\
\text { standby }\end{array}$ \\
\hline $\begin{array}{l}\text { Cloud } \\
\text { Standby }\end{array}$ & $\begin{array}{l}\text { Heliostats } \\
\text { Tracking } \\
\text { Receiver } \\
\text { Aim Points }\end{array}$ & $\begin{array}{l}\text { Pressures } \\
\text { Control, } \\
\text { Under } \\
\text { Reduced } \\
\text { Pressure }\end{array}$ & $\begin{array}{l}\text { Receiver } \\
\text { flow con- } \\
\text { trolled to } \\
\text { maintain } \\
\text { outlet tem- } \\
\text { perature of } \\
510^{\circ} \mathrm{C} \\
\left(950^{\circ} \mathrm{F}\right) \\
\text { under } \\
\text { theoretical } \\
\text { clear sky } \\
\text { conditions }\end{array}$ & Filled & Filled & On & $\begin{array}{l}\text { Level Con- } \\
\text { trol- Level } \\
\text { Variable }\end{array}$ & $\begin{array}{l}\text { Level } \\
\text { Control- } \\
\text { Level } \\
\text { Variable }\end{array}$ & $\begin{array}{l}\text { Flow routed } \\
\text { to Cold Tank }\end{array}$ & $\begin{array}{l}\text { De-energized } \\
\text { with controllers } \\
\text { at Normal Op- } \\
\text { eration tem- } \\
\text { perature set } \\
\text { points }\end{array}$ & $\begin{array}{l}\text { Salt wetted Sys- } \\
\text { tems Activated, } \\
\text { Flowing systems } \\
\text { standby }\end{array}$ \\
\hline
\end{tabular}



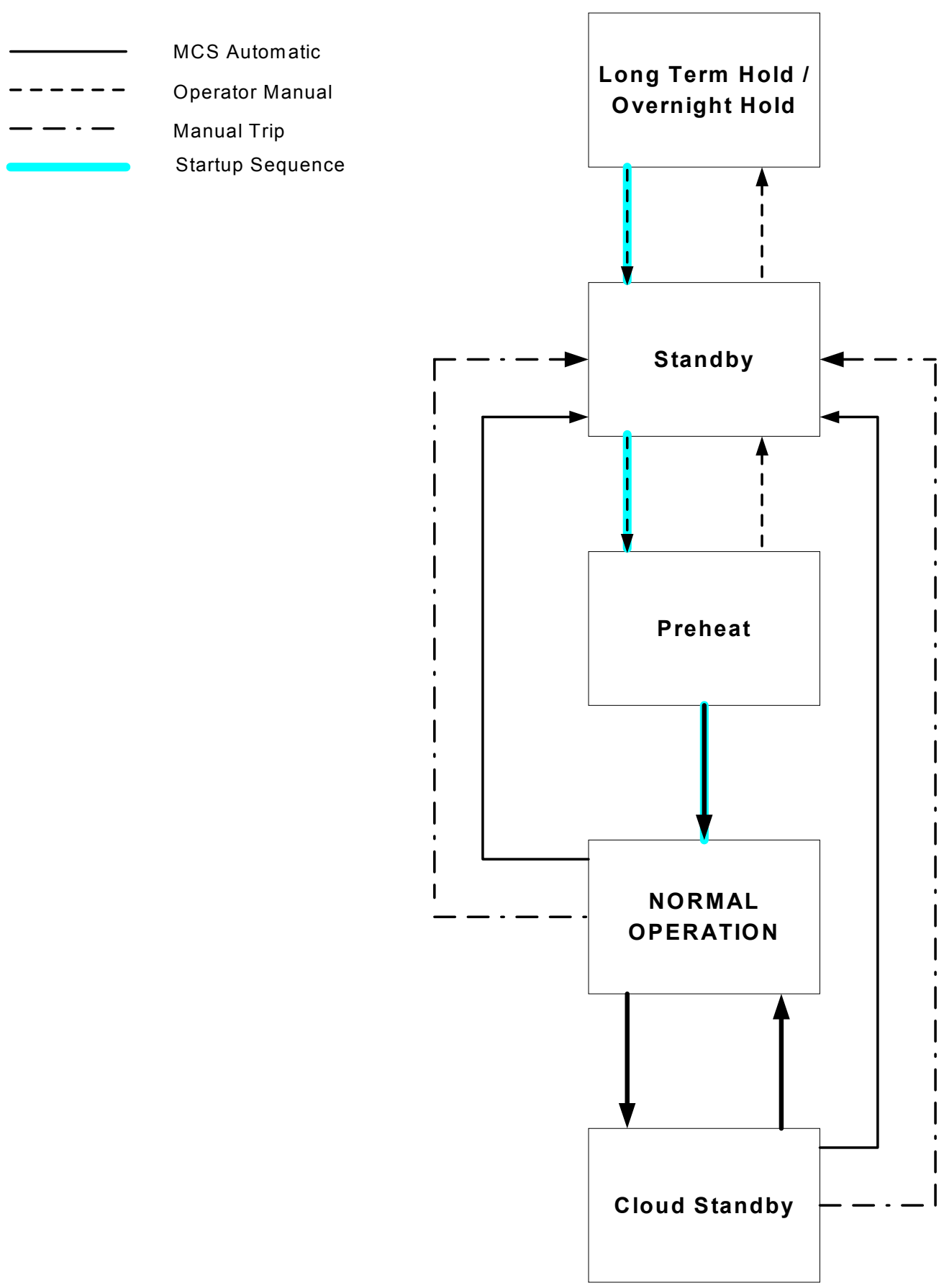

- Standby to Preheat. The temperatures of the receiver ovens and interpanel piping are raised to $315^{\circ} \mathrm{C}\left(600^{\circ} \mathrm{F}\right)$. The preheat heliostats, selected by the DAPS, are moved from the standby aim points to the preheat aim points.

- Preheat to Standby. The preheat heliostats are moved from the preheat aim points to the standby aim points. 
- $\quad$ Preheat to Normal Operation. The transition consists of the following steps: (1) the receiver is filled by flooding, (2) serpentine flow is established, (3) a flow rate corresponding to clear sky conditions is established, (4) the heliostats are moved from the standby (or preheat) aim points to the normal aim points, and (5) the flow rate is controlled to achieve a nominal outlet temperature of $565^{\circ} \mathrm{C}\left(1,050^{\circ} \mathrm{F}\right)$.

- Normal Operation to Cloud Standby. Automatic temperature control is suspended, and the flow rate is controlled to achieve an outlet temperature of $510^{\circ} \mathrm{C}\left(950^{\circ} \mathrm{F}\right)$ under theoretical clear sky conditions.

- Cloud Standby to Normal Operation. Automatic temperature control is resumed, and the flow rate is controlled to achieve a nominal outlet temperature of $565^{\circ} \mathrm{C}\left(1,050^{\circ} \mathrm{F}\right)$.

- Normal Operation to Standby. The heliostats are moved from the normal aim points to the standby aim points, the inlet vessel is vented to the atmosphere, and the receiver is drained.

- Cloud Standby to Standby. The heliostats are moved from the normal aim points to the standby aim points, the inlet vessel is vented to the atmosphere, and the receiver is drained.

- $\quad$ Standby to Long Term Hold. The heliostats are moved from tracking the standby aim points to the stow position, the receiver pump is stopped, and the electric heat trace circuits are inactive.

\subsection{State and Transition Definitions - Energy Conversion Section}

\subsubsection{States}

The energy conversion section operates in one of the following five states (Refer to Table 2-2 and Figure 2-2):

- Long Term Hold. The steam generator is drained, and the electric heat trace circuits and steam drum immersion heater are inactive.

- $\quad$ Overnight Hold. The attemperation pump supplies cold salt to the steam generator to keep the steam drum hot, but with steam production the rate is $0 \mathrm{~kg} / \mathrm{hr}(0 \mathrm{lb} / \mathrm{hr})$. The steam turbine is rotated by the turning gear. Steam drum immersion heaters de-energized at overnight hold temperature set points.

- Auxiliary Steam. A nominal saturated steam flow rate of TBD kg/hr (TBD lb/hr) is established by the auxiliary (electric) steam generator. Sealing steam is delivered to the turbine shaft seals, and a vacuum is established in the condenser using the auxiliary steam generator electric boiler and steam drum immersion heater set at auxiliary steam generator temperature set points. Auxiliary steam demand to preheat piping systems and other equipment will be supplied by the SGS. 
Table 2-2. Plant States: Equipment and System Status

\begin{tabular}{|c|c|c|c|c|c|}
\hline $\begin{array}{l}\text { Steam Generator, Turbine Gen- } \\
\text { erator, Thermal Storage }\end{array}$ & Long Term Hold & Overnight Hold & Auxiliary Steam & $\begin{array}{l}\text { Turbine Synchroniza- } \\
\text { tion }\end{array}$ & Normal Operation \\
\hline \multicolumn{6}{|l|}{ Steam - Generator } \\
\hline Salt Side & Empty & $\begin{array}{l}\text { Filled - Attemperation } \\
\text { Pumps provide cold } \\
\text { salt to maintain system } \\
\text { minimum temperature }\end{array}$ & Filled & Filled & Filled \\
\hline Water Side & Empty & $\begin{array}{l}\text { Filled No Steam gen- } \\
\text { eration }\end{array}$ & Filled & Filled & Filled \\
\hline Startup Feed Water Preheater & Empty & Filled & Filled & Filled & Filled \\
\hline \multicolumn{6}{|l|}{ Thermal Storage } \\
\hline Cold Tank & Filled & Level & Level & Level & Level \\
\hline Hot Tank & Heel & Level & Level & Level & Level \\
\hline \multicolumn{6}{|l|}{ Salt Pumps } \\
\hline SGS Circulation Pump & Off & Off & On & On & On \\
\hline SGS attemperation Pump & Off & $\begin{array}{l}\text { Periodic Operation to } \\
\text { maintain SGS mini- } \\
\text { mum temperatures }\end{array}$ & On & $\begin{array}{l}\text { Salt Attemperation As } \\
\text { required }\end{array}$ & $\begin{array}{l}\text { Salt Attemperation As } \\
\text { required }\end{array}$ \\
\hline \multicolumn{6}{|l|}{ Water Pumps } \\
\hline Condensate & Off & Off & On & On & On \\
\hline Feedwater & Off & Off & On & On & On \\
\hline $\begin{array}{l}\text { Recirculation (Evaporator and } \\
\text { Preheater) }\end{array}$ & Off & Off & On & On & On \\
\hline \multicolumn{6}{|l|}{ Auxiliary Steam } \\
\hline Electric Boiler & Off & Off & $\begin{array}{l}\text { Initial demand for tur- } \\
\text { bine seals }\end{array}$ & Off & Off \\
\hline SGS Aux. Steam & Off & Off & $\begin{array}{l}\text { Condenser Vacuum } \\
\text { and main steam dump } \\
\text { valve }\end{array}$ & On & On \\
\hline
\end{tabular}


Table 2-2. Plant States: Equipment and System Status (continued)

\begin{tabular}{|c|c|c|c|c|c|}
\hline $\begin{array}{l}\text { Steam Generator, Turbine Gen- } \\
\text { erator, Thermal Storage }\end{array}$ & Long Term Hold & Overnight Hold & Auxiliary Steam & $\begin{array}{l}\text { Turbine Synchroniza- } \\
\text { tion }\end{array}$ & Normal Operation \\
\hline \multicolumn{6}{|l|}{ Turbine - Generator } \\
\hline Turbine & Turning Gear & Turning Gear & Turning Gear & On -Part Load & On - Full Load \\
\hline Condenser & Empty & Nitrogen & Nitrogen & Vacuum & Vacuum \\
\hline Generator & Off & Off & On & On - Part Load & On - Full Load \\
\hline Balance-of-Plant & $\begin{array}{l}\text { As Required to support } \\
\text { sustaining Operation }\end{array}$ & $\begin{array}{l}\text { As Required to support } \\
\text { sustaining Operation }\end{array}$ & $\begin{array}{l}\text { As required top support } \\
\text { startup }\end{array}$ & On & On \\
\hline \multicolumn{6}{|l|}{ Thermal Conditioning } \\
\hline Immersion Heaters & $\begin{array}{l}\text { Tank Systems Ener- } \\
\text { gized }\end{array}$ & $\begin{array}{l}\text { Tanks Systems Inter- } \\
\text { mittent }\end{array}$ & $\begin{array}{l}\text { Tanks Systems Acti- } \\
\text { vated as required to } \\
\text { Support Aux Steam } \\
\text { Generation }\end{array}$ & Off & Off \\
\hline Electric Heat Tracing & $\begin{array}{l}\text { Off - all systems } \\
\text { drained }\end{array}$ & $\begin{array}{l}\text { Activated as required } \\
\text { for preheating and } \\
\text { protection of equip- } \\
\text { ment from salt freez- } \\
\text { ing. } \\
\text { Steam systems acti- } \\
\text { vated for preheat as } \\
\text { required }\end{array}$ & $\begin{array}{l}\text { Non-flowing salt wetted } \\
\text { Systems Activated, } \\
\text { Flowing systems } \\
\text { standby. Steam sys- } \\
\text { tems activated for pre- } \\
\text { heat as required }\end{array}$ & $\begin{array}{l}\text { Non-flowing Salt wet- } \\
\text { ted Systems Activated, } \\
\text { Flowing systems } \\
\text { standby. } \\
\text { Steam System Off }\end{array}$ & $\begin{array}{l}\text { Non-flowing Salt wet- } \\
\text { ted Systems Activated, } \\
\text { Flowing systems } \\
\text { standby. } \\
\text { Steam System Off }\end{array}$ \\
\hline Tank Air Volume Heating & $\begin{array}{l}\text { Activated as required } \\
\text { to prevent storage tank } \\
\text { temperature stratifica- } \\
\text { tion }\end{array}$ & Off & Off & Off & Off \\
\hline
\end{tabular}



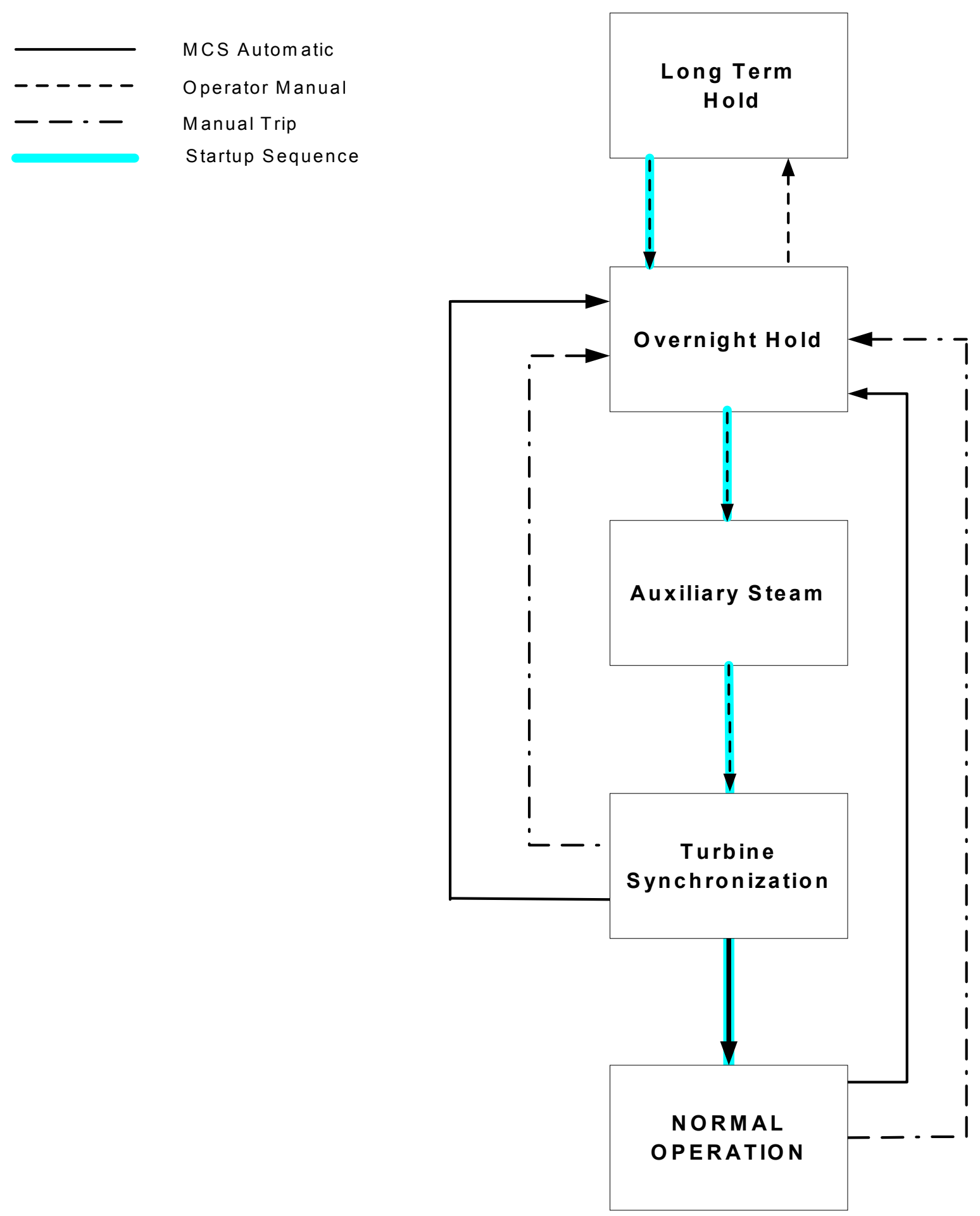

Figure 2-2. Energy Conversion Section: Operating States and Transitions.

- Turbine Synchronization. A live steam flow rate of TBD kg/hr (TBD lb/hr), with a temperature and pressure of $400^{\circ} \mathrm{C}\left(750^{\circ} \mathrm{F}\right)$ and $80 \mathrm{bar}$, pressure (bar) $\left(1,200 \mathrm{lb} / \mathrm{in}^{2}\right)$, respectively, are established. The turbine-generator is synchronized with the grid, and a minimum 
turbine output of TBD MWe is established. Steam drum immersion heaters are de-energized at normal operation temperature set points.

- Normal Operation. The extraction feedwater heaters are placed in service. A live steam flow rate of $\mathrm{TBD} \mathrm{kg} / \mathrm{hr}$, with a temperature and pressure of $550^{\circ} \mathrm{C}\left(1,022^{\circ} \mathrm{F}\right)$ and 125 bar $\left(1,815 \mathrm{lb} / \mathrm{in}^{2}\right)$, respectively, are established. Turbine-generator output at rated MWe turbinegenerator load is established. Steam drum immersion heaters are de-energized at normal operation temperature set points.

\subsubsection{Transition Between States}

The seven transitions between the states are as follows:

- $\quad$ Long Term Hold to Overnight Hold. The temperatures of the steam generator heat exchangers and intervessel piping are raised to $260^{\circ} \mathrm{C}\left(500^{\circ} \mathrm{F}\right)$ by the EHTS. The SGS attemperation pump is started, and a flow of cold salt is established through the heat exchangers.

- Overnight Hold to Auxiliary Steam. The auxiliary (electric) steam generator is started, a flow of saturated steam is established to the turbine shaft seals, and a vacuum is drawn in the condenser. Makeup water for the auxiliary steam generator is provided by a variable speed, positive displacement auxiliary feedwater pump.

- Auxiliary Steam to Turbine Synchronization. The SGS circulation pump is started, and the speed of the pump is increased so that the temperature of the mixed salt at the inlet to the superheater increases at a rate of $500^{\circ} \mathrm{C}\left(1,000^{\circ} \mathrm{F} / \mathrm{hr}\right)$. The live steam is throttled and sent to the condenser. As soon as the live steam achieves a superheat of $60^{\circ} \mathrm{C}\left(100^{\circ} \mathrm{F}\right)$, the turbine is accelerated to TBD rev/min and synchronized with the grid. The live steam throttle valve to the condenser is closed, and a minimum turbine output of TBD MWe is established.

- Turbine Synchronization to Normal Operation. The turbine is transferred from evaporator pressure control to speed control, the extraction feedwater heaters are placed in service, the reheater is placed in service, the attemperation flow of cold salt is reduced consistent with an allowable rate of temperature change in the heat exchangers of $500^{\circ} \mathrm{C}\left(1,000^{\circ} \mathrm{F} / \mathrm{hr}\right)$, and the flow rate of hot salt in increased to the design value.

- Normal Operation to Overnight Hold. The attemperation cold salt is started, and temperature of the mixed salt at the inlet to the superheater is reduced consistent with an allowable rate of temperature change of $500^{\circ} \mathrm{C}\left(1,000^{\circ} \mathrm{F} / \mathrm{hr}\right)$. The output of the turbine is reduced to TBD MWe, the live steam throttle valve to the condenser is placed in operation, the turbine is tripped, live steam is throttled to the condenser, and the temperatures of the heat exchangers are reduced to $285^{\circ} \mathrm{C}\left(550^{\circ} \mathrm{F}\right)$. Steam for the turbine shaft seals is provided by the auxiliary (electric) boiler.

- Turbine Synchronization to Overnight Hold. The output of the turbine is reduced to TBD $\mathrm{MWe}$, the live steam throttle valve to the condenser is placed in operation, the turbine is tripped, live steam is throttled to the condenser, and the temperatures of the heat exchangers 
1 are reduced to $285^{\circ} \mathrm{C}\left(550^{\circ} \mathrm{F}\right)$. Steam for the turbine shaft seals is provided by the auxiliary 2 (electric) boiler.

3 - Overnight Hold to Long Term Hold. The attemperation pump is stopped, and the electric 4 heat trace system is turned off. 
Design Basis Document

1 
1 3. System Descriptions, Scope of Study, and Design Bases

\subsection{Introduction}

\subsubsection{Process Flow Diagrams}

Two SPT Process Flow Diagrams (PFDs) depict a baseline SPT configuration described in Section 3.2. Instruments and valves for the primary process control functions are shown. The Nitrate Salt Systems PFD, Figure 3-1, shows the primary nitrate salt flow paths for the RS, TSS, and SGS. Minor lines, drains, and vents are not indicated. SGS feedwater/steam system PFD, Figure 3-2, covers the SGS feedwater and steam generation side of the process. PFDs for the EPGS and BOP are not included since these systems use proven conventional equipment and process technology.

\subsection{Collector System}

\subsubsection{System Description}

The collector System (CS) baseline consists of the following elements:

- Pedestal mounted heliostats, including glass mirror modules, a heliostat controller (HC), all structural support elements and drives, and a foundation.

- Heliostat Array Controller (HAC), including the software and hardware used to control the CS. It also includes a time base, a beam characterization system (BCS), static aim processing system (SAPS), and dynamic aim processing system (DAPS).

- The BCS is used to automatically calibrate/recalibrate each heliostat by setting its aim point on the receiver and the BCS target.

- The SAPS shifts the heliostat image up or down from the receiver equator to establish a uniform flux on the receiver. This aim point varies by time of year, time of day, and ambient temperature and is used for active control of the CS.

- The DAPS is used to automatically preheat and postheat the receiver on a daily basis.

- Redundant communications link, including all power and communications links (a) between the $\mathrm{HAC}$ and each $\mathrm{HC}$ and (b) between the power distribution motor control centers and each heliostat.

\subsubsection{Scope of Supply}

The CS package design and design integration package includes the overall system integration effort between the collector field technical specialists, heliostat designer and manufacturer, the 


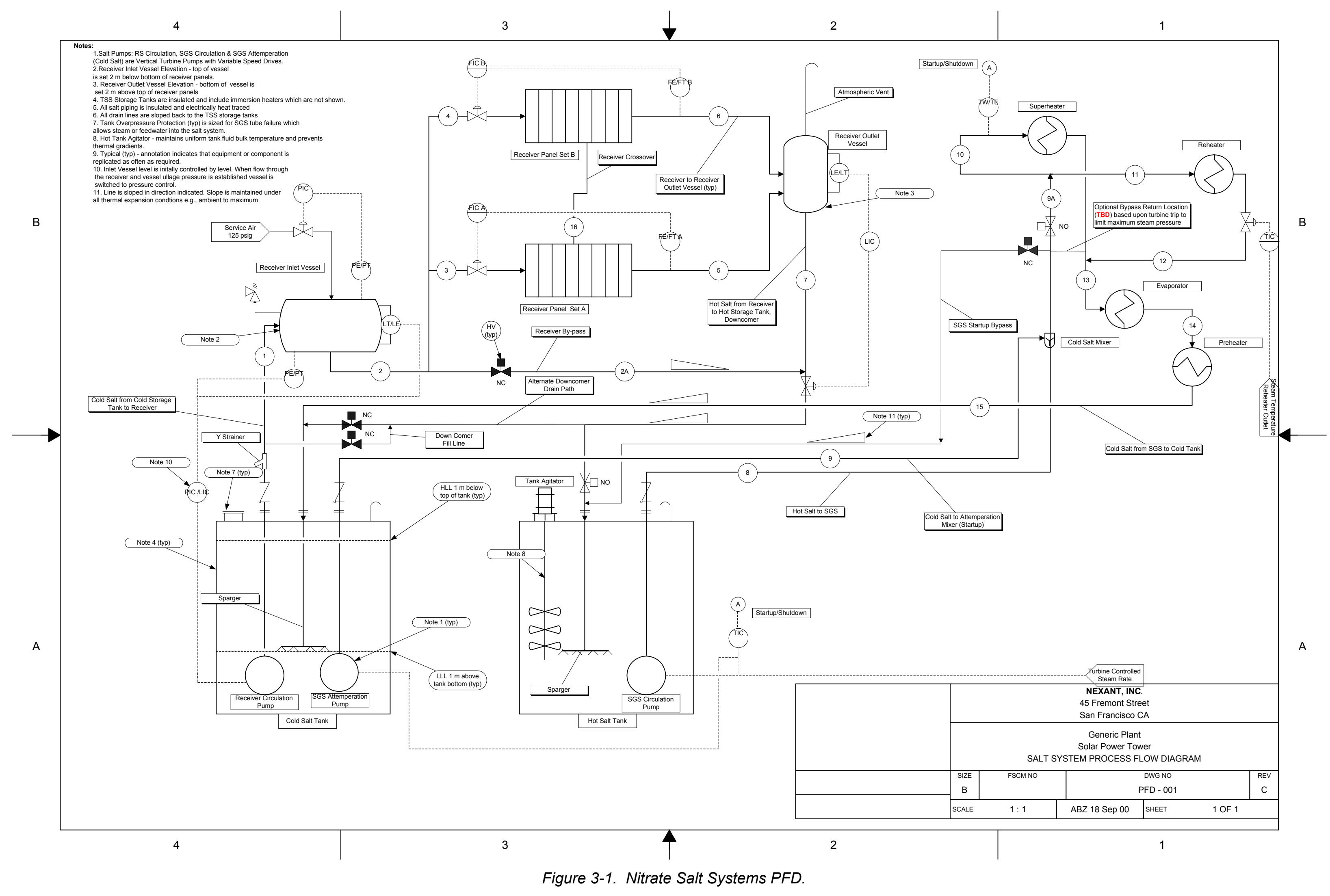




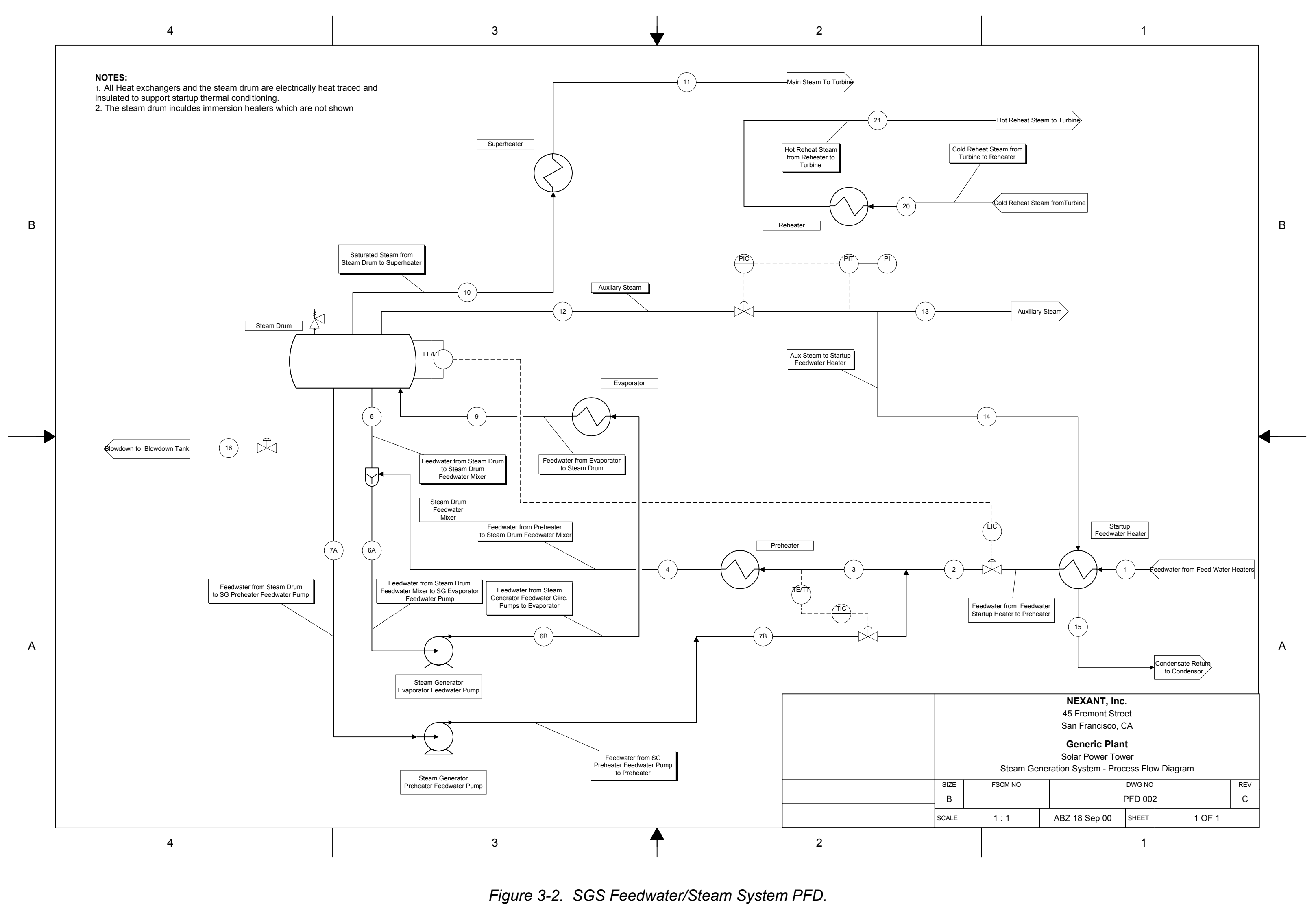


2

HAC hardware and software developer(s), the receiver absorber panel designer and manufacturer, the field installation subcontractor, etc. In addition, it includes heliostat foundation design, power, grounding and communications link cabling, routing, and design.

The heliostats design and manufacturing package includes the heliostat hardware (mirror modules, structural supports, drives systems, and the $\mathrm{HC}$ hardware and software) design, component manufacturing, fabrication, quality assurance, oversight of installation and installation testing, field heliostat canting, and performance of startup and activation testing. Heliostat equipment self-diagnosis (hardware and component error reporting) and coordinates input into the maintenance database. It also includes developing the heliostat error correction algorithms and the design and supply of heliostat mirror washing equipment.

The heliostat array controller software/hardware development package includes:

- All HAC hardware including controls and computers

- Industrial standard interface hardware and protocol to the plant Master Control System (MCS).

- HAC, BCS, DAPS, and SAPS software

- CS field control software and interface requirements with MCS

- HC interface hardware and protocols

- Heliostat point error software

- Hardware redundancy with hot stand-by

- Secondary equipment associated with the BCS

- All software simulation laboratory development and testing

- Field installation and testing; activation and activation support

- All documentation (hardware and software manuals, source code)

The HAC package and heliostat package may be procured from the same source.

The collector field technical specialist package includes all technical analysis and computations required to:

- Size the collector field (both area and quantity) using site insolation, terrain, and weather data,

- Determine the height of the receiver tower,

- Develop the receiver flux maps based upon a maximum allowable flux, 
- Develop algorithms for aiming and for SAPS, DAPS, and HAC,

- Support software development.

This is an iterative procedure and must be followed closely with the receiver and heliostat designer/manufacturer.

The heliostat installation subcontract package is part of the overall site facilities construction package and includes foundation construction, heliostat assembly, heliostat installation, support for heliostat canting, installation of all interconnecting cabling and wiring, continuity checking, and support testing through initial startup through system activation. The heliostat manufacturer will provide assembly and installation support oversight.

Heliostat Design Basis The proposed methodology discussed below is applicable with the current state-of the-art of heliostat technology for $50 \mathrm{~m}^{2}\left(540 \mathrm{ft}^{2}\right)$ to $150 \mathrm{~m}^{2}\left(1615 \mathrm{ft}^{2}\right)$ heliostats. Heliostat unit cost, structural strength requirements, and optical performance requirements drive heliostat design. Experience in the design of heliostats has determined that if the structural strength requirements are satisfied, the optical performance requirements with respect to structural rigidity and stiffness will likely be achieved. The issue then becomes how to trade heliostat unit cost with structural strength. Wind loads drive the design load cases.

\subsubsection{Wind Loading Conditions}

The wind definitions for heliostat structural design are given in Table 3-1.

Heliostat Design Structural Performance Heliostats must be able to take wind loads without suffering permanent damage that causes excessive performance losses. For example, the pedestal and foundation must not break free and rotate under wind loads. Since it is not possible to control the wind, simulated static wind moments should be used be used. Simulated wind moments should be applied individually to each axis of rotation of the heliostat. Force will be applied at one or two locations on the heliostat, providing a more extreme condition than wind loading for some parts of the heliostat structure. However, the application of static moments is less severe than dynamic wind moments that can be higher due to resonance with the heliostat structure. The heliostat will be designed for W3 level azimuth and elevation wind moments in the worst case operational orientation, and W4 level azimuth and elevation moments in the high wind stow orientation.

Static wind load definition The basic design wind pressures and moments should be computed using Peterka and Derickson (1992) for a solitary heliostat using the wind velocities in Table 31. If newer, more accurate data is available based upon modeling with turbulent wind conditions, then that methodology may be used to establish the peak equivalent static wind load. Note that the peak wind pressures over small areas will exceed the mean pressures determined by Peterka and Derickson (1992); therefore, heliostat components, such as the mirrors and mirror fasteners, should use appropriate load increases similar to those in ASCE 7-98 for roofs or wall cladding. 
Table 3-1. Wind Definitions for Heliostat Structural Design

\begin{tabular}{|c|c|c|}
\hline Wind Level & Condition & Wind Speed m/s (mph) @10m \\
\hline W1 & $\begin{array}{l}\text { Operational performance require- } \\
\text { ments. }\end{array}$ & $\begin{array}{l}12 \mathrm{~m} / \mathrm{s}(27 \mathrm{mph}) \text { Gust } \\
8 \mathrm{~m} / \mathrm{s}(18 \mathrm{mph}) \text { Mean }\end{array}$ \\
\hline W2 & $\begin{array}{l}\text { Stowage limit (Heliostat moving } \\
\text { from an operating mode to either } \\
\text { normal stow or high wind stow po- } \\
\text { sition. Refer to Section } 3.2 .2 .3 \text { ). }\end{array}$ & $\begin{array}{l}16 \mathrm{~m} / \mathrm{s}(35 \mathrm{mph}) \text { Gust } \\
10 \mathrm{~m} / \mathrm{s}(22 \mathrm{mph}) \text { Mean }\end{array}$ \\
\hline W3 & $\begin{array}{l}\text { Survival in any orientation. Sur- } \\
\text { vival wind speed in any orientation } \\
\text { may be adjusted to reflect site } \\
\text { specific requirements. }\end{array}$ & $\begin{array}{l}22 \mathrm{~m} / \mathrm{s}(50 \mathrm{mph}) \text { Gust } \\
14 \mathrm{~m} / \mathrm{s}(31 \mathrm{mph}) \text { Mean }\end{array}$ \\
\hline W4 & $\begin{array}{l}\text { Survival in high-wind stow orienta- } \\
\text { tion (Based upon ASCE } 7 \text {-98 - } \\
\text { Western United States). Survival } \\
\text { wind speed may be adjusted to } \\
\text { reflect site specific requirements. }\end{array}$ & $\begin{array}{l}40 \mathrm{~m} / \mathrm{s}(90 \mathrm{mph}) \text { Gust } \\
25 \mathrm{~m} / \mathrm{s}(56 \mathrm{mph}) \text { Mean }\end{array}$ \\
\hline
\end{tabular}

The structural analyses outlined below in combination with a rigorous a shop and field-test program should be applied to qualify a heliostat design for production. The design process is iterative and the heliostat development must allow sufficient schedule duration for testing and retesting.

Heliostat Failures Historically, heliostat drive failures occur more predominately than structural failures or facet failures. Structural members like torque tubes, trusses, pedestal, etc., should use the "Peterka Generated Loads." This may add a small additional cost for the additional struc10 ture, but the structural cost is small when compared to drive cost and the overall system cost.

11 The majority of the wind's energy is below a frequency of 1-2 Hz (the typical range of first

12 natural frequency of heliostats in this size range). Low frequency structural resonance/cyclic loading is the mechanism that has most likely resulted in previous failures.

14 The cost buildup of a heliostat from past experience is as follows:

- Drive 40-50\% (of the overall heliostat system cost)

- Structure $15-20 \%$

- Facets 15-25\%

- Foundation $2 \%$

- Field wiring 6\%

- $\mathrm{HC}$ and controls 7\% 
Drive Components. These include azimuth and elevation gear, motor drives, and all linkages. Based upon the historical structural performance and costs for a heliostat system, the drive unit is both the main cost driver, as well as the most likely component to fail. In order to validate the design and derive a consistent and cost effective unit, the drive should be tested to the criteria in "Heliostats Design Optical Performance," below. The drive system rated capacity should be based upon test rather than the manufacturer's nominal catalog ratings.

Heliostat Structural Components. These include all mirrors support, the mirror attachment screws, the frames, the torque tubes, and the foundations, but exclude the drive mechanism. These items should be designed using loads from Peterka and Derickson (1992) and the standard building code factors of safety. Note that wind force levels W1, W2, and W3 are considered operating load cases so no increases in allowable stresses should be included. For the W4 wind loads, allowable stresses may be increased as permitted by the codes for short-term loads.

Heliostat Unit Cost Achieving the lowest heliostat unit cost is a major project objective considering that $30-50 \%$ of an SPT's capital cost is tied to the collector field and the thousands of heliostats. The design objective should be to optimize heliostat structure/component designs so that heliostats may fail over the life of the plant under severe wind conditions and are not designed to preclude failure.

Field Testing A rigorous test program (shop and field) is required to qualify the heliostat structurally, as well as optically. This issue is discussed in more detail in "Heliostats Design Optical Performance," below. Test planning must accommodate heliostat failures during testing, repairs, and retesting. The test program must allow sufficient time to perform redesign and make design modifications to the test article. One of the objectives is to optimize heliostat design by removing structure, reducing structural weight and component strength to reduce cost.

Heliostats Design Optical Performance Optical performance is not a driving requirement of the initial structural support design. Heliostat stiffness and deflection are important, as they affect optical performance, but the connection between optical performance requirements and heliostat deflections is complicated and difficult to model. For example, a finite element model of a heliostat may neglect the deflections where the torque tube is bolted to the drive. Validation that a heliostat is stiff enough must be determined through a rigorous optical performance test of an installed heliostat under the range of conditions expected in service. Heliostat optical performance varies substantially with orientation, location in the field, and weather.

- Wind impacts both heliostat tracking and beam quality.

- North field heliostats generally have smaller reflection angles between the sun and target, thus less beam aberration, than do heliostats located elsewhere. This effect is typically modeled on the computer simulations, but second-order effects can make real heliostat performance worse than predicted.

- Structural sag due to gravity affects performance as a function of heliostat elevation angle. These effects are not typically computer-modeled. For a given orientation, aiming the mirror modules appropriately can compensate for gravity sag. However, heliostat orientation must change as the sun moves, and the further the elevation angle departs from where it was cor 
rected, the worse the problem. North field heliostats must travel through a smaller range of elevation motion than other heliostats, so these effects are less pronounced.

- Table 3-2 shows typical error stack-ups for tracking and beam quality in calm winds that a heliostat designer needs to establish as part of the design process. The error categories and values indicated are representative and will vary as a function of the actual design.

- Table 3-3 shows typical error stack-ups for tracking and for beam quality in windy conditions that a heliostat designer needs to establish as part of the design process. The error categories and values indicated are representative and will vary as a function of the actual design.

An error, $\alpha$, in the mirror-normal or pointing vector causes an error of twice the magnitude, $2 \alpha$, in the reflected beam. The conversion between the pointing and beam error types is accomplished with the relation.

$$
\text { Beam Error }=2 * \text { Pointing Error. }
$$

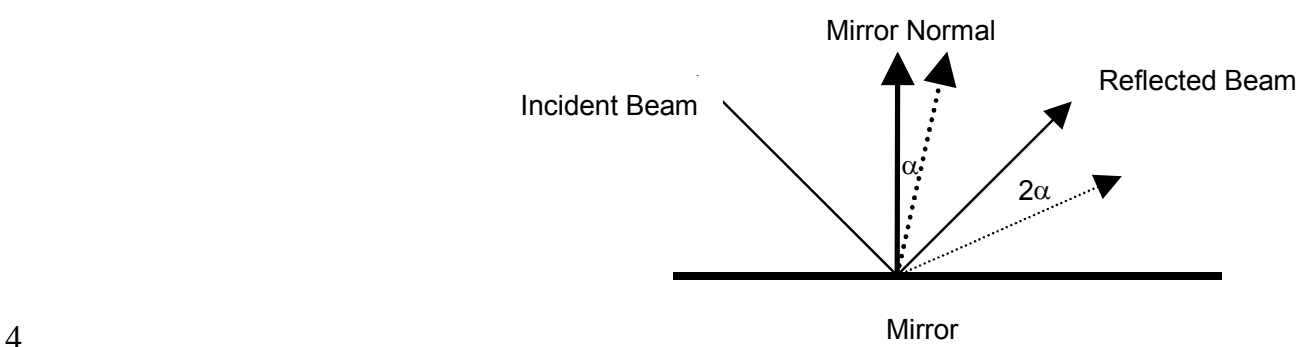

The typical error stack-ups have errors listed in two coordinate systems (mirror normal and reflected beam) for reference.

Table 3-2. Typical Error Stack-Ups for Tracking and Beam Quality in Calm Winds

\begin{tabular}{lcccc}
\hline \hline \multicolumn{1}{c}{ Tracking Errors } & \multicolumn{2}{c}{$\begin{array}{c}\text { Error Stack-up } \\
\text { Mirror-Normal } \\
\text { Coordinates } \\
\text { (mrad, RMS) }\end{array}$} & $\begin{array}{c}\text { Error Stack-up Beam } \\
\text { Coordinates } \\
\text { (mrad, RMS) }\end{array}$ \\
\hline Tracking Error Source & Azimuth & Elevation & Azimuth & Elevation \\
$\begin{array}{l}\text { Encoder resolution/drive back- } \\
\text { lash }\end{array}$ & 0.6 & 0.4 & 1.2 & 0.8 \\
Sun position prediction & 0.15 & 0.15 & 0.3 & 0.3 \\
Light refraction & 0.05 & 0.05 & 0.1 & 0.1 \\
Error corrected tracking* & 0.4 & 0.4 & 0.8 & 0.8 \\
Total error (RSS, mrad) & 0.74 & 0.59 & 1.48 & 1.17 \\
Total Error Req. (mrad, RMS) & 0.75 & 0.75 & 1.5 & 1.5 \\
Beam Quality Error Source & $\mathrm{X}$ & $\mathrm{Y}$ & $\mathrm{X}$ & $\mathrm{Y}$ \\
Slope error & 1.0 & 1.0 & 2.0 & 2.0 \\
\hline \hline
\end{tabular}


1 Table 3-2. Typical Error Stack-Ups for Tracking and Beam Quality in Calm Winds (continued)

\begin{tabular}{|c|c|c|c|c|}
\hline \multirow[b]{2}{*}{ Tracking Error Source } & \multicolumn{2}{|c|}{$\begin{array}{c}\text { Error Stack-up } \\
\text { Mirror-Normal } \\
\text { Coordinates } \\
\text { (mrad, RMS) }\end{array}$} & \multicolumn{2}{|c|}{$\begin{array}{c}\text { Error Stack-up Beam } \\
\text { Coordinates } \\
\text { (mrad, RMS) }\end{array}$} \\
\hline & Azimuth & Elevation & Azimuth & Elevation \\
\hline Mirror specularity & 0.25 & 0.25 & 0.5 & 0.5 \\
\hline Mirror alignment error & 0.25 & 0.25 & 0.5 & 0.5 \\
\hline Structural deflections from gravity & 0.8 & 0.8 & 1.6 & 1.6 \\
\hline Focal change with temperature & 0.5 & 0.5 & 1 & 1 \\
\hline Total error (RSS, mrad) & 1.33 & 1.33 & 2.66 & 2.66 \\
\hline Total Error Req. (mrad, RMS) & 1.8 & 1.8 & 3.6 & 3.6 \\
\hline
\end{tabular}

${ }^{*}$ software to correct for pedestal tilt, drive non-orthogonality, etc.

Table 3-3. Typical Error Stack-Ups for Tracking and for Beam Quality in Windy Conditions

\begin{tabular}{|c|c|c|c|c|}
\hline \multirow{2}{*}{$\begin{array}{l}\text { Tracking Errors } \\
\text { Tracking Error Source }\end{array}$} & \multicolumn{2}{|c|}{$\begin{array}{l}\text { Error Stack-Up } \\
\text { Mirror-Normal } \\
\text { Coordinates } \\
\text { (mrad, RMS) }\end{array}$} & \multicolumn{2}{|c|}{$\begin{array}{l}\text { Error Stack-up Beam } \\
\text { Coordinates } \\
\text { (mrad, RMS) }\end{array}$} \\
\hline & Azimuth & Elevation & Azimuth & Elevation \\
\hline Wind structural deflections & 0.75 & 0.75 & 1.5 & 1.5 \\
\hline Encoder resolution/drive backlash & 1 & 0.6 & 2 & 1.2 \\
\hline Sun position prediction & 0.15 & 0.15 & 0.3 & 0.3 \\
\hline Light refraction & 0.05 & 0.05 & 0.1 & 0.1 \\
\hline Error corrected tracking ${ }^{*}$ & 0.4 & 0.4 & 0.8 & 0.8 \\
\hline Total error (RSS, mrad) & 1.32 & 1.05 & 2.64 & 2.10 \\
\hline Total Error Req. (mrad, RMS) & 1.25 & 1.25 & 2.5 & 2.5 \\
\hline Beam Quality Error Source & $x$ & $\mathrm{Y}$ & $x$ & $\mathrm{Y}$ \\
\hline Wind structural deflections & 1.4 & 1.4 & 2.8 & 2.8 \\
\hline Slope error & 1.5 & 1.5 & 3 & 3 \\
\hline Mirror specularity & 0.25 & 0.25 & 0.5 & 0.5 \\
\hline Mirror alignment error & 0.25 & 0.25 & 0.5 & 0.5 \\
\hline Structural deflections from gravity & 0.8 & 0.8 & 1.6 & 1.6 \\
\hline Focal change with temperature & 0.5 & 0.5 & 1 & 1 \\
\hline Total error (RSS, mrad) & 2.29 & 2.29 & 4.57 & 4.57 \\
\hline Total Error Req. (mrad, RMS) & 2.3 & 2.3 & 4.6 & 4.6 \\
\hline
\end{tabular}

${ }^{*}$ software to correct for pedestal tilt, drive non-orthogonality, etc. 


\subsubsection{Tracking Performance Requirements}

Calm Winds The heliostat tracking error should be less than 0.75 mrad RMS in both of its axes of rotation (azimuth and elevation). At least 20 measurements (field qualification test program), spread over the course of a solar day (from sun elevations of 15 degrees after sunrise to 15 degrees before sunset) are required for the daily RMS calculation. Heliostat tracking accuracy will be calculated by measuring the difference between the measured beam centroid and the desired aim point and performing a coordinate conversion using knowledge of the heliostat orientation and geometry. The 0.75 mrad daily RMS heliostat tracking errors must be demonstrated on every day tested (minimum two days), over a minimum of three months that includes an equinox, without additional corrections or alterations to the control system parameters (initial configuration is permitted). These requirements apply under the following conditions:

- Heliostat Orientation: Tracking accuracy must be demonstrated across the full range elevation angles expected in the field (typically pointing from 15 degrees above horizon to face-up for a surround field). Care must be exercised in selecting the heliostat installation location to achieve this requirement. Tracking errors during the resolution of singularity are not counted in this requirement.

- Wind: Calm winds with gusts less than $3 \mathrm{~m} / \mathrm{s}(7 \mathrm{mph})$ at $10 \mathrm{~m}$ elevation within 30 seconds of measurement

- Temperatures: $0^{\circ}$ to $50^{\circ} \mathrm{C}\left(32^{\circ}\right.$ to $\left.122^{\circ} \mathrm{F}\right)$.

Windy Conditions Since wind conditions are uncontrollable, it is not possible to ensure a limited test regime will represent the full spectrum of winds encountered in practice. Heliostat tracking error must be less than 1.25 mrad RMS for each azimuth and elevation axis in W1 level winds. Heliostat tracking error must be less than $1.5 \mathrm{mrad}$ RMS for each azimuth and elevation axis in W2 level winds. At least 60 measurements are required over a period of no less than 30 seconds to establish the RMS values and winds must be within $\pm 20 \%$ of the W1 levels for the duration of each measurement period. Multiple tests under different wind speeds and directions are required. These requirements must be met when temperatures are from $0^{\circ}$ to $50^{\circ} \mathrm{C}\left(32^{\circ}\right.$ to $\left.122^{\circ} \mathrm{F}\right)$.

Singularity occurs when a heliostat's position must change in order to properly track the sun's image on the desired aim point more rapidly than it is capable of doing. This occurs for azimuth/elevation drive heliostats when the heliostat is tracking nearly face up and must rotate 180 degrees in azimuth (or "bend over backwards") to continue tracking. A heliostat's inability to move quickly typically causes tracking errors for a short period while this singularity position is resolved. The heliostat must resolve singularity in 15 minutes or less.

\subsubsection{Beam Quality}

Calm Winds Beam quality refers to the distribution of light intensity in the heliostat beam when it strikes a target, also referred to as the flux distribution or, in a simplified sense, the beam shape. The beam shape can vary significantly depending upon the geometry of the sun, heliostat, and target, so a fixed reference is meaningless. Rather, the heliostat must perform as predicted 
by optical modeling codes for the given conditions. Under calm winds, the beam quality shall be such that a minimum of $90 \%$ of the reflected energy shall fall within the area defined by a computer model predicted beam shape. The predicted beam shape shall be evaluated with the HELIOS model or another suitable substitute. The computer model predictions will include all the information available about the heliostat, including: the size and orientation of the mirror modules; the focal length (in $\mathrm{x}$ - and $\mathrm{y}$-directions) of the mirror modules, ideally as a function of temperature; the mirror module alignment, or canting, configuration; and measured mirror reflectivity. A measured or conservative estimate of the sun intensity (sunshape) distribution should be used in predicting the ideal beam shape. To this information the computer model should add 'slope' errors of $1.8 \mathrm{mrad}$ in heliostat mirror-normal coordinates or errors of $3.6 \mathrm{mrad}$ in reflected beam coordinates. This criteria must be demonstrated on at least two days and applies under the following conditions:

- Heliostat Orientation: Beam quality must be demonstrated across the full range of elevation angles expected in the field (typically pointing from 15 degrees above horizon to face-up for a surround field). Care must be exercised in selecting the heliostat installation location to achieve this requirement.

- Wind: Calm winds with gusts less than $3 \mathrm{~m} / \mathrm{s}$ (7 mph) at $10 \mathrm{~m}$ elevation within 30 seconds of measurement

- Temperatures: $0^{\circ}$ to $50^{\circ} \mathrm{C}\left(32^{\circ}\right.$ to $\left.122^{\circ} \mathrm{F}\right)$

Windy Conditions The beam quality should be measured under as many wind conditions as possible as there is no valid way to simulate the effects of winds on beam quality. Beam quality shall be such that a minimum of $90 \%$ of the reflected energy falls within the area defined by a computer model predicted beam shape including 'slope' errors of $2.3 \mathrm{mrad}$ (or $4.6 \mathrm{mrad}$ in reflected beam errors) in W1 level winds. These criteria must be met at all times of the day and demonstrated on at least two days. This criteria applies under the following conditions:

- Heliostat Orientation: Beam quality should be demonstrated over the full range of elevation angles expected in the field (typically pointing from 15 degrees above horizon to face-up for a surround field). Uncontrollable winds may prevent this from occurring.

- Temperatures: $0^{\circ}$ to $50^{\circ} \mathrm{C}\left(32^{\circ}\right.$ to $\left.122^{\circ} \mathrm{F}\right)$.

The heliostat drive system must:

- Have the capability of positioning a heliostat to a stow, cleaning, or directed maintenance position in TBD minutes from any operational orientation.

- Not drift in elevation or azimuth from the last commanded position due to environmental loading or component wear.

- Have the capability for local emergency HC override and to stow heliostats using the drive motors 
- Have a sealed drive system, including drive motors, thus protected from rain, mirror washing detergents/agents (type TBD), wind-blown dust, UV, etc.

Materials for cable harness(es) from HC to drive motors, position sensors, etc., will be selected to provide a 30-year design life considering UV and exposure to heliostat mirror washing agents. External coatings on drive systems, including the motors, must be specified for a 30 -year service life. Manufactures standard coating will typically not withstand the multiple heliostat wash cycles.

Internally lubricated vented drive systems (gear drives) must be designed to prevent lubricant leaks from contaminating either the drive motors or the environment. Oils/lubricants must be suitable over the entire operating temperature range and specifically address thermal expansion lubricant corrosiveness, maintenance, etc. It is recommended that, if the drive motors are directly coupled to the drive, they do not share a common seal.

Drive motors should be DC-capable of reverse operation with environmentally sealed, Totally Enclosed Nonventilated (TENV) housings.

Hail The heliostat, in any orientation, must survive TBD mm (TBD in) diameter, TBD specific gravity, hail impacting at TBD m/s (TBD ft/s). Temperature of simulated hail will be $\mathrm{TBD}^{\circ} \mathrm{C}$ $\left(\mathrm{TBD}^{\circ} \mathrm{F}\right)$. These requirement are site-specific. The typical US Military Standard requirement is as follows:

- Diameter: $25 \mathrm{~mm}(1 \mathrm{in}$.

- $\quad$ Specific Gravity 0.9

- Terminal Velocity $23 \mathrm{~m} / \mathrm{s}(75 \mathrm{ft} / \mathrm{sec})$

- Temperature $-6.7^{\circ} \mathrm{C}\left(20^{\circ} \mathrm{F}\right)$

Lightning Protection will be provided in accordance with NEC requirements under the following guidelines:

- Total destruction of a heliostat/HC from a direct hit is acceptable.

- Repairable damage of heliostats and HCs adjacent to a direct hit.

- The HAC and adjacent communication links shall be protected from a direct hit.

Mirror Canting is performed in conjunction with the initial heliostat assembly/installation and when mirror modules are replaced. The frequency of periodic maintenance mirror recanting will depend upon the specific heliostat design and is a TBD issue. The orientation of each mirror module on the heliostat requires adjustment so that the image from the mirror module overlaps at a distance equal to that from the heliostat to the receiver. This adjustment is defined as a cant, and the distance from the heliostat to the receiver is defined as the slant range. 
Each Heliostat will be provided with:

- TBD mirror module adjustment setscrews near the corners of each module, typically at each connection point with the structure.

- TBD fixed reference marks near the corners on each mirror module. The reference marks may be at either the top or bottom of the module with the bottom being preferred since the canting operation will be performed with heliostat in a horizontal, level position (stowed position). This will allow the canting operation to be performed from underneath the heliostat.

- A data package that establishes the slant angle setting for each heliostat as a function of its location in the heliostat field and position of each mirror module on the heliostat. The setscrew elevation adjustment table will be developed as part of the design process and is calculated for each mirror module reference mark with respect to a reference plane parallel to the heliostat. The adjustment is made with the heliostat in a horizontal, level position.

Two canting procedures for individual mirror modules are discussed below:

Manual Process The first procedure is a manual operation that uses a laser survey instrument and TBD scaled rulers mounted perpendicularly to a mirror module at predetermined reference marks. The laser survey instrument is positioned so that it can see all four corners of the mirror module and the scaled rulers and establish the parallel heliostat structural reference plane. Setscrews are then adjusted so that the laser beam intersects the scale at the required setscrew elevation adjustment table value for that mirror module.

Automated Process The second process uses a dual axis clinometer or inclinometer(s) mounted to a support frame (calibration device) that, in turn, is attached to a mirror module at predetermined reference points to measure angle/tilt from the horizontal plane and a portable PC. This procedure will require development and integration of supplier algorithms/software into a HAC software module that will link the amount of tilt from the horizontal to the setscrew elevation adjustment tables. The linking software will allow table values to be compared with the instrument readout and, by adjusting the setscrews to the equivalent tilt value, establish the proper cant setting.

Suggested Clinometer Source:

29 Schaevitz ${ }^{\mathrm{TM}}$ Sensors

301000 Lucas Way

31 Hampton, Virginia 23666

32 Phone: (757) 766-1500

33 Facsimile: (757) 7664297

34 Internet: www.schaevitz.com

35 Suggested Inclinometer Source

36 US Digital Corporation TM

$37 \quad 11100$ NE 34th Circle

38 Vancouver, WA 98682 USA

39 Phone: (360) 260-2468 


\section{Facsimile: (360) 260-2469}

Internet: www.usdigital.com

Mirror Cleaning Mirror cleaning should be performed on a continuous basis using two methods. The primary method will be a semi-automated high-pressure deionized water wash spray without scrubbing. The objective should be to wash the entire heliostat field on a two-week interval. A secondary method will be performed periodically using deionized water, a mild biodegradable detergent, and manual scrubbing. The frequency of the secondary manual scrubbing method is part of the heliostat design and is based upon site-specific, unique environmental conditions. The semi-automated high-pressure wash process requires a unique vehicle and wash mechanism design. Its concept must be developed early in the collector field design to establish (a) the horizontal clearances between heliostat rows and vertical clearances underneath heliostats for wash vehicle access, and (b) to establish the wash position of the heliostats. The wash hardware design and process must be optimized to minimize labor, assure quality and repeatability of the wash process, and maximize the wash rate.

HAC Design Basis The HAC resides in the MCS and provides primary control and monitoring of the CS. Its primary function is to control the heliostats through the communication link to the HCs. The HAC control functions to the HCs and its operating modes are described below in "HAC Control Functions" and "Heliostat Operating Modes." The functions of the SAPS, DAPS and BCS are discussed in sequence starting in Section 3.2.2.4.

HAC Control Functions The HAC shall function as appropriate for all steady-state modes (refer to "Heliostat Operating Modes," below) of plant operation. This shall include the capability of controlling all heliostats in tracking mode so that the incident flux on the receiver is removed within TBD seconds as determined by the Receiver Protection Trade Study. The primary HAC functions are to:

1. Receive operating mode commands from either an operator through the MCS - Distributed Control System (DCS) interface or from the HAC software.

2. Store the geographic location, drive characteristics, limit switch positions, pedestal tilt characteristics, gravitational correction factors, etc., for each heliostat.

293. Receive wind speed data from the local anemometer.

4. Automatically (or with operator intervention) initiate a command to stow the heliostats when the wind exceeds the operating wind design condition.

5. Monitor and maintain clock time for calculation of sun positions using an accurate time standard.

6. Send CS status data to the DCS.

7. Record system alarms. 
8. Receive, acknowledge, and act upon individual heliostat operating mode commands from DCS.

9. Send operating mode commands to the HCs.

10. Calculate and send sun position data to the HCs. HC CPU capability and cost will determine where the sun position pointing vector algorithm resides and where the computation is performed. The objectives are to minimize HC unit cost and distribute the computational processing as far down in the CS system as possible to limit communications traffic between the HAC and the HCs.

11. Calculate a new target once each second during the transition from standby mode to stow and transmit the target data to the $\mathrm{HC}$. This computation may be performed in either in the $\mathrm{HC}$ or HAC (TBD). The location depends upon the complexity of the computation and the capability of the HC. The preference would be to have the HC perform this operation.

12. Receive heliostat status and acknowledgement data from the HCs.

Beam Safety Move groups of heliostats from the normal stow position or high wind stow position to a standby tracking point along imaginary lines to prevent concentrating the image from more than one heliostat outside the plant boundaries. The process is reversed from the standby tracking point to either stow position. These paths will vary by season. The paths are sitedependent and the effort is a major heliostat and HAC software design task.

- Maintain individual heliostat reflectivity database and calculate overall collector field cleanliness for HAC software and DAPS.

- Transmit heliostat status to the maintenance database and report overall collector field status/readiness to the DCS interface. Provide input data to SAPS and DAPS for active or inactive status.

- Provide data for graphic displays of heliostat operating and functional status, which will be displayed on the CS DCS workstation interface.

The commercial software supplied with the Normal Incident Pyrheliometers and Total Radiation Pranometer (rotating shade) will reside on the HAC hardware and communicate with the HAC.

Heliostat Operating Modes The principal operating modes include:

High Wind Stow The heliostats are placed in the face-up position for high wind stow and for long-term plant outages.

Normal Stow and Wash Position The heliostat is pointed at the horizon with an elevation angle of TBD degrees and azimuth position perpendicular to a radial line originating at the receiver tower and terminating at the heliostat pedestal for mirror module cleaning and normal overnight stow. 
Off-line The heliostat does not respond to commands from the HAC; a manual command is required to return to active status. The heliostat may be down requiring maintenance or repair.

Track The heliostats are tracking the designated receiver aim points.

Standby The heliostats are tracking the designated standby aim points.

$B C S$ An individual heliostat is tracking the beam characterization system target.

Directed Position A heliostat has been moved to a given position for maintenance or testing.

Initialization The heliostat initialization task executes automatically upon operating system startup.

Mark This is the position of the heliostat for calibrating the relative position signals from the azimuth and elevation motor encoders.

\subsubsection{Static Aim Processing System Design Basis}

Each heliostat is aimed at the vertical centerline of the receiver. However, the image of each heliostat is shifted up or down with respect to the receiver equator to establish as uniform flux as possible over the length of a receiver panel. The number of aim points will vary as a function of receiver panel length and shall be determined during HAC system design. Image shifts will be determined as follows.

The heliostats with smallest image are assigned the largest shifts to illuminate the ends of the panel without causing excessive spillage losses. The heliostats with largest image are assigned a shift from zero that will reduce spillage losses.

The optimum length of each shift will vary with the relative position of the sun, heliostat, and receiver, and therefore varies with time of day and time of year. Ambient temperature also changes heliostat focal length and therefore the amount of shift.

SAPS will compute shift lengths every 5-6 minutes when the sun is less than $10^{\circ}$ above the horizon and every 30 minutes during the balance of the day.

\subsubsection{Dynamic Aim Processing System Design Basis}

The DAPS function is for receiver preheat prior to filling and postheat prior to emptying to prevent freezing salt or exceeding receiver tube strain levels. The thermal efficiency of the receiver is such that a very small flux is necessary to establish a preheat/postheat panel temperature of $232^{\circ} \mathrm{C}\left(450^{\circ} \mathrm{F}\right)$.

- At wind speeds less than $2.3 \mathrm{~m} / \mathrm{s}(5 \mathrm{mph})$, a flux of approximately 10 to $20 \mathrm{~kW} / \mathrm{m}^{2}$ is required to preheat the panels. 
- At wind speeds approaching $11.2 \mathrm{~m} / \mathrm{s}(25 \mathrm{mph})$, a flux of approximately $30-40 \mathrm{~kW} / \mathrm{m}^{2}$ (windward side) is required to preheat the panels.

A group of heliostats will be selected from the total field to provide the preheat flux. Aim points, different from the static aim points, will be established that extend well past the ends of the receiver to prevent cold zones at the header box interface. This will be a select group, but will vary by time of year (summer/winter) and potentially by time of day. For example, Solar Two identified 400 heliostats for the DAPS use out of a total of 2000 heliostats. The criteria for selecting preheat/postheat heliostats is as follows:

- Inner rows (small image),

- Uniformly distributed around the field,

- Preheat/postheat operations may occur at any time during the day.

DAPS calculates a theoretical incident flux on the receiver from the point in time that startup operations commence using the following information for each heliostat.

\section{1. direct normal radiation}

2. shading losses

3. cosine efficiency

4. mirror reflectivity

5. blocking losses

6. receiver back tube temperatures

7. atmospheric attenuation

8. static aim point position

The input variables are as follows:

- Direct normal radiation input will be obtained from HAC/DCS and by taking the largest values from redundant pyrheliometers measurements.

- The computation for heliostat shading losses, cosine efficiency, and blocking losses shall be calculated for intervals of one minute. The calculation will cover an entire day since a preheat/postheat operation may occur at any time.

- Receiver back tube temperatures will be obtained from the DCS through network link RS Panel thermocouples. A software algorithm will be developed to recognize inoperable or suspect thermocouples. 
- Mirror reflectivity shall be computed for each section of the collector field from the mirror cleanliness database records through periodic measurements of mirror cleanliness/reflectivity and input from the mirror washing maintenance program.

- Atmospheric attenuation will be based upon measurements of daily visual range.

- Wind velocity is used to determine a theoretical convection heat loss.

Preheat Sequence The preheat process, from start to finish (salt flow and receiver full power) takes up to one hour. DAPS applies a proper number of heliostats from standby to track required to provide an initial preheat theoretical flux of $20 \mathrm{kw} / \mathrm{m}^{2}$. DAPS updates this calculation during the warm up sequence and assigns/reassigns heliostats as needed from track to standby. The aim points shall include edge heating to assure even preheating over the entire length of the receiver. As the panel temperature approaches $650^{\circ} \mathrm{F}$, the allowable flux will be reduced to $12 \mathrm{~kW} / \mathrm{m} 2$. Additional flux will be applied to panels on the windward side of the receiver, where the temperature will be less than $650^{\circ} \mathrm{F}$. The postheat process will prevent salt freezing in the windward panels on windy days and is similar to the preheat process.

\subsubsection{Beam Characterization System Design Basis}

Each heliostat accumulates errors in pointing over time due to electromechanical system wear, pedestal movements, errors in drive motor revolution counts, canting alignment errors, etc. The Beam Characterization System (BCS) provides correction offsets to the HAC to compensate for these errors. The BCS is comprised of the BCS software, conventional imaging software, BCS target, and BCS camera system (four conventional charge coupled device cameras). It is required during heliostat installation and during normal operations. While automated, this operation takes time during initial heliostat installation and must be completed prior to RS startup. Sufficient time must be incorporated into the construction schedule to accommodate this activity.

The function of the BCS is to automatically instruct a heliostat to tack the center of the BCS target just below the receiver and then determine the distance between the center of the target and the centroid of the heliostat image and provide point correction factors to the HAC to compensate for the offsets errors.

A BCS array correction algorithm compensates for the net effect of the errors in canting alignment, electromechanical system ware, pedestal tilt, encoder reference position, and gravity deflections. The correction factors are developed by tracking a heliostat on the BCS target and measuring the difference between the center of target and the beam centroid TBD (at least 25) times during the day. The tracking errors are used in a curve fit program to develop pointing error correction factors to limit vertical and horizontal pointing errors to $1 \mathrm{mrad}$ rms or less per year. Each heliostat will be aligned using this process and the algorithm at installation and at least once per year.

The BCS target is part of the BOP receiver tower structure. The target is located immediately below the receiver and consists of four flat white surfaces facing north, south, east, and west. The target surface is canted towards the field so that the surface of the target is perpendicular to a 
line drawn from the midpoint of the heliostat field to the midpoint of the target (TBD). The size of each target surface is determined so that the heliostat furthest from the target in each quadrant can place an image on the target with margin in area of $300-400 \%$ and afford protection to personnel working on the receiver. The target will prevent an incident heliostat beam from entering the tower structure from just below the receiver elevation to approximately three deck levels be-

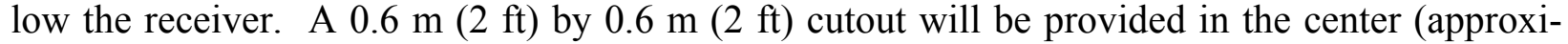
mate) of each target accessible by personnel at the inside the receiver structure from the platform deck level.

The architectural panels comprising the target surface will be coated with a heat-resistant white paint. The interior surface will insulated for personnel protection.

As a point of reference, on Solar Two each target face (trapezoidal shape) extended horizontally along the entire face of the tower structure and vertically for approximately three deck levels.

\subsubsection{Heliostat Controller Design Basis}

HCs require self-contained modularized controller housing, and electrical and electronic hardware (controller, CPU, batteries, power suppliers, inverters, motor contactor/controller, communications cards, etc.) to control all heliostat functions. "Modularized" means that any board within the $\mathrm{HC}$ can removed and replaced using plug-in-type connections. Hardwired terminal strip interfaces should be avoided. HC functions are to:

- Acquire time from the HAC.

- Point the heliostat.

- Continually calculate sun position or receive sun position data from the HAC. HC CPU capability and cost will determine whether sun position pointing vector algorithm resides in the HAC or HC. The preference is for the HC to minimize communications traffic between the HAC and the HCs.

- Continually calculate and update pointing vectors using correction algorithm and correction factors for corridor walks and for tracking and standby modes (refer to page 49, line 4 and page 53 , line 28 ).

- Provide the power and signal to control drive system azimuth and elevation motors.

- Receive limit switch signals (drive motors exceeding limits of drive system travel), shut down drive system motors, and alarm the error to the HAC.

- Retain last known vector point position in case of a power outage and be able to recover without having to reinitialize from a reference position. 
- Provide an internal error checking diagnostic that informs the HAC that a heliostat component-position encoder, limit switches, drive motor, motor controller, power supply and $\mathrm{HC}$ (if possible)-is failing or has failed.

- Provide communication status updates to the HAC that data transfers and commands have been received, if the communication loop protocol does not perform the function).

- Confirm that commands have been successfully executed.

\subsubsection{HC Hardware Requirements}

The maximum operating internal service temperature is $55^{\circ} \mathrm{C}\left(131^{\circ} \mathrm{F}\right)$

During extended long term holds, the collector field power will be shut down at the CS motor control centers to reduce parasitic losses. The HC hardware and firmware will be designed to reinitialize without having to reload software from the HAC.

Electronic/electrical cooling systems will be passive.

CPU reboot cycle time will be established by the receiver protection trade study (TBD $<30$ seconds). Refer to Section 3.2.4 for emergency power requirements.

\section{Exterior connections will consist of:}

- Power Supply to a HC isolation breaker, consisting of a single power source to a heliostat/HC that powers all electronics, communications, instruments, and heliostat motors and provides a convenience $120 \mathrm{~V}$ AC outlet for heliostat maintenance. Refer to Section 3.2.4 for emergency power requirements.

- Communications link to the HAC - Refer to Section 3.2.3.

- Grounding/lightning protection tie-in to a facility common grid.

The HC enclosure will be segmented to protect electronic components from internal power component noise/interference and external noise sources, e.g., drive system DC motors. Line filters may be required.

Ideally, the HC housing should consist of an industrial standard metallic housing suitable for dirty wet exterior applications (NEMA 4/4X or equal).

The selection of the HC processor is driven by cost, the amount of processing that must take place in $\mathrm{HC}$ versus the HAC, high system reliability, and the volume/rate of communications traffic between the HAC and all the HCs. As part of the preliminary design, prepare a design analysis to select the $\mathrm{HC}$ and $\mathrm{HAC}$ hardware configuration that addresses the above issues. The $\mathrm{HC}$ processor memory shall be nonvolatile so that a short-term loss of power will not require a re-initialization of the memory. The processor shall include internal error checking diagnostics 
and fault detection/isolation on all electromechanical subsystems, i.e., azimuth and elevation motor drives and limit switches.

\subsubsection{Field Communication Link Design Basis}

Communications between each $\mathrm{HC}$ and the $\mathrm{HAC}$ in the facility control center must be highly reliable and be comprised of industrial standard network components and hardware. It should incorporate communication error detection and correction protocols. A communications rate must be selected that supports 2000-3000 heliostats. A defocus command must be acted upon by the entire collector field within an extremely short time duration. The response rate will established by Receiver Protection Trade Study and the HAC and HC hardware design analysis/selection process (refer to page 54, line 9). Include redundant paths from the HAC to each HC. The path may be either direct-buried, armored-twisted-shield-pair-copper or fiber-optic with a 30-year design life. The communications link shall be protected from electrical transients, both power and from lightning, and shall be designed so that it is not affected by power distribution paths that may parallel its path.

\subsubsection{Emergency Heliostat Defocus Design Basis}

A trade study is required to determine emergency backup power systems and solutions for defocusing the heliostats from the receiver in a loss of cold nitrate flow emergency, e.g., loss of the cold salt pump or power failure. This study is part of the Receiver Protection Trade Study discussed in Section 5.2.

\subsection{Receiver System}

\subsubsection{System Description}

The RS baseline system elements are comprised of:

- Receiver circulation pump-a variable speed drive (VSD) vertical turbine pump mounted on top of the TSS cold salt storage tank supplying cold salt to the receiver inlet vessel.

- Receiver inlet vessel-an ASME Section VIII pressure vessel with air pressure blanket and a capacity for providing 60 seconds of uninterrupted flow to the receiver in the event of pump or power loss. Receiver inlet vessel is controlled initially by level and, once full, operation is established, it is switched to pressure control.

- Two-receiver flow loops that start on the North from the inlet vessel, flow through the receiver with serpentine flow, and exit from the receiver on the South in the outlet vessel. Piping includes interconnecting receiver piping to the receiver panel headers, crossovers, fill and drain lines, and inline instrumentation flow, pressure, temperature, and externally mounted flux photometers. 
- Receiver absorber panels designed and fabricated in accordance with either ASME Section VIII or I from a high nickel alloy including tubes, tube clips, and headers.

- Receiver outlet vessel-an ASME Section VIII pressure vessel leveled controlled via down comer throttling valve controlling flow returning hot salt to TSS hot salt storage tank.

- Receiver structural elements interfacing with the receiver panel support frame, receiver oven boxes, and providing support to all piping ladders, platforms, vessels, etc.

- A receiver tower crane to allow access to receiver panels for installation and replacement.

\subsubsection{Scope of Supply}

The RS design, physical and system integration, and procurement package includes all PFDs and process and instrument diagrams for the RS, receiver hardware and other equipment specifications, system hydraulic calculations, and hardware and services procurement for the receiver hardware (panels). In addition, it includes developing design, specifications, and procurement packages for the following hardware elements: RS circulation pump, receiver inlet and outlet vessels, interconnecting piping (riser, downcomer, crossovers, fill and drain lines, intrareceiver piping), pipe supports, thermal insulation, instrumentation/controls, interface with MCS, all valves, electrical power, and primary and secondary support structures, including the receiver tower crane. The system design also requires minimizing parasitic electrical power loads and thermal heat losses from piping and equipment in all states and through all transitions.

The receiver panel design package includes the receiver panels with tubes, headers, nozzles, tube clips, receiver panel support frames, receiver panel oven boxes, and design of all controls and instrumentation associated with the receiver. The receiver design package also includes the thermal fatigue and stress analysis to determine maximum life cycles for absorber tubes.

The receiver fabrication package includes the receiver panels with tubes, headers, nozzles, tube clips, receiver panel support frames, receiver panel oven boxes, and all controls and instrumentation hardware installation associated with the receiver.

The RS installation package includes receiver and receiver subsystem component installation, installation testing, and activation support. This work will be included in the overall site construction subcontract. Both the receiver panel designer and fabricator will be on contract to provide oversight during installation and all testing.

\subsubsection{Design Innovation}

There are three major receiver design innovation trade studies required. The scope and requirements for these studies is discussed in detail in Section 5.0. 


\subsubsection{Receiver Design Basis}

\subsubsection{Receiver Physical Configuration}

General Configuration. The nitrate salt receiver is configured to approximate an external cylinder with vertical panels arranged on the surface to provide two parallel salt flow paths. Inlet flow is introduced on the north side of the receiver and exits on the south side. One or more crossovers in the flow path are provided to keep energy capture of the two paths in balance over the complete range of operating conditions, including startup. The receiver is comprised of individual panel sections and includes an inlet header, inlet nozzles, tubes, outlet nozzles, outlet header, tube clips, and panel support structure. The panels are supported at the top and allowed to grow freely in the downward direction. The design allows the receiver panels to be filled uniformly using either a serpentine or flood fill technique.

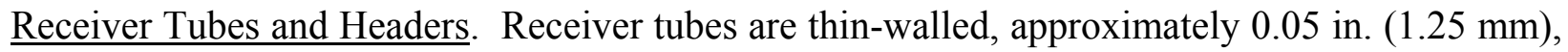
and are welded to thick walled inlet and outlet header/nozzles. The nozzle-to-header interfaces are the location of highest thermal stresses, which result from rapid temperature changes due to cloud transients and the difference in wall thickness. The rate of temperature change for the 30year SPT commercial plant is $2.8^{\circ} \mathrm{C} / \mathrm{sec}\left(5^{\circ} \mathrm{F} / \mathrm{sec}\right)$ and 36,000 cycles.

ASME Code Case N 47 and ASME Section III, Subsection NH. The incident solar flux on the receiver produces temperature gradients through the tube wall large enough to develop plastic strains. Plastic strains are cumulative and the tubes will eventually fail through low cycle fatigue. ASME Code Case N 47 provided the Solar Two basis for calculating tube strains and fatigue life for a molten nitrate salt receiver operating at temperature ranges from $427^{\circ} \mathrm{C}$ to $760^{\circ} \mathrm{C}\left(800^{\circ} \mathrm{F}\right.$ to $1400^{\circ} \mathrm{F}$ ). Material property data (fatigue and creep) in N 47 exists for Type 304 and 316 Stainless Steels, 2 1/4 Cr-1Mo steel, and Alloy 800 Nickel Steel. After Solar Two, Code Case N-47 was superceded by Subsection NH of ASME Section III. Subsection NH is identical to Code Case N-47.

The next generation SPT will use a high nickel alloy and may require the application of the rules in Subsection NH of ASME Section III. Plastic strain may not be an issue with this material. However, if this is a requirement, then material fatigue and creep data will have to be developed for the high nickel alloy prior to receiver design. This metallurgy will permit higher strains for a given fatigue life and will allow a simplified tube to header nozzle interface. The design flux level with nickel alloy metallurgy and tube wall thickness of approximately $1.25 \mathrm{~mm}(0.05 \mathrm{in}$.) is a nominal $1 \mathrm{MW} / \mathrm{m}^{2}$ with local adjustments for salt velocity and temperature. Flux levels shall be confirmed through fatigue-creep analysis for the final material selected.

The design, fabrication, and welding of these assemblies is critical, and is affected by a requirement to have 360-degree access clearance around the tubes for fabrication welding and field replacement. A typical header will have in excess of 30 tube-to-header interface welds and 30 tube-to-nozzle welds. The header interface to the receiver intrareceiver piping is welded. The interface plane between the header and the intrareceiver piping is a zero stress load interface. Clearance to gain access to weld the tubes to header nozzle requires five to six different three-dimensional tube bend configurations. 
Header Nozzles. Solar Two required three different nozzle configurations.

- All of the connections on the bottom header used a thermal sleeve on the outside of the tube; salt trapped in the annular space between the tube and the sleeve moderated the thermal transitions at the welded joints.

- The connections at the ends of the upper header used a re-entrant nozzle. The tube extended into the header about $2.54 \mathrm{~cm}(1 \mathrm{in}$.), and a sleeve between the end of the tube and the wall of the header formed the pressure boundary. The differential expansion between the tube and the header was accommodated by flexure in the curved portions of the sleeve.

- The connections at the center of the upper header used flared, long radius nozzles. The fluid velocities were higher near the center of the header, and the corresponding increase in the heat transfer coefficients reduced the transient stresses to levels that did not require a reentrant nozzle. In addition, the flared nozzles did not extend into the header, which allowed the upper headers to drain completely.

Subsequent to the Solar Two manufacturing process, Research, Development, Test and Evaluation has demonstrated that header nozzles can be pulled directly from a header billet avoiding nozzle-to-header welding.

Tube and Header Weld nondestructive examination (NDE). All tube weld and header welds require NDE to verify weld quality and integrity. Each panel will be hydrotested to 1.5 times the operating pressures in accordance with ASME code requirements. In addition, each panel will be pressurized with helium to TBD bar (TBD psig) and the panel assembly helium leak tested in accordance with ASME Section V. Molten nitrate salt is an excellent wetting agent and will penetrate porous surfaces and minute cracks that will not be apparent with a hydrotest.

Tube clips. Each tube is supported at the top by a receiver panel support frame and periodically guided over their entire length by tube clips. These clips are individually welded to each tube. The attachment of the tube clips to the tubes will be designed and tested to assure that the applied weld procedure limits the penetration of the tube wall to the minimum amount necessary to assure complete fusion. Full penetration, pinholes, and burn-through will not be permitted.

The location of the tube clip (startup and warm up condition) on the tube relative to the oven box structural interface is critical. The tube clip acts as a heat sink. If the tube clip location coincides with the oven box structure, there will be no physical space available to add heat and salt freezing may ensue. Tube clips must be located outside the oven box envelope from the minimum to maximum thermal expansion condition.

Receiver Panel Support Frame. The receiver panel support frame is a close tolerance structural element that supports the tube header assembly at the top and guides, which allow free expansion of the tubes/bottom headers in the downward direction without binding. The following will be accommodated in the design of the receiver panel and panel support frame:

- The tube support frame will be designed to accommodate unlimited thermal growth of the tubes. "Unlimited" is defined as the point at which the tubes will melt. 
- The tube clip is required to slide freely in the tube guide and therefore tube guide material must be selected that will prevent gauling and binding.

- The frame restrains the tubes from bowing outwards and to sides, and prevents gaps from opening between tubes to the backside of the receiver.

- The structure accommodates oven boxes, oven box insulation system, oven box electric heaters, oven box power feeds, thermocouple (back of tube) tube clip guides, tube supports, EHT, panel insulation, etc.

- Stainless steel-jacketed thermal insulation (mineral wool) panels will be attached to the backside of each receiver panel sealing the backside of the tubes. The design must accommodate the daily panel thermal expansion and contraction cycles. The jacketing is intended to protect the mineral wool insulation and its binder from moisture.

- All back of panel instrumentation, e.g., thermocouples, must be allowed free movement with the panel over the maximum range of movement.

- The frame interfaces with the receiver secondary support steel and is designed to accommodate dead loads, thermal loads, wind loads, etc.

- Individual panel tubes must be designed to be replaced during an eight-hour nighttime maintenance shift. The cutting and welding operations are performed from inside the receiver. Tube removal and new tube fit-up occur from the outside. The receiver design must encompass field welding equipment, work access stands, lighting, and environmental shielding. Environmental shielding must permit the welding operations to be conducted with a $22 \mathrm{~m} / \mathrm{s}(50 \mathrm{mph})$ wind.

- The receiver structural frame and panel will be designed for removal and replacement within a 40-hour period (long-term hold).

\subsubsection{Receiver Vent and Drain System}

A receiver vent and drain system is required to fill the receiver during daily startup and drain the receiver during shutdown. The function of vent and drain system is to:

- Uniformly fill the receiver.

- Assure that no air is trapped in the receiver panels during the fill process resulting in receiver damage.

- Allow for rapid receiver a shut down and draining in $\leq 1 \mathrm{~min}$ to preclude freezing salt in the panels.

There are two methods to fill the receiver - a flood fill method from bottom to top, and serpentine fill method from receiver inlet to outlet. The preferred method is the flood fill, which allows 
the fastest uniform fill rate and the highest probability that all air will be vented as the receiver is filled. However, both methods need to be allowed in the design in order to provide operational flexibility.

There are a number of design options available for the vent and drain systems. Each option has pluses and minuses. The state-of-the-technology of molten nitrate salt system components, specifically valves, will dictate the lowest risk and lowest cost solution. As part of the design development, an industrial survey should be conducted relative to improvements in valve technology. Sandia National Laboratories (SNL) - Sun Lab should also be contacted as a technical source to determine which option should be implemented. The following is a discussion of these options.

Vent orifices. If vent system orifices are used, they will be sized to vent air during the fill process and supply air for the drain process. Figure 3-3 presents a design solution using line orifices. The vent orifice design is completely passive and eliminates problematic valves; however, the vents will continually flow a small quantity of salt into the outlet vessel during receiver operation, which reduces receiver efficiency. Individual vent lines from the panel jump over to the outlet vessel are required to assure that recirculation/back flow between panels does not occur. The individual vent lines will require EHT and insulation.

Vent valves. If vent valves are used, a reliable high temperature nitrate salt valve $565^{\circ} \mathrm{C}$ $\left(1050^{\circ} \mathrm{F}\right)$ that eliminates stem packing will have to be tested and qualified. A common vent line may be used. The major design issue is how to confirm that all receiver panels are filled, and that all air is vented before closing the valves to transition to serpentine flow. Infrared (IR) camera images of the receiver panels during the fill, back of receiver tube temperatures, and header temperatures outlet temperatures down stream of the valves are possible indications of a uniform fill.

The individual return headers may be consolidated into a single header with larger line size, as long as the common header pressure is maintained approximately equal to the downcomer pressure. This is to assure that receiver recirculation flow does not occur. A multiport vent valve will further reduce piping, but will require both a development program and a test program to qualify the valve before actual use.

Common to all options are the vent headers from the panel jumper piping to the receiver outlet vessel. It is critical that the vent headers are sloped and that the outlet vessel tie-in points are at the elevation high point under all thermal expansion conditions. Each header must be capable of self-draining back through the panel jumper. The piping design near the panel headers, jumpers, and vent headers is congested and very complex.

Receiver drain valves are two position valves - full open or full closed gate valves. Valve position indication, as well as flow indication through each circuit, is required. 


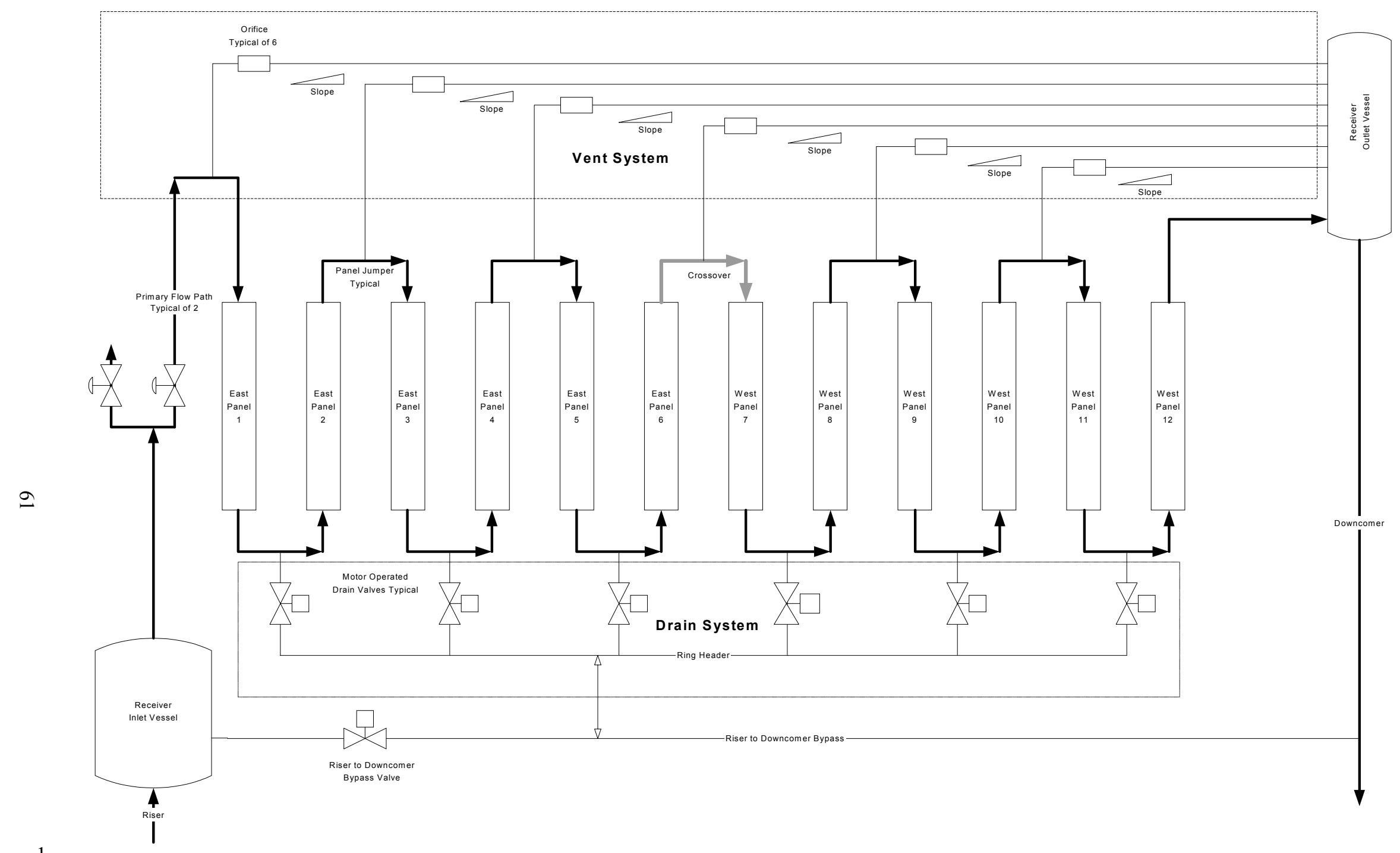

Figure 3-3. Design Solution Using Line Orifice. 


\subsubsection{Oven Boxes}

2 Panel headers, inlets, and outlets, will be protected by removable insulated thermally3 conditioned (electrically heated) oven boxes. The oven box radiant heaters are required to pre4 heat the header assemblies to $315^{\circ} \mathrm{C}\left(600^{\circ} \mathrm{F}\right)$ within 0.5 hour while exposed a wind speed of 23 $5 \mathrm{~m} / \mathrm{s}(35 \mathrm{mph})$ during the transition from preheat to normal operation. Figure 3-4 is a conceptual sectional view of the oven box assembly.

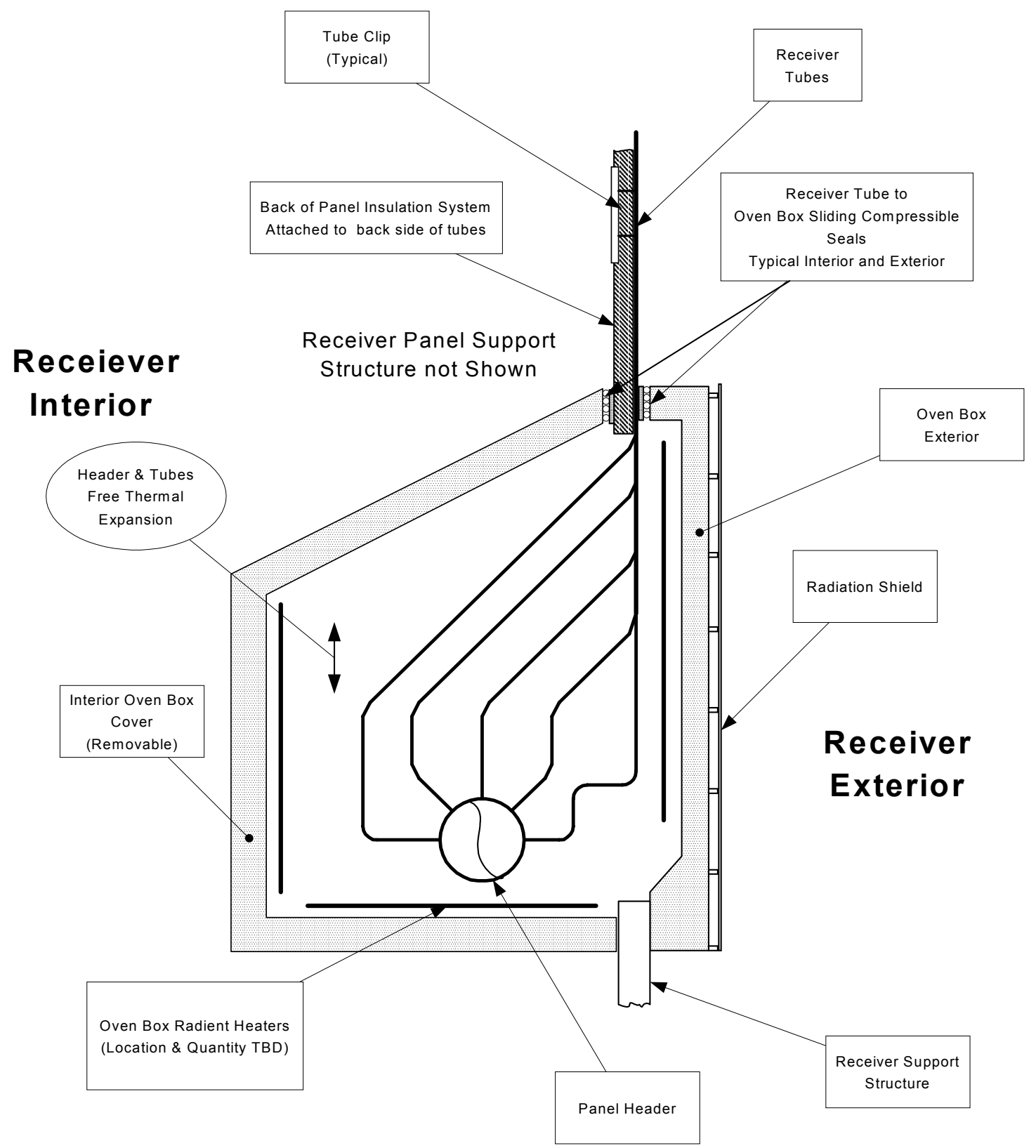

Figure 3-4. Conceptual Sectional View of Oven Box Assembly. 
The physical configuration of the oven box makes it practically impossible to completely seal gaps and spaces between the receiver tubes and the oven box. There are air passages at the oven box interface with the tubes on both sides that allow for tube expansion. There are also gaps between tubes themselves. These openings will result in convection heat losses, especially on windy days, if not sealed.

The oven box-to-tube interface design will include a means of sealing the interface while allowing for tube expansion e.g., compressible seal, spring loaded sealing surface. The backside of the panels will be sealed with insulation.

Radiant electric heating elements will be located on the oven box wall surrounding the header assembly. In addition, the receiver panel tube penetration interface with the oven box must be analyzed to determine if additional EHT is required on the panel surface with the oven box.

The header orientation relative to the receiver panel will be such that the header and the tube bends are located facing towards the inside of the receiver to reduce convection losses. The design and clearance envelopes and available space to accommodate the oven box inside the receiver is non-trivial and must address:

- Removal of the oven box assembly,

- Removal and access for maintenance of the heater elements,

- Removal and replacement of individual tubes and complete panel assemblies,

- Clearances for intrareceiver piping and its insulation and electrical heating,

- Pipe supports and receiver panel support structures,

- Instrumentation and electrical raceway and conduit,

- Secondary support steel, ladders, platforms, etc.,

- Removable weather sealing and thermal insulation, and

- Weather sealing the receiver, oven boxes, and the insulation to reduce wind losses and provide rain protection.

Refer to page 63, line 9 on receiver sizing to address the cost trade-off on receiver size versus reduction of thermal losses. Accommodating the oven boxes inside the receiver will result in a receiver of larger diameter.

An oven box exterior radiation shield is required to protect the oven boxes from excessive flux spillage from the heliostats. Both the top and bottom oven box exteriors require protection. The radiation shield requirement are as follows:

- The shield will be designed to accommodate 150 to $200 \mathrm{~kW} / \mathrm{m}^{2}$.

- The shield will be designed to be replaceable in a single night shift of eight hours.

- Shield material will be Type 304 or 316 stainless steel sheet 1.6 to $2 \mathrm{~mm}-(\sim 0.07$ in.-) thick coated with white Pyromark ${ }^{\circledR}$ ceramic paint. 
- The coverage area will extend 360 degrees circumferentially around the receiver with a TBD panel height. Shield height is TBD m (TBD ft) and will be specified as part of the receiver and heliostat field design.

\subsubsection{Receiver Sizing Methodology}

The analysis required to determine receiver thermal duty MWt for the RS is discussed in Section 1.4.1. This section determines the basis for sizing the receiver and receiver panels.

Establish the allowable incident flux as a function of bulk salt temperature, allowable cumulative tube strains, and tube corrosion rates at the salt film temperature.

Allowable receiver flux. The receiver size is driven by the maximum allowable flux on a receiver panel $\left(\mathrm{MW} / \mathrm{m}^{2}\right)$. Cost of energy from a heliostat is relatively expensive, which provides economic incentive to design receivers with high thermal efficiency. High receiver efficiency is achieved by reducing the radiation and convection thermal losses by reducing the absorber area - the smaller the receiver, the higher the efficiency and higher the flux levels. Current receivers are designed to operate with very high flux levels, which, in turn, produce a temperature gradient through the tube wall. Based upon the tube metallurgy selected, these fluxes are large enough to develop plastic strains. Plastic strain is cumulative and receiver tubes eventually fail through low cycle fatigue. In addition, thin-walled receiver tubes allow high heat transfer rates, reduce the temperature gradient, and therefore improve efficiency. The receiver tube to header connection is the point of greatest thermal stress in the receiver due to rapid temperature changes associated with cloud transients and the difference in wall thickness between the receiver tube and the header.

Establish curve of allowable incident flux as a function of circumferential position on the receiver.

Estimate annual receiver spillage losses, reflection losses, and heat losses due to convection (wind velocity), conduction, and radiation for various combinations of receiver height and diameter. The height and diameter (aspect ratio) are selected consistent with the allowable maximum fluxes at the top and bottom of the receiver.

Receiver aspect ratio (height to diameter) will be 1.2 to 1.5 . A taller height receiver is desirable due to the pointing accuracy that heliostats can be aimed at the receiver while minimizing spillage. A larger diameter receiver is desirable to maximize interior volume necessary to accommodate header tube bends and oven header boxes, internal piping, outlet vessel, crossover piping, support structure, ladders, and platforms losses. A space allocation design analysis is required to optimize the selection of aspect ratio with respect to loss in receiver efficiency resulting from increased thermal losses (convection and conduction) due to larger diameter.

Receiver oven box radiation shield height and depth may be as large as necessary to protect equipment including the crane, receiver outlet vessel, etc.

Receiver dimensions should be selected that give the best combination of CS cost and RS cost. 


\subsubsection{Receiver System Design Temperatures}

RS design temperatures are shown in Table 3-4.

Table 3-4. Receiver Maximum Design Temperatures

\begin{tabular}{|c|c|c|c|}
\hline \multirow{2}{*}{ Operating Condition } & \multicolumn{2}{|c|}{ Maximum Temperatures } & \multirow{2}{*}{$\begin{array}{c}\text { Cumulative } \\
\text { Time (hours) }\end{array}$} \\
\hline & Bulk ${ }^{\circ} \mathrm{C}\left({ }^{\circ} \mathrm{F}\right)$ & Film ${ }^{\circ} \mathrm{C}\left({ }^{\circ} \mathrm{F}\right)$ & \\
\hline Steady State & $\begin{array}{c}580^{\circ} \mathrm{C} \\
\left(1075^{\circ} \mathrm{F}\right)\end{array}$ & $\begin{array}{c}600^{\circ} \mathrm{C} \\
\left(1112^{\circ} \mathrm{F}\right)\end{array}$ & Unlimited \\
\hline Transient (5 minutes) & $\begin{array}{c}602^{\circ} \mathrm{C} \\
\left(1115^{\circ} \mathrm{F}\right) \\
\end{array}$ & $\begin{array}{c}616^{\circ} \mathrm{C} \\
\left(1140^{\circ} \mathrm{F}\right) \\
\end{array}$ & $2500 \mathrm{Hrs}$ in $30 \mathrm{Yrs}$ \\
\hline Receiver Trip & $\begin{array}{c}616^{\circ} \mathrm{C} \\
\left(1140^{\circ} \mathrm{F}\right)\end{array}$ & $\begin{array}{c}630^{\circ} \mathrm{C} \\
\left(1165^{\circ} \mathrm{F}\right)\end{array}$ & None \\
\hline
\end{tabular}

4

$\underline{\text { Receiver operating design temperatures }}$

Receiver inlet temperature: $285^{\circ} \mathrm{C}\left(550^{\circ} \mathrm{F}\right)$

Receiver outlet temperature: $565^{\circ} \mathrm{C}\left(1050^{\circ} \mathrm{F}\right)$

Design temperatures for equipment and piping upstream and downstream of the receiver. Cold salt loop piping maximum design temperature will be $400^{\circ} \mathrm{C}\left(750^{\circ} \mathrm{F}\right)$. This includes the cold salt circulation pump, receiver inlet tank, cold salt pumps riser piping, supply piping to the receiver, and bypass piping up to the isolation valve. The minimum cold salt loop design temperature shall be $260^{\circ} \mathrm{C}\left(500^{\circ} \mathrm{F}\right)$.

Hot salt loop piping design temperature shall be $593^{\circ} \mathrm{C}\left(1100^{\circ} \mathrm{F}\right)$. This includes the piping outlets from the receiver, receiver crossover piping, receiver outlet vessel, downcomer piping, and bypass piping to and including the isolation valve.

\subsubsection{RS Panels Coatings}

Receiver panels and housing will be coated with a Pyromark ${ }^{\circledR}$ ceramic coating. Application and curing of the coating to receiver elements requires care because the thickness is critical to its performance. Pyromark ${ }^{\circledR}$ is located at:

Tempil, Inc.

2901 Hamilton Boulevard

South Plainfield, NJ 07080

Phone: 1 (800) 757-8301

Facsimile: 1-908-757-9273

Email: tempil@tempil.com 
1 Absorption - Receiver panel tubes will be coated with black Pyromark ${ }^{\odot}$ Coating to enhance in-

2 solation absorption. The Pyromark ${ }^{\odot} 2500$ Series product has the following characteristics for

3 thermal design:

4 - 0.96 (new) solar absorptivity

5 - 0.93 (effective over life time) solar absorptivity

6 - 0.83 IR emissivity

7 Reflection - Receiver oven boxes and non-absorbing structural elements exposed to focused in8 solation will be protected with a white Pyromark ${ }^{\odot}$ coating. The Pyromark ${ }^{\odot} 2500$ Series product

9 has the following characteristics for thermal design.

$10 \quad 0.80$ Solar - reflectivity

$11 \bullet 0.84$ IR emissivity

$12 \quad$ 3.3.5 Receiver System Materials

13 The receiver, inlet and outlet vessels, and pump are defined in Table 3-5.

Table 3-5. Receiver Materials Specification

\begin{tabular}{|c|c|c|}
\hline Equipment/Component & Materials & $\begin{array}{c}\text { Corrosion Allowance and } \\
\text { Remarks }\end{array}$ \\
\hline \multicolumn{3}{|l|}{ Receiver } \\
\hline Tubing & High Nickel Alloy & \\
\hline Tube Clips & High Nickel Alloy & \\
\hline Headers & High Nickel Alloy & $\begin{array}{l}\text { Corrosion allowance } 0.7 \mathrm{~mm}(25 \\
\text { mils) }\end{array}$ \\
\hline Nozzles, Forged & High Nickel Alloy & \\
\hline Inlet Vessel & & $\begin{array}{l}\text { Corrosion allowance } 0.3 \mathrm{~mm}(10 \\
\text { mils) }\end{array}$ \\
\hline Plate & Carbon Steel, ASTM A516, Gr 70 & \\
\hline Nozzles & Carbon Steel, ASTM A105 & \\
\hline Outlet Vessel & & $\begin{array}{l}\text { Corrosion allowance: } \\
\text { Type } 3470.7 \mathrm{~mm}(25 \text { mils) } \\
\text { Type } 321 \text { TBD (refer to Section } \\
\text { 4.3.1.1) }\end{array}$ \\
\hline Plate & $\begin{array}{l}\text { Stainless Steel, ASTM A240, Gr } \\
321 \text { or } 347\end{array}$ & \\
\hline Nozzles & $\begin{array}{l}\text { Stainless Steel, ASTM A182, Gr } \\
\text { F321 or F347 }\end{array}$ & \\
\hline \multicolumn{3}{|l|}{ Receiver Circulation Pump } \\
\hline & $\begin{array}{l}\text { Carbon Steel, ASTM A216, Gr } \\
\text { WCB }\end{array}$ & \\
\hline
\end{tabular}




\subsubsection{Receiver Inlet Vessel Design Basis}

The inlet vessel performs the following functions:

- Stores a quantity of salt adequate to supply the receiver for 60 seconds following a failure of the cold salt pump or power.

- Provides a free surface for establishing a level during system filling and initial normal operation. The level in the inlet vessel is monitored by a nuclear level detector, a passive device; refer to page 63, line 16 and Section 4.6.6.1 for source of supply. It uses two cesium sources on one side of the inlet vessel and a vertical tube detector on the other. Salt level inside the vessel attenuates the radiation. The vertical radiation distribution is measured by the detector and the distribution converted to level reading.

- Provides a free surface for establishing a level during standby; the position of the throttle valves in the downcomer is adjusted to maintain a set point for the inlet vessel level.

- Provides an ullage volume above the salt inventory for compressed air (oil free plant service air); the ullage pressure is set once during startup to provide the potential energy to supply the receiver for 60 seconds following a failure of the cold salt pump.

\section{$\underline{\text { Receiver inlet vessel design characteristics }}$}

- The vessel shall be designed and fabricated to Section VIII of the ASME Pressure Vessel Code and shall be code stamped.

- The dimensions of the vessel are selected so that

- The inventory of salt is adequate to supply the receiver for 60 seconds following a loss of the receiver pumps with a flow rate adequate to protect the receiver. The initial ullage pressure is established during the daily startup using the plant air system with a maximum available pressure of (typically) $862 \mathrm{kPa}$ (125 psig). Refer to line 16, above.

- The ullage volume is large enough that the decay in the pressure does not cause the salt flow rate to drop below that required to protect the receiver.

- Inlet Vessel design pressure will be receiver cold salt circulation pump shut off head plus $10 \%$.

- Provides a $862 \mathrm{kPa}$ (125 psig) $100 \%$ oil-free compressed air supply connection to the inlet vessel. No vent connection is required. The connection will be used for an initial inlet vessel pressurization during startup. A fixed mass of air is trapped in the ullage volume when the vessel is filled. The air supply must be regulated from TBD $\mathrm{kPa}$ (TBD psig) minimum to the plant air system maximum, and provided with check valve and a positive shutoff to assure that nitrate salt, liquid or vapor, does not enter the system. 
- The speed of the receiver circulation pump is controlled to establish a calculated ullage pressure; the pressure is that required to overcome the pressure losses through the receiver with a salt flow rate suitable for clear sky conditions.

- Preliminary calculations have shown an inlet vessel with passive level and pressure control is somewhat larger than one with an active control. However, the additional expense for the larger vessel is justified by improvements in the reliability of the receiver.

- Receiver inlet vessel level instrument will be a nuclear level detector or equivalent manufactured by:

TN Technologies

Round Rock, Texas

Telephone: $512-388-9100$

Web Address: http://www.tn-technologies.com.

- Receiver inlet vessel pressure instruments will be diaphragm-type with a fluid filled capillary to isolate the sensor from the molten salt. Capillaries may be filled with NaK (liquid at ambient conditions), organic salt (liquid at ambient conditions), or HITEC XL Salt (must be heat traced).

\subsubsection{Receiver Outlet Vessel Design Basis}

The outlet vessel performs the following functional requirements:

- Provides a free surface for establishing a level during normal operation; the position of the primary downcomer throttle valve is adjusted to maintain a set point for the level. The level in the vessel is monitored by two independent level gages.

- Provides a storage volume for the salt inventory in the inlet vessel. If the flow in the downcomer were blocked, the outlet vessel would store the inventory from the inlet vessel for a period of at least 60 seconds. During this time, the collector field must be defocused and the cold salt pump stopped.

Receiver outlet vessel design characteristics:

- Vessel shall be designed and fabricated to Section VIII of the ASME Pressure Vessel Code and shall be code stamped.

- The diameter will allow fluid levels to vary at a rate comparable to the flow rate into and out of the vessel so that small variances in flow do not result in large changes in level. Vessel diameter will be constant.

- The bottom of vessel elevation will be above the top of receiver panel header elevation in all modes of operation and at all temperatures. 
- Thermowell elevation will be below the low liquid level (LLW) to assure the probe is always in wetted region of the vessel.

- Atmospheric level instrument should be a bubbler type.

- Pressure instruments will be diaphragm type with a fluid filled capillary to isolate the sensor from the molten salt. Capillaries may be filled with $\mathrm{NaK}$ (liquid at ambient conditions), organic salt (liquid at ambient conditions), or HITEC XL Salt (must be heat traced).

- Base line design for receiver outlet vessel will include an atmospheric vent TBD m (TBD ft) height above the top elevation of the receiver. A failure modes study will be performed to determine what surge conditions will result in a vent over flow. Design solution must consider accommodating one minute of full flow conditions from the receiver. The lowest cost design solution will be selected that will accommodate the surge condition considering the following options:

- Route the molten salt to the TSS hot tank through a dedicated vent line. The vent and drain line will be insulated and heat traced.

- Capture the event in a tank located at the receiver deck elevation.

- Provide a vent spray nozzle that will disperse the flow into fine droplets (prill size) that will allow cooling and solidification before reaching ground elevation under the maximum ambient temperature with no wind. Spray nozzle will direct molten salt away from the tower structure. This approach will require safety review and possible approval from local environmental authorities.

3.3.8 Receiver Circulation Pump Design Basis

\subsubsection{Pump type}

The receiver circulation pump will be a single vertical turbine pump with VSD. The pump will be supported by a bridging structure on top of the cold salt tank and take suction directly from the cold salt tank. The shaft length will be between 12 to $14 \mathrm{~m}$ (40 to $45 \mathrm{ft}$ ) measured from the

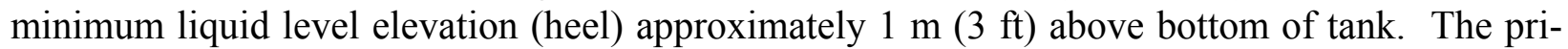
mary supply source for qualified receiver circulation pumps, SGS circulation pumps, and SGS attemperation pumps is:

Nagle Pumps, Inc.

1249 Center Avenue

Chicago Heights,

Illinois 60411

Telephone: 1 (708) 754-2940

Facsimile: 1 (708) 754-29944

Email: www.naglepumps.com

Technical Contact Mr. Daniel L. Barth 
The baseline approach is to install a single nitrate salt pump is each service and warehouse a complete spare pump and motor with additional spare parts as recommended by the manufacturer. The traditional approach of having an installed spare results in additional piping and valves, which lowers overall system reliability. Each pump will be supplied with a tail pipe of sufficient length to extend into the heel to empty a tank in case of a leak.

\subsubsection{Pump rating}

The pump will be sized for $100 \%$ receiver flow through both circuits plus $10 \%$ margin. Pump will be capable of operating from $0 \%$ flow through $110 \%$ of capacity. Pump head is determined by the sum of the line and control valve losses, static head due to receiver tower measured to top of receiver, pressure drop through the receiver, and the ullage pressure necessary to maintain flow through the receiver for 60 seconds on the "best" day, summer solstice (maximum ullage pressure).

\subsubsection{Pump discharge interface}

The pump discharge may be either a ring-type joint (RJT) or Reflange R-Con Connector type. Ring gasket or Hub ring shall be TBD 321 or 347 stainless steel.

\subsubsection{Pump mounting interface}

Pump will be flange mounted to the structural support frame and its shaft will extend into the cold salt tank through an insulated gland. The pump will be capable of being removed and replaced during a single shift.

\subsubsection{Receiver Control System}

Typical receiver system operations are discussed below:

The basic objective is to maintain tube strains within acceptable limits while simultaneously regulating salt flow temperature to $565^{\circ} \mathrm{C}\left(1050^{\circ} \mathrm{F}\right)$. Refer to attached ASME Paper: Automatic Control of Solar Two Receiver for an overview of the flow-control algorithm implemented at Solar Two. Baseline control system is recommended as follows:

- A combination of feed-forward signal sets flow rate control demand signal on the control valves from two groups of photometers viewing concentrated flux reflected from each of the receiver panel flow circuits.

The photometers consist of a filter, a collimator, and a photodiode. Refer to Section 4.6.5 for the manufacturer. A receiver with a 24-panel configuration uses eight photometers each viewing the average reflected light from three adjacent panels. The incident flux on the semiconductor diode produces a voltage proportional to the flux. Photometer calibration is a trial-and-error process where the feed-forward calculation is adjusted until it closely matches 
the flow rates determined by experimentation to yield an outlet nitrate salt temperature of $565^{\circ} \mathrm{C}\left(1050^{\circ} \mathrm{F}\right)$.

- Two proportional-integral feedback temperature signals from thermowells (redundant elements) on the outlet of each flow circuit trim the flow rate signal.

- Flow from the receiver inlet vessel through the east and west receiver panel circuits is controlled a single flow control valves (fail open) in each circuit.

- Flow control to the receiver inlet vessel is based upon modulating the speed of the cold salt pump's VSD to maintain either a pressure or level set point of the receiver inlet vessel.

- Panel high temperature protection and heliostat defocus basic algorithm will defocus approximately $30 \%$ of heliostats on a high temperature alarm, approximately $60 \%$ on a high high temperature alarm, and defocus all heliostats on a high - high - high temperature alarm. Protection system will comprised of back of tube thermocouples. The number and location of thermocouples will be such that the entire surface of each panel is protected to include the top, center, bottom, and four edges, seven thermocouples per panel minimum.

- Four permanent IR cameras capable of viewing the entire receiver surface will be used by the plant operators to support the daily preheat, daily receiver flood fill/serpentine fill processes, and daily receiver drain. Cameras should be collocated with the BCS cameras. IR cameras will be used to check the receiver for cold spots to prevent freezing salt during the fill process and drain process and for receiver hot spots. Refer to Section 4.6.7 for IR camera requirements and the manufacturer.

\subsubsection{Typical Sequence of Operations}

\subsubsection{General Discussion}

Heliostats transition from Standby to Preheat when receiver panels are preheated to between $260^{\circ} \mathrm{C}$ to $320^{\circ} \mathrm{C}\left(500^{\circ} \mathrm{F}\right.$ to $\left.600^{\circ} \mathrm{F}\right)$. A typical daily receiver flood fill and serpentine fill procedure begins with the receiver in Long Term Hold/Overnight Hold and proceeds as described in the sections below. Two receiver filling processes are described; however, the flood fill procedure is preferred since it offers the least risk.

\subsubsection{Flood Fill Procedure}

Step 1. Receiver inlet vessel is under level control-minimum level with a minimum ullage pressure and receiver circulation pump speed above point at which pump will stall. Downcomer is filled. Heliostats are in Standby.

Step 2. Receiver drain and vent valve are closed and receiver flow valves are closed.

Step 3. Air valve is opened and inlet vessel pressurized to a TBD kPa (TBD psig). The design pressure is driven by the size of the receiver inlet vessel and is limited by the maximum pressure 
of the BOP utility air system. Level is maintained. Receiver pumps speed increases to compensate driving the pressure up with a slight increase in level.

Step 4. Receiver panels are confirmed preheated and ready. Receiver transitions from Preheat to Normal Operation.

\section{Step 5. Open vent and drain valves.}

Step 6. Verify receiver bypass valve is open. Pump is maintaining level in inlet vessel and flowing salt through the bypass and downcomer returning salt to the cold.

\section{Step 7. Downcomer throttle is in manual operation and open.}

Step 8. Verify receiver flow valves are closed, pump speed is ramped to increase receiver inlet vessel level, and initiate flood fill of receiver.

Step 9. Receiver flood fill confirmed by receiver inlet vessel level, temperature rise is detected by IR cameras on receiver panels and by thermocouples in vent header outlets detecting rise in temperature above EHT $260^{\circ} \mathrm{C}\left(500^{\circ} \mathrm{F}\right)$ set point.

Step 10. Close receiver drain valves; open receiver flow control valves and close bypass valve. When outlet vessel level reaches normal liquid level (NLL), change the set point on throttle valve from manual to automatic outlet vessel level control.

Step 11. Switch control of the receiver circulation pump from the level control set point to the pressure control set point. The vessel level and ullage pressure are coupled by the ideal gas law $(\mathrm{pV}=\mathrm{NRT})$. The nuclear level controller monitors level to ensure that leakage through the air supply line or relief valve does not cause the level to drift.

\subsubsection{Serpentine Fill Procedure}

Step 1. Receiver inlet vessel under level control-minimum level with a minimum ullage pressure and receiver circulation pump speed above point at which pump will stall. Downcomer is filled. Heliostats are in Standby.

Step 2. Receiver drain and vent valve are closed.

Step 3. Air valve is opened and inlet vessel pressurized to a TBD kPa (TBD psig). The design pressure is driven by the size of the receiver inlet vessel and is limited by the maximum pressure of the BOP utility air system. Level is maintained. Receiver pumps speed increases to compensate driving the pressure up with a slight increase in level.

Step 4. Receiver panels are confirmed preheated and ready. Receiver transitions from preheat to normal operation.

Step 5. Verify that drain valves are closed. Verify that vent valve(s) are open. 
Step 6. Receiver bypass valve closed.

Step 7. Downcomer throttle is in manual operation and closed.

Step 8. Receiver flow valves are opened, throttle valve is opened, and pump speed ramped to maintain receiver inlet vessel level.

Step 9. Receiver fills serpentine flow is established.

Receiver serpentine flow is confirmed by receiver inlet vessel level, temperature rise detected by IR cameras and by thermocouples in vent headers detecting rise in temperature above EHT $260^{\circ} \mathrm{C}\left(500^{\circ} \mathrm{F}\right)$ set point.

Step 10. When outlet vessel level reaches NLL, change the set point on throttle valve from manual to automatic outlet vessel level control.

Step 11. Switch control of the receiver circulation pump from the level control set point to pressure control set point. The vessel level and ullage pressure are coupled by the ideal gas law (pV

$=\mathrm{NRT}$ ). The nuclear level detector monitors level to ensure leakage through the air supply line or relief valve do not cause the level to drift.

\subsubsection{Minimum Receiver Fill Conditions}

Minimum receiver fill conditions required to initiate preheat and fill sequence are:

- Wind Speed $<35 \mathrm{mph}$

- Sun $>2^{\circ}$ above the horizon

- No minimum ambient temperature condition

- Minimum receiver surface temperature of $230^{\circ} \mathrm{C}\left(450^{\circ} \mathrm{F}\right)$

\subsection{Thermal Storage System}

\subsubsection{System Description}

The TSS baseline system elements are comprised of:

- Cold nitrate salt storage tank. An American Petroleum Institute (API) 650 atmospheric tank includes manways, pressure relief, vents, tank sparger ring, instrumentation, and tank insulation system. The tank stores cold salt from steam generator and supplies cold salt to RS circulation pump and SGS attemperation pump.

- Hot nitrate salt storage tank. An API 650 atmospheric tank includes manways, vents, tank sparger ring, pressure relief components, instrumentation, and tank insulation system, and stores hot from the receiver and supplies hot salt to the SGS circulation pump. 
- Cold and hot nitrate salt tank foundations, including insulation, passive foundation cooling system, and leak detection system.

- Cold nitrate salt storage tank immersion heaters that maintain tank temperatures above $260^{\circ} \mathrm{C}$ $\left(500^{\circ} \mathrm{F}\right)$ and are capable of heating cold tank salt inventory to $400^{\circ} \mathrm{C}\left(750^{\circ} \mathrm{F}\right)$.

- Hot nitrate salt storage tank immersion heaters that maintain tank temperature above $260^{\circ} \mathrm{C}$ $\left(500^{\circ} \mathrm{F}\right)$ and are capable of heating hot tank salt inventory to $540^{\circ} \mathrm{C}\left(1000^{\circ} \mathrm{F}\right)$.

- Internal volume air heater system used to thermally condition air volume in both tanks during initial startup and to thermally condition hot tank air volume to prevent tank heating rate from exceeding $56^{\circ} \mathrm{C} / \mathrm{hr}\left(100^{\circ} \mathrm{F} / \mathrm{hr}\right)$.

- Hot nitrate salt storage tank mixer. A mechanical system to mix the content of the hot tank to prevent temperature gradients in excess of $56^{\circ} \mathrm{C}\left(100^{\circ} \mathrm{F}\right)$.

\subsubsection{Scope of Supply}

TSS design, physical design, and integration package includes PFDs, process and instrument diagrams, technical specifications, general arrangement drawings, nozzle orientation schedule, physical design of interconnecting piping, structural, electrical, and control systems, tank subcontract package, specification and procurement of the bulk premixed nitrate salt, shop drawing review, construction and startup and activation. The site work includes tank foundations, berms, and a passive cooling system. Also included is the design task to thermally condition the TSS from the long term hold state through the transition to normal operation while minimizing parasitic electrical power loads and thermal heat losses.

The TSS salt storage tank design, fabrication, field erection, and startup support subcontract package includes the design calculations, detailed tank design, shop drawings, insulation mat and insulation systems, leak detection system, tank insulation systems, tank material procurement and tank erection, tank testing, and tank startup and activation support.

The nitrate salt procurement package includes the supply and transportation form the point of manufacture to the plant site of bulk premixed nitrate salt.

The nitrate salt handling and melting subcontract or equipment procurement package includes providing the melting process equipment, bulk material handling equipment, and performing the work. Depending upon the cost to the project, the package may be structured as either an equipment rental or an equipment purchase. Work includes all required melting equipment and process fired heater fuel, operating the equipment on a 24-hour, seven-day-per-week basis until the entire solid bulk inventory has been melted and installed in the hot tank. Plan for and accommodate the nitrous oxides (NOX) off gassing. Long lead delivery nitrate salt unique pumps, valves, and instruments may be provided by the project on a loan basis. 


\subsubsection{Thermal Storage System Design Basis}

\subsubsection{Hot and Cold Tank Design Basis}

Tanks will be designed in accordance with API 650. Tanks will be an insulated vertical cylindrical design with flat or domed roofs.

\section{Tank Sizing. Tank sizing will be based upon the following criteria:}

- The volume of nitrate salt required to sustained operations for base time period, e.g., 16 hours of storage for a 24-hour-per-day SPT operation. Height is limited by the maximum length of the vertical turbine pump barrels both in liquid and dry minus the following:

- $\quad 1.0 \mathrm{~m}(3 \mathrm{ft})$ for tank heel

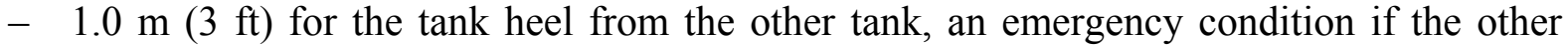
tank has a leak

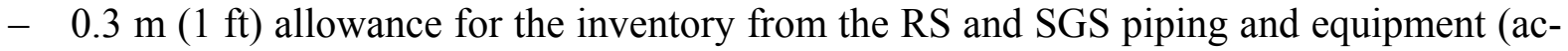
tual liquid volume will need to be converted to equivalent height to confirm the allowance)

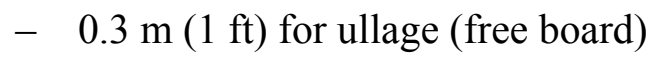

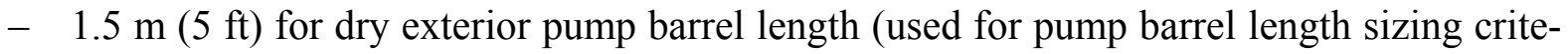
ria, not tank sizing)

- Pumps will be mounted on a ridged structural steel support bridging the storage tanks including structural support member depth and platform steel.

- Insulation and jacketing thickness on the top of the tanks

- Tank thermal expansion clearance

- Vertical access clearance

- The maximum barrel length on vertical turbine pumps from preliminary contact with industry is in the range of 12 to $14 \mathrm{~m}$ (40 to $45 \mathrm{ft}$ ). This includes tank liquid/dry level data above that will establish the tank height.

- The thermal fatigue life of the tank floor to wall joint is dependent upon the magnitude and frequency of the pressure and thermal cycles of each tank. The tank internal pressure cycles can be controlled and are not an issue. A commercial SPT with 24-hour dispatchable power will have substantially larger tanks than Solar Two. Thermal fatigue at this joint may be an issue. The tank design/erector should evaluate both the welded orthogonal joint and a curved joint (lower outside section of a torus) as an option to reduce thermal fatigue. 


\subsubsection{Tank Vents and Pressure Reliefs}

Tank vents and pressure reliefs are required to:

- Equalize daily swings in tank levels due to normal tank liquid volume changes.

- Accommodate tank overpressure events based upon an SGS tube rupture, which allows steam into the salt flow causing high overpressure surge into either storage tank.

- Accommodate tank vacuum pressure event resulting from blockage in the vent system, which will preclude the tank from breathing or a rapid decrease in tank temperature from cold salt.

Vent and Relief Requirements. Provide an atmospheric tank vent on each tank to accommodate daily volumetric air changes within the each tank. Provide tank overpressure protection to accommodate the worst case scenario of a SGS tube rupture, which allows steam flow back into the tanks. Provide tank vacuum pressure protection in the event the atmospheric vent becomes plugged.

Salt mists are present inside each tank. The salt mist will condense on any surface when the surface temperature falls below $240^{\circ} \mathrm{C}\left(465^{\circ} \mathrm{F}\right)$. Therefore, the vent and relief systems must be electric heat traced and insulated from the intake/discharge point to the entry point into each tank. A common vent system tying the two tanks together is not acceptable since the EHT power consumption requirements will far exceed any benefit of tying the two together.

Independent pressure and vacuum relief devices are required. All components will be exposed to nitrate salt and shall be selected on the basis that they will be subject to both nitrate salt mist and water vapor simultaneously. All components will be corrosion-resistant stainless steel material minimum American Society for Testing and Materials (ASTM) 321 for housings, springs, seats, etc.

The overpressure relief system will use the cross-sectional area available from the man-ways rather than use specialized overpressure relief devices. Just raising the man-ways cover off the seats results in excessive heat losses and is not acceptable. The design solution developed in conjunction with the tank subcontractor should consider:

- Compliance with API 650

- Minimizing thermal losses (sealing, insulation, and EHT)

- Blockage due to salt mist condensation

- Long-term corrosion protection of the device and the surrounding insulation system.

- Reliability with possible redundancy

The vacuum pressure relief system may have to be independent from the tank vents due to crosssectional area requirements. The vacuum relief must comply with API 650 requirements and provide reliable protection.

Tank vents will be electric heat traced, insulated, and use corrosion-resistant materials. Both vent deigns will take the initial NOX off gassing into consideration, but will be converted to 
"goose neck" configurations after the chemical reaction has completed. The off gassing vent may be a stack TBD feet tall, if environmental regulations allow direct NOX discharge. The thermal system design will consider that the airflow will fluctuate as a function of temperature and varying tank liquid levels. The rate of ambient (cool) airflow into the tank will determine EHT: watt density, location of the temperature sensors limits, possible zone definition, etc.

Vent and Relief Protection System Sizing. Tank overpressure and vacuum relief size will be in accordance with API 650.

Overpressure relief will be sized to accommodate a tube rupture in the SGS that allows steam into the tanks. It is intended that pressure relief system design use the tank "man-ways" as the relief device, rather than specialized relief valves. An analysis must be performed in conjunction with SGS system/equipment designer to determine the maximum steam pressure pulse criteria and the area necessary to protect each tank.

Vacuum relief will be sized for abnormal decreases in tank pressure caused either by a blocked vent, or a rapid decrease internal tank temperature caused by the introduction of cold salt into tank with low salt level at a higher temperature.

Tank vents will be sized to accommodate normal operating changes in tank liquid level, atmospheric pressure changes, etc. In addition, the vent systems must accommodate the NOX off gassing during initial salt melting.

\subsubsection{Tank Immersion Heaters}

Tank immersion heaters are required in each tank to:

- Prevent salt from freezing due to conduction, radiation, and convection heat losses from tank floor, sidewalls, and roof during long-term holds.

- Have the capability to raise bulk salt storage temperature in each tank to

- $\quad 400^{\circ} \mathrm{C}\left(750^{\circ} \mathrm{F}\right)$ cold tank

$-540^{\circ} \mathrm{C}\left(1000^{\circ} \mathrm{F}\right)$ hot tank

The temperature heat-up rate is TBD, differs for each tank, and will be determined by analysis. The heat-up rate is not critical.

System Requirements. Immersion heater housing assemblies are capped pipes mounted in the tank walls that extend radially into each tank. The heater will be installed at an elevation within the heel $(<1 \mathrm{~m}[3 \mathrm{ft}]$ from tank floor), allowing permanent submergence.

The capped pipe will form the heater element to liquid pressure boundary and provide a means to easily replace heater elements. The pipe schedule will be a minimum schedule 40 . The capped pipe material will operate at a higher temperature than the bulk liquid temperature in the tank, and therefore material selection must be coordinated between the tank designer and the immer 
sion heat manufacturer. The capped pipe material metallurgy may be different from the tank material and the penetration interface fitting.

The capped pipe assembly will be supported from the tank floor to minimize the bending stresses at the wall joint. A mounting flange will be provided on the tank wall to retain and support the heater assembly.

The design of the heater must accommodate the power and control connections and the interface with tank wall insulation system. The exterior heater assembly will be insulated with an easily removable/replaceable maintenance jacket. The thickness of the jacket will match the tank insulation thickness.

Immersion Heater Sizing. The immersion heaters will be selected so that the immersion heat flux through the pipe will not cause a pipe wall surface temperature to exceed $593^{\circ} \mathrm{C}\left(1100^{\circ} \mathrm{F}\right)$ for the hot tank, and $430^{\circ} \mathrm{C}\left(800^{\circ} \mathrm{F}\right)$ for the cold tank when fully immersed in molten nitrate salt. Immersion heater load will be determined to meet the most severe requirement stated above.

A minimum of $100 \%$ installed and connected spare capacity will be provided in each tank.

\subsubsection{Air Tank Heating System}

An air tank heating system (temporary or permanent) is required for the hot salt tank and temporally for the cold tank to:

- Thermally condition the hot and cold tanks in conjunction with initial liquid salt loading operations. Tank internal temperature must be raised to a minimum of $370^{\circ} \mathrm{C}\left(700^{\circ} \mathrm{F}\right)$ before any liquid salt filling operations can occur and until the salt liquid level covers the immersion heaters and they can be energized.

- Prevent extreme thermal gradients from forming within the hot tank due to low salt liquid levels and low salt temperature when transitioning from long-term hold to normal operations. Temperature ramp rates in excess of 120 to $180^{\circ} \mathrm{C} / \mathrm{hr}\left(250\right.$ to $\left.300^{\circ} \mathrm{F} / \mathrm{hr}\right)$ are possible when the hot tank bulk salt temperature is $370^{\circ} \mathrm{C}\left(700^{\circ} \mathrm{F}\right)$ with a LLW and hot salt from the receiver is introduced at $510^{\circ} \mathrm{C}\left(950^{\circ} \mathrm{F}\right)$. The hot tank volumetric temperature must be raised to $\mathrm{TBD}^{\circ} \mathrm{F}$ within TBD hours; refer to Section 3.4.4.

- Determine if the immersion heaters, if properly sized, can raise the hot tank internal temperature (liquid and volumetric) to $\mathrm{TBD}^{\circ} \mathrm{F}$ within $\mathrm{TBD}$ hours after a long-term hold to meet this requirement rather than a permanent air heating system. A temporary system is still required for the initial nitrate loading and melting.

System Requirements. The air tank heating system may be either an electrical- or fuel-based system, e.g., electric duct heater, propane heater exhaust, natural gas, etc. (Solar Two used a portable propane heater and directed the exhaust gas into each tank. The propane burner was able to heat and maintain the tank volumetric temperature at $\left(370^{\circ} \mathrm{C}\left(700^{\circ} \mathrm{F}\right)\right)$. Heated air for initial operations must be supplied near the tank bottom (snorkel) to assure that the tank floor 
and floor to wall joints are thermally conditioned. The snorkel is no longer required once liquid salt reaches the $1 \mathrm{~m}(3 \mathrm{ft})$ heel level and the immersion heater can be energized.

The air heating system inlet and outlet points will be through the tank roof. Heating systems using exhaust directly must use a clean fuel (propane, natural gas, etc.) or exchange the exhaust against a clean air flow stream before introducing it into either tank.

The tank inlets/outlets will be valved (butterfly) or blind flanged to positively seal the tank and heater ducts from each other when not in use. Valves and a portion of the duct system may have to be electrically heat traced to prevent salt buildup on sealing/setting surfaces.

The commercial heating system specified should have sufficient spare capacity and a turndown capability.

Air Heater Sizing. Evaluate the costs and the minimum time duration to raise internal hot salt tank temperature with $1 \mathrm{~m}(3 \mathrm{ft})$ heel of salt at $370^{\circ} \mathrm{C}\left(700^{\circ} \mathrm{F}\right)$ to $\mathrm{TBD}^{\circ} \mathrm{F}$ in TBD hours so $510^{\circ} \mathrm{C}$ $\left(950^{\circ} \mathrm{F}\right)$ salt can be introduced into the hot tank without exceeding the maximum tank heating rate; refer to Section 3.4.4. Determine if this system is adequate without the $370^{\circ} \mathrm{C}\left(700^{\circ} \mathrm{F}\right)$ heel for initial tank thermal conditioning considering tank thermal conduction, convection losses, and the minimum amount of time.

\subsubsection{Hot Salt Tank Agitator}

Evaluate options and provide an active hot salt tank inventory tank mixing capability to prevent a liquid temperature gradient from forming inside the hot tank during long-term hold. (Experience from Solar Two operations determined that salt density differences as a function of temperature were not large enough to establish natural circulation within the hot tank and large temperature gradients developed.) Mixing options to be investigated are:

- Using the hot salt SGS circulation pump at a low flow rate to pump salt from the bottom of the tank and returning it via a ring header at the top. This will require additional piping, valves, including a riser valve, controls, and EHT, all of which, from experience, are problematic.

- Providing a separate recirculation system with dedicated pumps and their own dedicated piping systems. This system will have similar issues - more piping, more valves, and more potential for problems. However, a means of transferring the heel inventory from the hot salt tank to the cold salt tank, or the reverse, may be required, and the same pumping system could serve double duty.

- Using a mechanical mixer, motor-driven paddle-wheel-type mounted on the TSS bridging structure. 


\subsubsection{Tank Heel Salt Inventory Transfer Capability}

As part of the design, provide a capability for transferring the heel salt inventory from the hot salt tank to cold salt tank, or the reverse, in case of a TSS tank leak. The recommended approach is to provide tail pipe extensions for the SGS circulation pump, RS circulation pump, and SGS attemperation pump that will allow the pump to take suction from the heel in an emergency. Separate pump and piping systems are not recommended since these will increase to the overall complexity of the TSS.

\subsubsection{Tank Manway}

Tank manway(s) access will be provided to each tank in accordance with API 650 requirements but should be limited to top entry, if possible, to avoid flanged access in the tank side walls.

\subsubsection{Tank Inlet Sparger Ring}

Each tank will be provided with a tank inlet sparger ring(s) to inject salt upwards into each tank to enhance mixing to minimize thermal stratification of the operating salt volume. The sparger

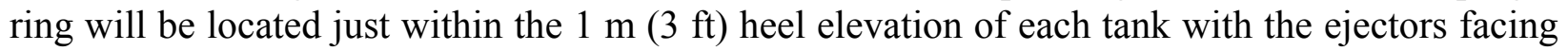
upwards to minimize mixing within the heel volume. The temperature of the tank heel liquid volume should be allowed to remain relatively constant to act as a buffer volume to minimize the affects of temperature cycling on the tank floor and between the floor and wall joint.

\subsubsection{Tank Instrumentation}

Provide thermowells and sensors to measure and map temperature gradients within each tank. Temperature measurement points should be provided both circumferentially and at regular elevation intervals.

Provide standpipe mounted and supported by tank sidewall for level gage, air-bubbler-type to measure tank level in each tank. Gage will be capable of measuring tank level to within $3.85 \mathrm{~cm}$ (1.5 in.) of tank bottom. Reference leg for bubbler will be vented to the inside of each tank into the ullage volume.

Provide high-temperature strain gauges on the tank sidewall to floor joints to confirm analytical thermal stress models. Since these will be the largest high temperature tank systems ever constructed, it is critical to verify the analytical model against actual performance.

\subsubsection{Design Temperatures, Heating Rates, and Tank Thermal Cycles}

The design temperatures, heating rates, and tank thermal cycles are shown in Table 3-6 and discussed in Section 3.4.4.1 to 3.4.4.4. 
Table 3-6. Design Temperatures and Heating Rates

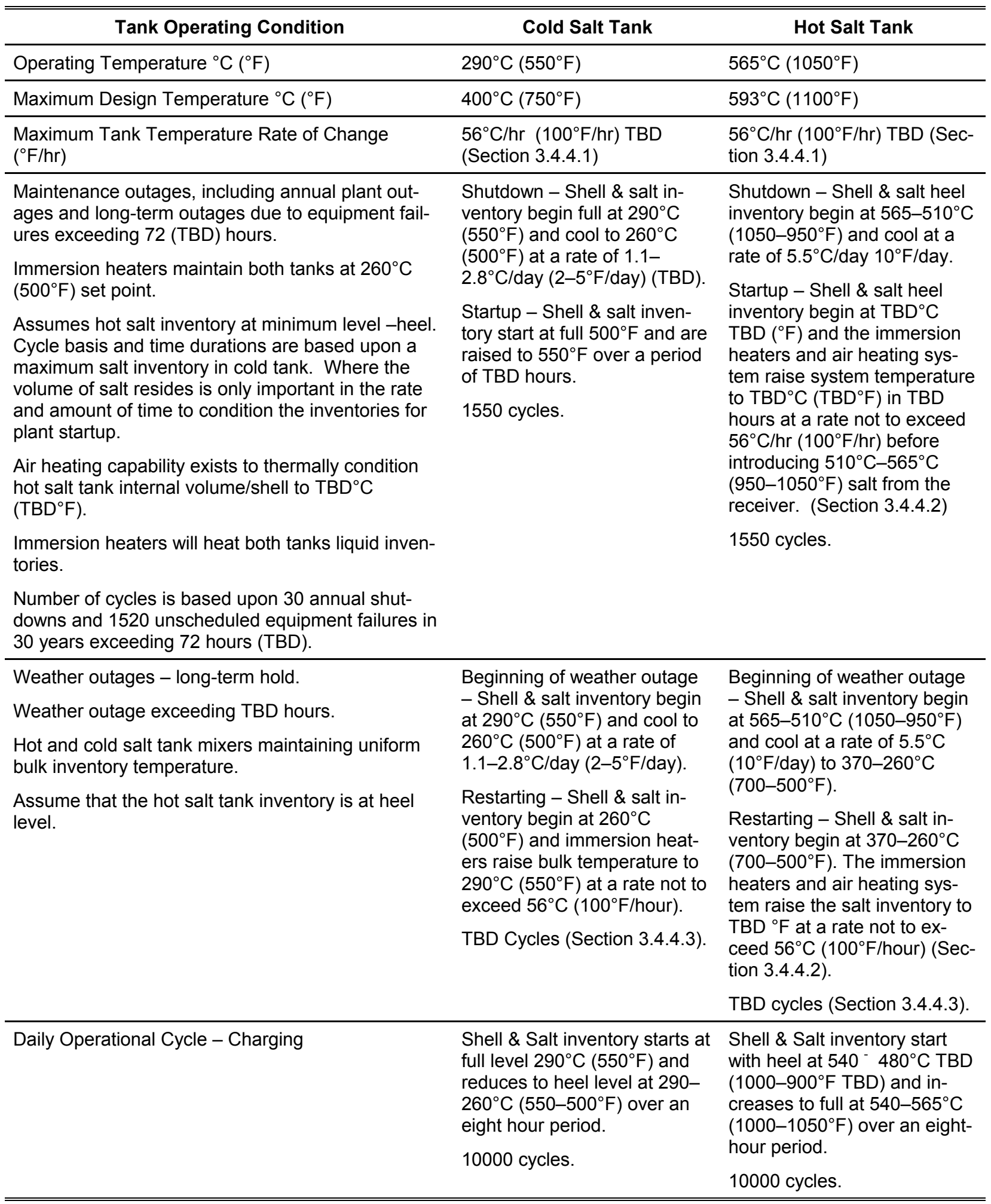


Table 3-6. Design Temperatures and Heating Rates (continued)

\begin{tabular}{|c|c|c|}
\hline Tank Operating Condition & Cold Salt Tank & Hot Salt Tank \\
\hline Daily Operation Cycle - Generating & $\begin{array}{l}\text { Shell \& Salt inventory starts } \\
\text { with heel at } 260^{\circ} \mathrm{C} \text { to } 290^{\circ} \mathrm{C} \\
\left(500^{\circ} \mathrm{F} \text { to } 550^{\circ} \mathrm{F}\right) \text { and increase } \\
\text { to full at } 290^{\circ} \mathrm{C}\left(550^{\circ} \mathrm{F}\right) \text { over a } \\
16 \text { hour period if plant oper- } \\
\text { ates on a } 24 \text { hours/day basis. } \\
10000 \text { cycles. }\end{array}$ & $\begin{array}{l}\text { Shell \& Salt inventory start at } \\
\text { full level at } 1000-1050^{\circ} \mathrm{F} \text { and } \\
\text { reduce to heel level at } 480- \\
540^{\circ} \mathrm{C} \text { TBD }\left(1000-900^{\circ} \mathrm{F}\right. \\
\text { TBD) over a } 16 \text { hour period if } \\
\text { plant operates on a } 24 \\
\text { hour/day basis. } \\
10000 \text { cycles. }\end{array}$ \\
\hline $\begin{array}{l}\text { Salt Diversion } \\
\text { Receiver operates at low thermal output and diverts } \\
\text { salt at } 370^{\circ} \mathrm{C}\left(700^{\circ} \mathrm{F}\right) \text { to the cold tank for a period } \\
\text { not to exceed one hour (TBD). Tank temperature } \\
\text { rate of change cannot exceed } 56^{\circ} \mathrm{C} / \mathrm{hr}\left(100^{\circ} \mathrm{F} / \mathrm{hr}\right) \text {. } \\
\text { Number of cycles is based upon TBD. }\end{array}$ & $\begin{array}{l}\text { Shell and Salt inventory start } \\
\text { at } 290^{\circ} \mathrm{C}\left(550^{\circ} \mathrm{F}\right) \text { and salt is } \\
\text { introduced into the cold tank } \\
\text { over a period of one hour } \\
\text { (TBD) until the inventory tem- } \\
\text { perature reaches } 370^{\circ} \mathrm{C} \\
\left(700^{\circ} \mathrm{F}\right) \text {. } \\
10000 \text { cycles. }\end{array}$ & $\mathrm{N} / \mathrm{A}$ \\
\hline
\end{tabular}

\subsubsection{Maximum Tank Heating Rate}

The stated maximum temperature rate of change, $56^{\circ} \mathrm{C} / \mathrm{hr}\left(100^{\circ} \mathrm{F} / \mathrm{hr}\right) \mathrm{TBD}$, is based upon Solar Two tank design criteria. This temperature rate of change criteria will be revalidated in conjunction with the field erected tank suppliers/erectors to select a rate appropriate for the state of the technology, considering:

- materials selected for tank construction,

- joint designs for thermal stress loading and number of thermal cycles, and

- thermal conditioning approach and procedures.

\subsubsection{Startup Hot Tank Salt Inventory Temperature}

11 The storage tank inventory and tank volumetric temperatures (system temperature) receiver 12 startup must be sufficiently high that when hot salt from the receiver is introduced into the hot 13 tank at $510^{\circ} \mathrm{C}$ to $565^{\circ} \mathrm{C}\left(950^{\circ} \mathrm{F}\right.$ to $\left.1050^{\circ} \mathrm{F}\right)$, it does not result in the tank temperature rate to ex14 ceed $56^{\circ} \mathrm{C} / \mathrm{hr}\left(100^{\circ} \mathrm{F} /\right.$ hour $)$. This requires that the hot tank system temperature be greater than $15370^{\circ} \mathrm{C}\left(700^{\circ} \mathrm{F}\right)$ at startup. The startup temperature must be determined through design analysis.

16 (For example: on Solar Two, after a 72-hour weather outage, the hot tank system temperature 17 fell to $370^{\circ} \mathrm{C}\left(700^{\circ} \mathrm{F}\right)$. At startup, this resulted in a $\left(139^{\circ} \mathrm{C} / \mathrm{hr}\left(250^{\circ} \mathrm{F} / \mathrm{hr}\right)\right.$ tank heating rate if salt 18 were introduced at $540^{\circ} \mathrm{C}\left(1000^{\circ} \mathrm{F}\right)$. In order to not exceed the $56^{\circ} \mathrm{C} / \mathrm{hr}\left(100^{\circ} \mathrm{F} / \mathrm{hr}\right)$ rate limit, the 19 receiver was operated at a lower temperature to allow the tank sufficient time to come to tem20 perature. This resulted in a one- to two-hour startup period.) 


\subsubsection{Weather Outages}

The number of weather outage cycles must be determined from historical weather data for the actual SPT site. The duration of a weather outage will be determined by the cool down rate of the salt inventory in the hot storage tank that results in system temperature requiring tank thermal conditioning.

\subsubsection{Daily Receiver Startup}

The daily receiver startup is applicable with either the flood fill or serpentine fill processes. As flow is being established through the receiver, salt is recirculated back to the cold tank until the cold tank bulk temperature reaches $370^{\circ} \mathrm{C}\left(700^{\circ} \mathrm{F}\right)$, at which point the flow is diverted to the hot tank. This operation can take upwards of 30 minutes.

Plant Maintenance Outage. The shutdown cycle of the cold tanks begins with a bulk storage temperature of $290^{\circ} \mathrm{C}\left(550^{\circ} \mathrm{F}\right)$ and cools naturally to $260^{\circ} \mathrm{C}\left(500^{\circ} \mathrm{F}\right)$ at a rate of 1.1 to $2.8^{\circ} \mathrm{C} /$ day ( 2 to $5^{\circ} \mathrm{F} /$ day) (TBD). The immersion heaters maintain bulk temperature at the $260^{\circ} \mathrm{C}\left(500^{\circ} \mathrm{F}\right)$ level. The hot tank heel inventory begins with a bulk temperature of 540 to $565^{\circ} \mathrm{C}(1000$ to $\left.1050^{\circ} \mathrm{F}\right)$ and cools at a rate of $5.5^{\circ} \mathrm{C} /$ day $\left(10^{\circ} \mathrm{F} /\right.$ day $)$ to $\mathrm{TBD}^{\circ} \mathrm{F}$. The rate of temperature decay was taken from direct operating experience at Solar Two and was based upon minimum tank liquid level with the passive cooling system vents unplugged.

Plant Outage. The startup cycle of the cold tank salt inventory starts at $260^{\circ} \mathrm{C}\left(500^{\circ} \mathrm{F}\right)$. Hot tank inventory starts at $\mathrm{TBD}^{\circ} \mathrm{F}$. Cold tank immersion heaters raise tank inventory to $290^{\circ} \mathrm{C}\left(550^{\circ} \mathrm{F}\right)$. Hot tank immersion heaters and air heater raises liquid and shell temperature to $\mathrm{TBD}^{\circ} \mathrm{C}\left(\mathrm{TBD}^{\circ} \mathrm{F}\right)$ at a rate not to exceed $56^{\circ} \mathrm{C} / \mathrm{hr}\left(100^{\circ} \mathrm{F} / \mathrm{hr}\right)$. The cold salt mixer prevents temperature stratification.

\subsubsection{Thermal Storage System Tank Materials}

The TSS tank materials selection is given in Table 3-7.

\subsubsection{Tank Insulation}

\subsubsection{Foundation Mat Insulation}

Foundation mat insulation is installed on top of the passive cooling system and consists of a sandwiched insulation system is constructed of "foamglass" and refractory brick. The insulation system descriptions below are typical.

The cold salt tank insulation system is comprised of two separate radial zones. The thickness of the cold tank insulation system on Solar Two was $420 \mathrm{~mm}$ (1 ft to $4.5 \mathrm{in}$ ) measured from the top foundation/passive cooling system to bottom of tank floor. Typical zone construction consists of the following: 
Table 3-7. TSS Tank Material Selection

\begin{tabular}{lll}
\hline \multicolumn{1}{c}{ Materials } & \multicolumn{1}{c}{ Cold Salt Tank } & \multicolumn{1}{c}{ Hot Salt Tank } \\
\hline Tank Shells & & \\
\hline Plate & Carbon Steel, ASTM A516, Gr70 & $\begin{array}{l}\text { Stainless Steel } \\
\text { ASTM A 240, Gr 321 or 347 }\end{array}$ \\
\hline Bar Stock & Carbon Steel, ASTM A181 & $\begin{array}{l}\text { Stainless Steel ASTM A193 B8R } \\
\text { Studs } \\
\end{array}$ \\
& & A194 8R Heavy Hex. Nuts \\
\hline Tank Nozzles & Carbon Steel, ASTM A181 & $\begin{array}{l}\text { Stainless Steel, ASTM A182, Gr } \\
\text { F321 or F347 }\end{array}$ \\
\hline Internal Structural & & \\
\hline Structural Tubing & Carbon Steel, ASTM A 500 & $\begin{array}{l}\text { Stainless Steel, ASTM A249, } \\
\text { Grade TP321H / TP347H }\end{array}$ \\
\hline External Clips and Attachments & Carbon Steel, ASTM A506 & $\begin{array}{l}\text { Stainless Steel, ASTM A240, Gr } \\
\text { 304 }\end{array}$ \\
\hline Corrosion Allowance (30 year) & (0.4 mm (15 mils) & $\begin{array}{l}\text { Type 347 (0.7 mm (25 mils) } \\
\text { Type 321 TBD (refer to Section } \\
\end{array}$ \\
& & 4.3.1.1) \\
\hline \hline
\end{tabular}

- The outer most zone (TBD mm (TBD ft) wide annulus) supports the tank side walls and accommodates thermal expansion. It consists of two types of fire brick-multiple bottom courses of insulating firebrick and a top course of hard firebrick. A leak detection liner, discussed below, rests on top of the hard firebrick. The firebricks courses are staggered and are dip mortared together. The refractory rings are segmented circumferentially and the gap between segments is packed with mineral wool.

- The inner zone supports the tank floor and consists of multiple staggered courses of foamglass insulation, the leak detection liner, and a dry sand layer upon which the tank floor is constructed. The interface between zones is packed with mineral wool.

The hot salt tank insulation system is comprised of two separate radial zones. The thickness of the hot tank insulation system on Solar Two was $495 \mathrm{~mm}$ (1 ft to $7.5 \mathrm{in}$ ) measured from the top foundation/passive cooling system to bottom of tank floor. The zones consisted of the following:

- The outer zone (TBD mm (TBD ft) wide annulus) supports the tank side walls and accommodates thermal expansion. It consists of two types of fire brick-multiple bottom courses of insulating firebrick and a top course of hard firebrick. A leak detection liner discussed below rests on top of the hard firebrick. The firebricks courses are staggered and are dip mortared together. The refractory rings are segmented circumferentially and the gap between segments is packed with mineral wool.

- The inner zone supports the tank floor and consists of multiple staggered courses of foamglass insulation, two staggered top courses of insulating brick, the leak detection liner, and a 
dry sand layer upon which the tank floor is constructed. The interface between zones is packed with mineral wool.

The refractory firebrick and foamglass is susceptible to chemical attack by the nitrate salt and requires protection from potential tank leaks.

\subsubsection{Tank Sidewall and Roof Insulation}

Tank sidewall and roof insulation will be multiple staggered courses of high-temperature mineral wool and/or high-density calcium silicate insulation. The calcium silicate will be used in applications susceptible to foot traffic, requiring structural reinforcement and access, e.g., tank roof and nozzle penetrations. The insulation thickness will be determined through analysis that the system selected provides the greatest degree of thermal protection using the following guidelines:

- Selecting an insulation thickness based upon cost tradeoff that compares insulation system cost to the amount of thermal energy lost at a TBD \$/British Thermal Unit (Btu) rate.

- Limiting insulation jacket surface temperature for protection of personnel to $<140^{\circ} \mathrm{F}\left(<60^{\circ} \mathrm{C}\right)$ (TBD U.S. OSHA ) based upon $0 \mathrm{~m} / \mathrm{s}(0 \mathrm{mph})$ wind and a TBD ambient temperature (TBD).

- Providing insulation and the insulation jacket over instrumentation and other tank-mounted devices that is capable of being easily being removed and reinstalled as a single unit.

- Providing tank insulation jacketing material of aluminum.

\subsubsection{Thermal Storage System Foundations}

TSS foundations requirements are given below.

\subsubsection{Tank Foundations Mats}

The tank foundations mats will be constructed under the BOP site development subcontract. The foundations will include a prepared soil mat, elevated tank concrete foundation mats, and a foundation ring, passive-cooling system. The tank foundation system is comprised of the following elements:

- Prepared soil mat (BOP)

- Reinforced concrete mat and ring wall (BOP)

- Passive cooling system piping (BOP)

- Foamglass and firebrick insulation system (TSS)

- Leak detection system, including liner (TSS) 


\subsubsection{Tank Area Berms}

The TSS area will be surrounded by a tank berm. The bermed area will have sufficient volume to contain the entire nitrate salt inventory in case of a tank failure and include a minimum of $.6 \mathrm{~m}$ $(2 \mathrm{ft})$ of free board. Provide:

- Vehicular access into the bermed area,

- Berm drain to remove standing water, and

- Equipment laydown area within the bermed maintenance equipment and salt melting equipment.

\subsubsection{Passive Cooling System}

Heat conduction through the foundation insulation system will eventually reach thermal equilibrium, e.g., temperature of the salt inventory. Concrete will begin to fail if its temperature reaches $100^{\circ} \mathrm{C}\left(212^{\circ} \mathrm{F}\right)$ and if the water of hydration is removed. A passive cooling system is required and is comprised of:

- Rows of parallel carbon steel pipes, pipe schedule TBD, installed on top of the concrete mat.

Both ends will be open to the atmosphere with one end attached to a vertical chimney. The pipe diameter and height of the chimney will be calculated by performing an iterative heat transfer analysis that will limit the foundation temperature to $<90^{\circ} \mathrm{C}\left(<200^{\circ} \mathrm{F}\right)$. Use the maximum ambient air temperature at SPT location. Air velocities in the cooling passages, driven by the buoyant forces of the heated air in the chimneys, provide the cooling.

- Temperature monitoring to confirm that foundation temperatures are $<90^{\circ} \mathrm{C}\left(<200^{\circ} \mathrm{F}\right)$.

- A cooling system that is capable of being capped during long-term shutdowns to reduce system thermal losses without damaging the concrete mats.

- Cooling pipes that penetrate through the tank foundation support ring.

\subsubsection{Leak Detection System}

Provide a leak detection system to indicate that a tank floor has a molten nitrate salt leak. The leak detection system is not indented to identify leak location, only that there is a problem. The leak detection system will consist of overlapping 16 gauge stainless steel sheets, Type 304 or 316 with seal welded seams that form a sealed drip pan on top of the firebrick/foamglass. Liner will extend through the base foundation to the tank exterior, full circumference, and be visible for inspection. Provide a thermocouple grid of approximately 100 thermocouples -1.5 to $2 \mathrm{~m}$ (5 to $7 \mathrm{ft}$ ) center to center spacing, underneath the drip pan to identify hot spots and potential tank leaks. The signals from the thermocouple grid will be incorporated into MCS and the output trended and monitored. 


\subsection{Steam Generation System}

\subsubsection{System Description}

The SGS baseline system elements will be located in the receiver tower structure at an elevation that allows the molten nitrate salt in the exchangers to self-drain back to the TSS. The SGS is comprised of:

- An ASME Section VIII superheater. Tubular Exchanger Manufacturers Association (TEMA) shell and tube heat exchanger with salt on the shell side and steam on the tube side.

- An ASME Section VIII pressure vessel steam drum.

- An ASME Section VIII evaporator. TEMA shell and tube heat exchanger with salt on the shell side and boiler feed water on the tube side.

- An ASME Section VIII preheater. TEMA shell and tube heat exchanger with salt on the shell side and boiler feed water on the tube side.

- An ASME Section VIII startup feedwater heater. TEMA shell and tube heat exchanger with boiler feed water on the tube side and auxiliary/condensate on the shell side.

- An ASME Section VIII reheater. TEMA shell and tube heat exchanger with salt on the shell side and extraction steam on the tube side.

- SGS circulation pump (hot salt). A VSD vertical turbine pump mounted on the hot salt tank supplying hot salt to the SGS.

- SGS attemperation pump (cold salt). A VSD vertical turbine pump mounted on top of the cold salt tank supplying cold salt to SGS.

- Steam drum feedwater mixer. An equipment component (B31.1 or ASME Section VIII) mixing boiler feed water from the steam drum and from the preheater to supply the steam generator feed water pump.

- SGS evaporator feedwater circulation pump. A horizontal centrifugal pump recirculating boiler feedwater from the steam drum to the evaporator to control the steaming rate within the steam drum.

- SGS preheater feedwater circulation pump. A horizontal centrifugal pump recirculating boiler feedwater from the steam drum to the preheater to control feedwater temperature to the evaporator.

\subsubsection{Scope of Supply}

The SGS system design, physical design, and system integration package includes PFDs, process and instrument diagrams, general arrangement drawings, physical design of interconnecting 
piping, electrical and control systems, structural design, SGS heat transfer equipment procurement package, specification and purchase of the SGS pumps, miscellaneous equipment and materials, shop drawing review, construction, startup, and activation. Also included is the design task to thermally condition the SGS from the long-term hold and overnight hold states through the transition to normal operation while minimizing parasitic electrical power loads and thermal heat losses.

The SGS heat transfer equipment design, fabrication, and startup/activation support package includes the design calculations, system engineering support, detailed design, shop drawings, and shop fabrication. The detailed design will also encompass SGS insulation systems, steam drum thermal conditioning, detailed analysis to determine steam pressure surge rate to TSS in the event of tube failure, recommend control schemes, SGS system calculations for partial load conditions, and SGS startup and activation planning.

The SGS installation and construction subcontract package includes all field construction activities, construction testing, and activation support for the SGS. This package is included in the overall site construction package. The SGS designer and fabricator will be on contract to support installation and all testing.

\subsubsection{Steam Generation System Design Basis}

\subsubsection{Steam Generation System Temperatures and Pressures}

Nominal full load SGS equipment design temperature and pressure conditions are specified in Table 3-8.

Table 3-8. Nominal Full Load SGS Equipment Design Temperature and Pressure Conditions

\begin{tabular}{|c|c|c|c|c|}
\hline \multirow{2}{*}{ Equipment } & \multicolumn{2}{|c|}{ Nitrate Salt } & \multicolumn{2}{|c|}{ Water/Steam } \\
\hline & Inlet & Outlet & Inlet & Outlet \\
\hline \multicolumn{5}{|l|}{$\begin{array}{l}\text { Superheater } \\
\text { Shell Side: Salt } \\
\text { Tube Side: Steam } \\
\text { Nominal }\end{array}$} \\
\hline $\begin{array}{l}\text { Temperature }{ }^{\circ} \mathrm{C}\left({ }^{\circ} \mathrm{F}\right) \\
\text { Pressure bar }\left(\mathrm{lbs}_{\mathrm{f}} / \mathrm{in}^{2}\right)\end{array}$ & $\begin{array}{c}565^{\circ} \mathrm{C}\left(1050^{\circ} \mathrm{F}\right) \\
2.7 \mathrm{bar}\left(39 \mathrm{lbs}_{\mathrm{f}} / \mathrm{in}^{2}\right)\end{array}$ & 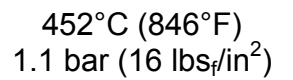 & $\begin{array}{c}331^{\circ} \mathrm{C}\left(628^{\circ} \mathrm{F}\right) \\
126 \operatorname{bar}\left(1829 \mathrm{bs}_{\mathrm{f}} / \mathrm{in}^{2}\right)\end{array}$ & $\begin{array}{c}552^{\circ} \mathrm{C}\left(1025^{\circ} \mathrm{F}\right) \\
126 \operatorname{bar}\left(1829 \mathrm{bs}_{f} / \mathrm{in}^{2}\right)\end{array}$ \\
\hline Maximum & & & & \\
\hline $\begin{array}{l}\text { Temperature }{ }^{\circ} \mathrm{C}\left({ }^{\circ} \mathrm{F}\right) \\
\text { Pressure bar }\left(\mathrm{lbs}_{\mathrm{f}} / \mathrm{in}^{2}\right)\end{array}$ & $\begin{array}{l}593^{\circ} \mathrm{C}\left(1100^{\circ} \mathrm{F}\right) \\
\text { Refer to Note } 1\end{array}$ & $\begin{array}{l}593^{\circ} \mathrm{C}\left(1100^{\circ} \mathrm{F}\right) \\
\text { Refer to Note } 1\end{array}$ & $\begin{array}{c}593^{\circ} \mathrm{C}\left(1100^{\circ} \mathrm{F}\right) \\
145 \text { bar }\left(2100 \mathrm{lbs}_{\mathrm{f}} / \mathrm{in}^{2}\right)\end{array}$ & $\begin{array}{c}593^{\circ} \mathrm{C}\left(1100^{\circ} \mathrm{F}\right) \\
145 \operatorname{bar}\left(2100 \mathrm{lbs}_{f} / \mathrm{in}^{2}\right)\end{array}$ \\
\hline
\end{tabular}


Table 3-8. Nominal Full Load SGS Equipment Design Temperature and Pressure Conditions (continued)

\begin{tabular}{|c|c|c|c|c|}
\hline \multirow{2}{*}{ Equipment } & \multicolumn{2}{|c|}{ Nitrate Salt } & \multicolumn{2}{|c|}{ Water/Steam } \\
\hline & Inlet & Outlet & Inlet & Outlet \\
\hline \multicolumn{5}{|l|}{$\begin{array}{l}\text { Reheater } \\
\text { Shell Side: Salt } \\
\text { Tube Side: Steam } \\
\text { Nominal }\end{array}$} \\
\hline $\begin{array}{l}\text { Temperature }{ }^{\circ} \mathrm{C}\left({ }^{\circ} \mathrm{F}\right) \\
\text { Pressure bar }\left(\mathrm{Ibs}_{\mathrm{f}} / \mathrm{in}^{2}\right)\end{array}$ & $\begin{array}{c}565^{\circ} \mathrm{C}\left(1050^{\circ} \mathrm{F}\right) \\
2.7 \mathrm{bar}\left(39 \mathrm{lbs} / / \mathrm{in}^{2}\right)\end{array}$ & $\begin{array}{c}452^{\circ} \mathrm{C}\left(846^{\circ} \mathrm{F}\right) \\
1.1 \mathrm{bar}\left(16 \mathrm{lbs}_{\mathrm{f}} / \mathrm{in}^{2}\right)\end{array}$ & $\begin{array}{c}380^{\circ} \mathrm{C}\left(716^{\circ} \mathrm{F}\right) \\
34.4 \mathrm{bar}\left(456 \mathrm{lbs}_{f} / \mathrm{in}^{2}\right)\end{array}$ & $\begin{array}{c}552^{\circ} \mathrm{C}\left(1025^{\circ} \mathrm{F}\right) \\
30.6 \operatorname{bar}\left(444 \mathrm{lbs}_{\mathrm{f}} / \mathrm{in}^{2}\right)\end{array}$ \\
\hline Maximum & & & & \\
\hline $\begin{array}{l}\text { Temperature }{ }^{\circ} \mathrm{C}\left({ }^{\circ} \mathrm{F}\right) \\
\text { Pressure bar }\left(\mathrm{lbs}_{\mathrm{f}} / \mathrm{in}^{2}\right)\end{array}$ & $\begin{array}{l}593^{\circ} \mathrm{C}\left(1100^{\circ} \mathrm{F}\right) \\
\text { Refer to Note } 1\end{array}$ & $\begin{array}{l}593^{\circ} \mathrm{C}\left(1100^{\circ} \mathrm{F}\right) \\
\text { Refer to Note } 1\end{array}$ & $\begin{array}{c}593^{\circ} \mathrm{C}\left(1100^{\circ} \mathrm{F}\right) \\
38 \operatorname{bar}\left(550 \mathrm{lbs}_{\mathrm{f}} / \mathrm{in}^{2}\right)\end{array}$ & $\begin{array}{c}593^{\circ} \mathrm{C}\left(1100^{\circ} \mathrm{F}\right) \\
38 \mathrm{bar}\left(550 \mathrm{lbs}_{\mathrm{f}} / \mathrm{in}^{2}\right)\end{array}$ \\
\hline \multicolumn{5}{|l|}{$\begin{array}{l}\text { Evaporator } \\
\text { Shell Side: Salt } \\
\text { Tube Side: Saturated } \\
\text { Feedwater } \\
\text { Nominal }\end{array}$} \\
\hline $\begin{array}{l}\text { Temperature }{ }^{\circ} \mathrm{C}\left({ }^{\circ} \mathrm{F}\right) \\
\text { Pressure bar }\left(\mathrm{lbs}_{\mathrm{f}} / \mathrm{in}^{2}\right)\end{array}$ & $\begin{array}{l}452^{\circ} \mathrm{C}\left(846^{\circ} \mathrm{F}\right) \\
\quad 62 \mathrm{lbs}_{\mathrm{f}} / \mathrm{in}^{2}\end{array}$ & $\begin{array}{c}334^{\circ} \mathrm{C}\left(634^{\circ} \mathrm{F}\right) \\
2.7 \operatorname{bar}\left(39 \mathrm{lbs}_{f} / \mathrm{in}^{2}\right)\end{array}$ & $\begin{array}{c}328^{\circ} \mathrm{C}\left(622^{\circ} \mathrm{F}\right) \\
126 \operatorname{bar}\left(1829 \mid \mathrm{bs}_{f} / \mathrm{in}^{2}\right)\end{array}$ & $\begin{array}{c}331^{\circ} \mathrm{C}\left(628^{\circ} \mathrm{F}\right) \\
126 \operatorname{bar}\left(1829 \mathrm{lbs} / \mathrm{in}^{2}\right)\end{array}$ \\
\hline Maximum & & & & \\
\hline $\begin{array}{l}\text { Temperature }{ }^{\circ} \mathrm{C}\left({ }^{\circ} \mathrm{F}\right) \\
\text { Pressure bar }\left(\mathrm{Ibs}_{\mathrm{f}} / \mathrm{in}^{2}\right)\end{array}$ & $\begin{array}{l}510^{\circ} \mathrm{C}\left(950^{\circ} \mathrm{F}\right) \\
\text { Refer to Note } 1\end{array}$ & $\begin{array}{r}510^{\circ} \mathrm{C}\left(950^{\circ} \mathrm{F}\right) \\
\text { Refer to Note } 1\end{array}$ & $\begin{array}{c}510^{\circ} \mathrm{C}\left(950^{\circ} \mathrm{F}\right) \\
145 \operatorname{bar}\left(2100 \mathrm{lbs}_{\mathrm{f}} / \mathrm{in}^{2}\right)\end{array}$ & $\begin{array}{c}510^{\circ} \mathrm{C}\left(950^{\circ} \mathrm{F}\right) \\
145 \operatorname{bar}\left(2100 \mathrm{lbs}_{\mathrm{f}} / \mathrm{in}^{2}\right)\end{array}$ \\
\hline \multicolumn{5}{|l|}{$\begin{array}{l}\text { Preheater } \\
\text { Shell Side: Salt } \\
\text { Tube Side: Feedwater } \\
\text { Nominal }\end{array}$} \\
\hline $\begin{array}{l}\text { Temperature }{ }^{\circ} \mathrm{C}\left({ }^{\circ} \mathrm{F}\right) \\
\text { Pressure bar }\left(\mathrm{lbs}_{\mathrm{f}} / \mathrm{in}^{2}\right)\end{array}$ & $\begin{array}{c}334^{\circ} \mathrm{C}\left(634^{\circ} \mathrm{F}\right) \\
90 \mathrm{lbs}_{\mathrm{f}} / \mathrm{in}^{2}\end{array}$ & $\begin{array}{l}290^{\circ} \mathrm{C}\left(550^{\circ} \mathrm{F}\right) \\
\quad 62 \mathrm{lbs}_{\mathrm{f}} / \mathrm{in}^{2}\end{array}$ & $\begin{array}{c}239^{\circ} \mathrm{C}\left(462^{\circ} \mathrm{F}\right) \\
126 \operatorname{bar}\left(1829 \mid \mathrm{bs} f / \mathrm{in}^{2}\right)\end{array}$ & $\begin{array}{c}326^{\circ} \mathrm{C}\left(618^{\circ} \mathrm{F}\right) \\
126 \operatorname{bar}\left(1829 \mathrm{lbs} / \mathrm{in}^{2}\right)\end{array}$ \\
\hline Maximum & & & & \\
\hline $\begin{array}{l}\text { Temperature }{ }^{\circ} \mathrm{C}\left({ }^{\circ} \mathrm{F}\right) \\
\text { Pressure bar }\left(\mathrm{Ibs}_{\mathrm{f}} / \mathrm{in}^{2}\right)\end{array}$ & $\begin{array}{l}400^{\circ} \mathrm{C}\left(750^{\circ} \mathrm{F}\right) \\
\text { Refer to Note } 1\end{array}$ & $\begin{array}{l}400^{\circ} \mathrm{C}\left(750^{\circ} \mathrm{F}\right) \\
\text { Refer to Note } 1\end{array}$ & $\begin{array}{c}400^{\circ} \mathrm{C}\left(750^{\circ} \mathrm{F}\right) \\
145 \operatorname{bar}\left(2100 \mathrm{lbs}_{f} / \mathrm{in}^{2}\right)\end{array}$ & $\begin{array}{c}400^{\circ} \mathrm{C}\left(750^{\circ} \mathrm{F}\right) \\
145 \operatorname{bar}\left(2100 \mathrm{lbs}_{\mathrm{f}} / \mathrm{in}^{2}\right)\end{array}$ \\
\hline \multicolumn{5}{|l|}{$\begin{array}{l}\text { Startup Feedwater } \\
\text { Heater } \\
\text { Shell Side: Feedwater } \\
\text { Tube Side: Feedwater } \\
\text { Nominal }\end{array}$} \\
\hline $\begin{array}{l}\text { Temperature }{ }^{\circ} \mathrm{C}\left({ }^{\circ} \mathrm{F}\right) \\
\text { Pressure bar }\left(\mathrm{Ibs}_{\mathrm{f}} / \mathrm{in}^{2}\right)\end{array}$ & $\begin{array}{l}N / A \\
N / A\end{array}$ & $\begin{array}{l}N / A \\
N / A\end{array}$ & $\begin{array}{c}149^{\circ} \mathrm{C}\left(300^{\circ} \mathrm{F}\right) \\
126 \operatorname{bar}\left(1832 \mathrm{lbs} f / \mathrm{in}^{2}\right)\end{array}$ & $\begin{array}{c}149^{\circ} \mathrm{C}\left(300^{\circ} \mathrm{F}\right) \\
126 \operatorname{bar}\left(1832 \mathrm{lbs}_{\mathrm{f}} / \mathrm{in}^{2}\right)\end{array}$ \\
\hline Maximum & & & & \\
\hline $\begin{array}{l}\text { Temperature }{ }^{\circ} \mathrm{C}\left({ }^{\circ} \mathrm{F}\right) \\
\text { Pressure bar }\left(\mathrm{lbs}_{\mathrm{f}} / \mathrm{in}^{2}\right)\end{array}$ & $\begin{array}{l}\text { N/A } \\
\text { N/A }\end{array}$ & $\begin{array}{l}\text { N/A } \\
\text { N/A }\end{array}$ & $\begin{array}{c}260^{\circ} \mathrm{C}\left(500^{\circ} \mathrm{F}\right) \\
145 \operatorname{bar}\left(2100 \mathrm{lbs}_{f} / \mathrm{in}^{2}\right)\end{array}$ & $\begin{array}{c}260^{\circ} \mathrm{C}\left(500^{\circ} \mathrm{F}\right) \\
145 \operatorname{bar}\left(2100 \mathrm{lbs}_{\mathrm{f}} / \mathrm{in}^{2}\right)\end{array}$ \\
\hline \multicolumn{5}{|l|}{$\begin{array}{l}\text { Steam Drum } \\
\text { Feedwater and saturated } \\
\text { Steam } \\
\text { Nominal }\end{array}$} \\
\hline $\begin{array}{l}\text { Temperature }{ }^{\circ} \mathrm{C}\left({ }^{\circ} \mathrm{F}\right) \\
\text { Pressure bar }\left(\mathrm{lbs}_{\mathrm{s}} / \mathrm{in}^{2}\right)\end{array}$ & N/A & N/A & $328^{\circ} \mathrm{C}\left(622^{\circ} \mathrm{F}\right)$ & $331^{\circ} \mathrm{C}\left(628^{\circ} \mathrm{F}\right)$ \\
\hline $\begin{array}{l}\text { Pressure } \\
\text { Maximum }\end{array}$ & $\mathrm{N} / \mathrm{A}$ & A & bal & $\left.\operatorname{lbs}_{\mathrm{f}} / \mathrm{in}^{2}\right)$ \\
\hline $\begin{array}{l}\text { Temperature }{ }^{\circ} \mathrm{C}\left({ }^{\circ} \mathrm{F}\right) \\
\text { Pressure bar }\left(\mathrm{lbs}_{\mathrm{f}} / \mathrm{in}^{2}\right)\end{array}$ & $\begin{array}{l}\text { N/A } \\
\text { N/A }\end{array}$ & $\begin{array}{l}N / A \\
N / A\end{array}$ & $\begin{array}{c}343^{\circ} \mathrm{C}\left(650^{\circ} \mathrm{F}\right) \\
145 \mathrm{bar}\left(2100 \mathrm{lbs} / \mathrm{in}^{2}\right)\end{array}$ & $\begin{array}{c}343^{\circ} \mathrm{C}\left(650^{\circ} \mathrm{F}\right) \\
145 \mathrm{bar}\left(2100 \mathrm{lbs} / \mathrm{in}^{2}\right)\end{array}$ \\
\hline
\end{tabular}


Table 3-8. Nominal Full Load SGS Equipment Design Temperature and Pressure Conditions (continued)

\begin{tabular}{|c|c|c|c|c|}
\hline \multirow{2}{*}{ Equipment } & \multicolumn{2}{|c|}{ Nitrate Salt } & \multicolumn{2}{|c|}{ Water/Steam } \\
\hline & Inlet & Outlet & Inlet & Outlet \\
\hline \multicolumn{5}{|l|}{$\begin{array}{l}\text { SGS Circulation Pump } \\
\text { Hot Salt } \\
\text { Nominal }\end{array}$} \\
\hline Temperature ${ }^{\circ} \mathrm{C}\left({ }^{\circ} \mathrm{F}\right)$ & $565^{\circ} \mathrm{C}\left(1050^{\circ} \mathrm{F}\right)$ & $565^{\circ} \mathrm{C}\left(1050^{\circ} \mathrm{F}\right)$ & N/A & N/A \\
\hline $\begin{array}{l}\text { Pressure bar }\left(\mathrm{lbs}_{\mathrm{f}} / \mathrm{in}^{2}\right) \\
\text { Maximuum }\end{array}$ & NPSHR - MaxTank & TBD & $\mathrm{N} / \mathrm{A}$ & $N / A$ \\
\hline $\begin{array}{l}\text { Maximum } \\
\text { Temperature }{ }^{\circ} \mathrm{C}\left({ }^{\circ} \mathrm{F}\right)\end{array}$ & $\begin{array}{l}\text { Head } \\
593^{\circ} \mathrm{C}\left(1100^{\circ} \mathrm{F}\right)\end{array}$ & $593^{\circ} \mathrm{C}\left(1100^{\circ} \mathrm{F}\right)$ & N/A & N/A \\
\hline Pressure bar $\left(\mathrm{lbs}_{\mathrm{f}} / \mathrm{in}^{2}\right)$ & N/A & Pump shut off head & $\mathrm{N} / \mathrm{A}$ & $\mathrm{N} / \mathrm{A}$ \\
\hline \multicolumn{5}{|l|}{$\begin{array}{l}\text { SGS Attemperation } \\
\text { Pump } \\
\text { Cold Salt } \\
\text { Nominal }\end{array}$} \\
\hline Temperature ${ }^{\circ} \mathrm{C}\left({ }^{\circ} \mathrm{F}\right)$ & $290^{\circ} \mathrm{C}\left(550^{\circ} \mathrm{F}\right)$ & $290^{\circ} \mathrm{C}\left(550^{\circ} \mathrm{F}\right)$ & $N / A$ & $\mathrm{~N} / \mathrm{A}$ \\
\hline Pressure bar $\left(\mathrm{lbs}_{\mathrm{f}} / \mathrm{in}^{2}\right)$ & NPSHR - Max Tank & TBD & $N / A$ & N/A \\
\hline Maximum & Head & & & \\
\hline Temperature ${ }^{\circ} \mathrm{C}\left({ }^{\circ} \mathrm{F}\right)$ & $400^{\circ} \mathrm{C}\left(750^{\circ} \mathrm{F}\right)$ & $400^{\circ} \mathrm{C}\left(750^{\circ} \mathrm{F}\right)$ & $N / A$ & $\mathrm{~N} / \mathrm{A}$ \\
\hline Pressure bar $\left(\mathrm{Ibs}_{f} / \mathrm{in}^{2}\right)$ & N/A & Pump shut off head & N/A & $\mathrm{N} / \mathrm{A}$ \\
\hline
\end{tabular}

Steam Generator pre-

heater and Evaporator

Feedwater Circulation

Pumps

Feedwater

Nominal

Temperature ${ }^{\circ} \mathrm{C}\left({ }^{\circ} \mathrm{F}\right)$
Pressure bar $\left(\mathrm{lbs}_{\mathrm{f}} / \mathrm{in}^{2}\right)$

Maximum

Temperature ${ }^{\circ} \mathrm{C}\left({ }^{\circ} \mathrm{F}\right)$

Pressure bar $\left(\mathrm{lbs}_{\mathrm{f}} / \mathrm{in}^{2}\right)$

\begin{tabular}{|c|c|c|c|}
\hline $\begin{array}{l}N / A \\
N / A\end{array}$ & $\begin{array}{l}N / A \\
N / A\end{array}$ & $328^{\circ} \mathrm{C}\left(622^{\circ} \mathrm{F}\right)$ & $331^{\circ} \mathrm{C}\left(628^{\circ} \mathrm{F}\right)$ \\
\hline $\mathrm{N} / \mathrm{A}$ & $\mathrm{N} / \mathrm{A}$ & $343^{\circ} \mathrm{C}\left(650^{\circ} \mathrm{F}\right)$ & $343^{\circ} \mathrm{C}\left(650^{\circ} \mathrm{F}\right)$ \\
\hline$N / A$ & $\mathrm{~N} / \mathrm{A}$ & 145 bar $\left(2100 \mathrm{lbs}_{f} / \mathrm{in}^{2}\right)$ & $145 \operatorname{bar}\left(2100 \mathrm{lbs}_{\mathrm{f}} / \mathrm{in}^{2}\right)$ \\
\hline
\end{tabular}

Note 1. The maximum pressure is either pump shut off head $+20 \%$ or the maximum pressure created by a tube rupture and the resulting high-pressure steam pulse. Refer to Section 3.5.3.3.

\subsubsection{Thermal Duty}

3 Gross thermal duty will be determined duty from turbine rating MWe divided by the turbine effi-

4 ciency.

5 A thorough analysis of all possible nitrate salt temperatures in all system states and during all 6 system transitions, including the effects of recirculation water flow rate and startup feedwater 7 heater performance, is essential to sizing the heat exchangers and auxiliary equipment. Solar

8 Two required a minimum of 500 computer simulations.

9 Optimize SGS/EPGS daily system startup with a goal to limit startup energy to $\leq 25 \%$ of one 10 hour of SGS thermal demand.

11 An SGS heat and mass balance computer model is essential for plant operations and startup. Re-

12 quired input parameters are 
- Primary feedwater flow rate, temperature, and pressure

- Steam generator circulation feedwater flow rate and temperature

- Primary hot salt flow rate and temperature

- Attemperated salt flow rate to superheater or reheater

- Cold salt (attemperation) flow rate and temperature

- Evaporator water recirculation flow rate

- Steam drum blowdown flow rate

- Steam drum auxiliary steam rate, temperature, and pressure

- Heat transfer coefficients in the reheater, preheater, evaporator, and superheater.

10 The overall heat transfer coefficient is defined as follows (Note: as long as consistent unit conventions are used, these equations will hold for both English and Metric units):

$$
\mathrm{U}_{\mathrm{o}}=\frac{1}{\frac{1}{\mathrm{U}_{\text {inside adjusted }}}+\frac{1}{\mathrm{U}_{\text {outside }}}+\mathrm{R}_{\text {inside fouling factor }}+\mathrm{R}_{\text {outside fouling factor }}+\mathrm{R}_{\text {tube wall }}}
$$

$\mathrm{U}_{\text {inside }}$ is equal to $\left(\mathrm{Nu}_{\text {inside }}\right)(\mathrm{k}) /\left(\mathrm{D}_{\text {inside }}\right)$. The Nusselt number for fully developed turbulent flow inside a pipe is defined as follows:

$$
\mathrm{Nu}=0.023 \operatorname{Re}^{0.8} \operatorname{Pr}^{1 / 3}\left[\frac{v}{v_{\text {wall }}}\right]^{0.14}
$$

where Re is the Reynolds number, $\operatorname{Pr}$ is the Prandtl number, $v$ is the viscosity, $v_{\text {wall }}$ is the viscosity at the wall film temperature, $\mathrm{k}$ is the thermal conductivity of the fluid, and $\mathrm{D}_{\text {inside }}$ is the inside diameter of the pipe. The inside convection coefficient is converted to an equivalent coefficient based on the outside surface area of the tubes as follows:

$$
\mathrm{U}_{\text {inside adjusted }}=\mathrm{U}_{\text {inside }}\left(\mathrm{D}_{\text {inside }} / \mathrm{D}_{\text {outside }}\right) \text {. }
$$

The outside convection coefficient $\mathrm{U}_{\text {outside }}$ is equal to $\left(\mathrm{Nu}_{\text {outside }}\right)(\mathrm{k}) /\left(\mathrm{D}_{\text {outside }}\right)$. The Nusselt number for fully developed turbulent flow over a tube bank is defined as follows:

$$
\mathrm{Nu}=0.36\left[\frac{\mathrm{G}_{\max } \mathrm{D}_{\text {outside }}}{v_{\text {absolute }}}\right]^{0.35} \operatorname{Pr}^{1 / 3}
$$

where $G_{\max }$ is the peak mass flux between the tubes, $D_{\text {outside }}$ is the outside tube diameter, $v_{\text {absolute }}$ is the absolute viscosity, and Pr is the Prandtl number.

Under part load conditions, the fluid velocities inside and outside the tubes are determined by heat and mass balances. The convection coefficients $\mathrm{U}_{\text {inside adjusted }}$ and $\mathrm{U}_{\text {outside }}$ are determined directly once the fluid velocities are known. The fouling factors and tube wall thermal resistance are assumed to be independent of load. 


\subsubsection{Maximum Design and Over Pressures}

Maximum salt side design pressure will be based upon the SGS pump shut off head. Maximum salt side overpressure protection will be based on exchanger tube rupture, which allows nitrate salt and either feedwater or steam to come in direct contact. The overpressure pressure transient can exceed shell yield stress before a pressure relief valve can operate. Yielding of the shell will likely occur, requiring replacement. In addition, the high-pressure steam pulse will also impact the TSS nitrate salt storage tank pressure relief system.

The plant designer will assess the relative probabilities of failures and determine where the pressure safety relief valves (PSV) or rupture discs are required, where they are to be installed, and appropriately size the valves/rupture discs to comply with code requirements. Refer to Section 3.6.4.5 on EHT for PSV EHT requirements.

A separate vent header system will be downstream of the PSVs/rupture discs. If PSVs are required, the vent system will be heat traced and insulated over its entire length.

Maximum steam side pressure relief valve sizing will be in accordance with code requirements.

\subsubsection{Auxiliary Steam}

Auxiliary steam will be produced from two sources:

- Lower demand $\leq 2 \%$ of rated SGS design duty using a small electric boiler to generate sufficient steam for turbine shaft seals and establishing the condenser vacuum.

- Higher demand $>2 \%$ of rated SGS design duty using SGS auxiliary feedwater heater, preheater, evaporator, and steam drum will be required after the condenser vacuum has been established for main steam line warm-up, feedwater heating, and rolling the turbine through turbine synchronization.

While auxiliary steam production is not the primary function of the evaporator/steam drum, supply of saturated steam for startup was demonstrated at Solar Two by daily operation of the evaporator/steam drum at $5 \%$ of the design duty. The benefits of using the evaporator/steam drum for auxiliary steam production are:

- Thermal conditioning of the superheater and evaporator to nominal value of $360^{\circ} \mathrm{C}\left(675^{\circ} \mathrm{F}\right)$ with the simultaneous production of preheat steam without exceeding the allowable temperature change rates.

- Preheating the heat exchangers without steam production will require very low salt flow rates, which will likely produce local regions of high thermal stresses. Salt flow rates required for auxiliary steam production are larger and will ensure a reasonably uniform temperature distribution in the heat exchangers. 
- To support the low demand requirement for saturated steam, the SGS circulation and attemperation pumps and VSD must be capable of turndown on the order of 2 to $5 \%$ of rated design flow.

\subsubsection{Thermal Fatigue}

SGS exchanger components temperature cyclic fatigue life will be 30 years. The number of thermal cycles will depend upon whether the SGS operates on a daily thermal cycle with minimal storage or dispatches energy 24 hours day. The SGS will remain filled with molten salt during an overnight hold and the SGS attemperation pumps will be periodically bumped to maintain temperature and prevent salt freezing. The temperature rate of change (TRC) will be selected so that the daily temperature cycle from overnight hold to operation will occur within a one-hour time frame or at a rate of not less than $\mathrm{TBD}^{\circ} \mathrm{C} / \mathrm{hr}$ ( $\mathrm{TBD}^{\circ} \mathrm{F} /$ hour). The maximum TRC will have to be established in consultation with the SGS exchanger designer/manufacturer. SGS heat exchangers will be electrically heat traced to:

- Assist with thermal conditioning of the equipment prior to flowing cold/attemperated salt,

- Prevent salt freezing, and

- Assist with salt thawing in the event of a freeze condition.

Minimum - Thermal Storage Cycles. The maximum number of daily thermal cycles, including maintenance outages for the minimum storage case, will be 11,000. The daily SGS superheater/ reheater thermal cycle consists of a cold salt start from 260 to $565^{\circ} \mathrm{C}\left(500^{\circ} \mathrm{F}\right.$ to $\left.1050^{\circ} \mathrm{F}\right)$, while the evaporator and preheater rate will rise from $260^{\circ} \mathrm{C}\left(500^{\circ} \mathrm{F}\right)$ to the maximum salt inlet temperature for the piece of equipment. The number of maintenance cycles planned and unplanned will be 60 from $290^{\circ} \mathrm{C}\left(550^{\circ} \mathrm{F}\right)$ to ambient.

24 Hour/Day Dispatchability Cycles. The number of days that an SPT can dispatch power on a 24 hour/day basis is between 60 to 90 days under the best solar insolation conditions. Therefore, the number of thermal cycles for a 24 hour/day facility will range from 8,300 to 9,200 .

\subsubsection{SGS Exchanger Arrangement}

The SGS system heat exchangers will be located in the receiver tower structure at an elevation sufficient to allow all SGS components to drain by gravity back to either TSS storage tank. The SGS will fill from the bottom through the superheater and reheater.

Exchanger tube bundles will be designed so the tube bundle can be extracted, removed from the shell without removal of the exchanger from the stack, and lowered to grade elevation. A monorail crane or equivalent should be considered since overhead access may be restricted by the location of the stack in receiver tower structure. Consider an anchor point incorporated into the tower structure capable of accommodating the extraction loads. 


\subsubsection{SGS Drain Process}

The SGS drain process is by gravity through the return piping. SGS is complete when there no is static head measured from the preheater or reheater outlet to cold tank inlet. With the temperatures of the SGS exchanger shell still measuring $>260^{\circ} \mathrm{C}\left(>500^{\circ} \mathrm{F}\right)$, use either $\mathrm{NaK} / \mathrm{HiTec} /$ Organic Salt differential pressure sensors. Evaluate if the SGS circulation pump and SGS attemperation pump counter-rotation protection is required and include check valves on the pump discharges with a bypass return line tying into the tank return line. It is preferable to avoid additional piping and valves.

\subsubsection{Heat Exchanger Tube Rupture}

A heat exchanger tube rupture in any of the SGS nitrate salt exchanges will introduce steam into the SGS piping system and the TSS salt storage tanks. A quick method of draining feedwater and nitrate salt from the SGS should be evaluated during the SGS design and, if practical, incorporated into the design baseline.

\subsubsection{Steam Generation System Shell and Tube Heat Exchanger Design Requirements}

SGS shell and tube heat exchanger design requirements (superheater, evaporator, preheater, reheater, and startup feedwater heater) are given below:

- Preferred mode of operation during overnight hold is to "button up" the exchangers and periodically bump the SGS attemperation pump to keep the internal exchanger temperatures above $260^{\circ} \mathrm{C}\left(500^{\circ} \mathrm{F}\right)$ without producing steam.

- All Exchangers will be insulated. All exchangers will be electric heat traced with the exception of the startup feedwater heater. EHTS will be designed for thermally conditioning the exchanger shells and tubes prior to startup in addition to nitrate salt freeze protection.

- Exchangers will experience multiple thermal cycles, potentially daily, with the superheater and reheater experiencing a temperature rise from 260 to $565^{\circ} \mathrm{C}\left(500^{\circ} \mathrm{F}\right.$ to $\left.1050^{\circ} \mathrm{F}\right)$. The rate at which the SGS can be preheated affects plant performance. The more rapid the rate, the better the performance. The maximum allowable temperature rate of change (TRC) $\left(\mathrm{TBD}^{\circ} \mathrm{C} / \mathrm{hr}\left({ }^{\circ} \mathrm{F} / \mathrm{hr}\right)\right)$ should be established in consultation with the exchanger design/manufacturers and be a specified evaluation criteria in the procurement process.

- Shell side (superheater, evaporator, preheater, and reheater) requirements will be welded construction including rear end heads and inlet and outlet piping interface connections.

- Tube side channel covers will be removable to allow for periodic cleaning of tube bundles with high-pressure water. Since all exchangers will experience daily thermal cycling, the removable bolted channel partition plates should be double-bolted and seal-welded to avoid having the bolts work loose. Solar Two experience determined that with multiple thermal cycles, the bolts loosened and leakage occurred, resulting in a reduction in exchanger performance. 
- The superheater should provide a thermowell capable of accepting dual temperature elements in the tube side inlet of the superheater.

- Evaporator, preheater, and feedwater heater will be sized for both full load duty and for startup/auxiliary steam production.

\subsubsection{Steam Drum Design Requirements}

Steam drum design requirements are given below.

- The steam drum must be sized for both full load duty and startup/auxiliary steam production.

- The steam drum will experience daily thermal cycles and should be specified to match the exchanger TRC maximum.

- Provide startup steam drum immersion heaters with sufficient capacity to preheat the flooded steam drum to $260^{\circ} \mathrm{C}\left(500^{\circ} \mathrm{F}\right)$ within two (TBD) hours. Immersion heaters will be spared at $100 \%$. Immersion heaters will controlled through the MCS to preheat the steam generation system feedwater prior to introduction molten salt.

- Provide condensate drain(s) between steam drum and superheater for condensate removal prior to steam drum startup from overnight hold.

- Provide steam drum level gauge cooling to maintain gauge water temperature below the saturation value. Monitoring gauge temperature and applying correction factors for water density as a function of temperature are used in the level measurements.

- Provide an automated steam drum SGS blowdown system with visual sight glass. Location of blowdown extraction point on steam drum will remove steam drum contents and not enter feedwater.

- In sizing the BOP water treatment system, consideration should be given to higher carbon dioxide $\left(\mathrm{CO}_{2}\right)$ concentrations in the feedwater than is normal. Carbon dioxide is normally removed by the vacuum pump in the condenser; however, with daily cyclic plant operations, much higher equilibrium concentrations of $\mathrm{CO}_{2}$ may result. Dissolved $\mathrm{CO}_{2}$ forms carbonic acid $\left(\mathrm{H}_{2} \mathrm{CO}_{3}\right)$ in regions where steam and water coexist, leading to increased corrosion. $\mathrm{CO}_{2}$ is typically absorbed from the air in the makeup water tanks, the condenser, and the deaerator, and is produced as a decomposition byproduct of chemicals added for scavenging oxygen.

- Primary feedwater mixing will occur externally to the steam drum in feedwater piping.

- Provide redundant steam drum immersion heaters to support SGS startup/thermal conditioning from the transition form long-term hold to overnight hold in TBD (estimated two hours) hours. As an option, the immersion heaters may be used to maintain steam drum temperature during overnight hold in combination with circulation of cold salt. 
- Steam drum will be insulated and electrically heat traced. The EHTS will be designed to thermally condition the vessel for startup so that the vessel temperature rate of change does not exceed the vessel cyclic fatigue design limits.

- Provide protection from rapid decay in feedwater saturation pressure by providing a rapid steam drain system (isolation valve, flash tank, and pressure switch).

\subsubsection{Steam Generation System Circulation Pump and Steam Generation System Attemperation Pump Design Requirements}

\subsubsection{Pump Type}

Both pumps will be vertical turbine pumps with VSDs. The SGS circulation pump will be supported by a bridging structure spanning the hot salt tank and take suction directly from the hot salt tank. The SGS attemperation pump will be supported by a bridging structure spanning the cold salt tank. It shares the structure with the RS circulation pump and takes suction directly from the cold salt tank. Both pump shaft lengths will be between 12.2 and $13.7 \mathrm{~m} \mathrm{(40} \mathrm{and} 45 \mathrm{ft}$ ) positioned at the minimum liquid level approximately $1 \mathrm{~m}(3 \mathrm{ft})$ above bottom of the tank. Installed spare pumps will not be provided. The baseline approach is to install a single nitrate salt pump in each service and warehouse a complete spare pump and motor with additional spare parts as recommended by the manufacturer. The traditional approach of having installed spare pumps results in additional piping and valves, which lowers overall system reliability. Each pump will be supplied with a tail pipe of sufficient length to extend into the heel to empty a tank in case of a nitrate salt leak.

SGS circulation pump functions are to provide hot salt for steam generation and for reheat over a full range of load conditions, including startup, auxiliary steam production, and for turbine operations on a 24-hour-day basis.

SGS circulation pump will be sized for $110 \%$ SGS flow and head through the superheater and reheater circuits. The pump will be capable of operating from $0 \%$ flow to $110 \%$ of capacity. The pump head is determined by the sum of the line losses, salt mixer, static head due to SGS location on the receiver tower measured to top of the SGS entry into the superheater, and pressure drop through each SGS exchanger. The SGS circulation pump head characteristics need to be matched to the SGS attemperation pump support startup, normal operations, and shutdown.

SGS attemperation pump functions are to:

- Maintain a fixed attemperating salt flow rate to the superheater during startup,

- Modulate the flow of cold salt to the superheater in the transitions to overnight hold following a steam generator trip.

- Periodically flow salt to through the exchanger train during overnight hold to maintain system internal temperature above $260^{\circ} \mathrm{C}\left(500^{\circ} \mathrm{F}\right)$. 
The SGS attemperation pump will be sized to supply 260 to $290^{\circ} \mathrm{C}\left(500\right.$ to $\left.550^{\circ} \mathrm{F}\right)$ salt to the superheater and reheater for thermal conditioning the SGS exchangers during filling/startup and shutdown to:

- Assure the TRC limits are not exceeded.

- Support auxiliary steam generation.

- Provide cold salt flow that fills the SGS exchanger shells without the aid of a back pressure control valve(s) on the downstream side of the return loop. Refer to Section 3.5.9 for a discussion on the SGS fill process.

- Match the head characteristic of the SGS circulation pump to assure it can develop sufficient head to match the SGS circulation pump during startup normal operations and shutdown.

\subsubsection{Pump Mounting Interface}

Pumps will be flange-mounted to the TSS structural support frame (BOP item) and their shafts will extend into the cold salt tank through an insulated gland. The pump will be capable of being removed and replaced on a single shift.

\subsubsection{Electric Heat Tracing and Insulation Requirements}

Both pumps will be electric heat traced and insulated. The EHT systems will be designed to prevent salt freezing and to thermally condition the pump barrels. The EHT system must consider all pump operating states and transitions.

\subsubsection{Variable Speed Drive Over-Temperature Protection}

The VSD overt temperature protection may require external cooling systems when the pumps are either in operation and when the pumps are not in operation in an overnight hold. Motor cooling may not be operational when the pumps are not functioning.

\subsubsection{Steam Generation System Preheater Feedwater Pump(s) and Steam Generation System Evaporator Feedwater Pump(s) Design Basis}

\subsubsection{Pump Type}

Prime and spare for both services are required. Pumps may be either horizontal or in-line centrifugal pumps with canned rotors or magnetic drives. Both pumps will operate through a daily thermal startup cycle from ambient to over $260^{\circ} \mathrm{C}\left(500^{\circ} \mathrm{F}\right)$. Standard centrifugal pumps with mechanical shaft seals proved to be very problematic on Solar Two and are not recommended. Potential supply sources for these pumps are: 


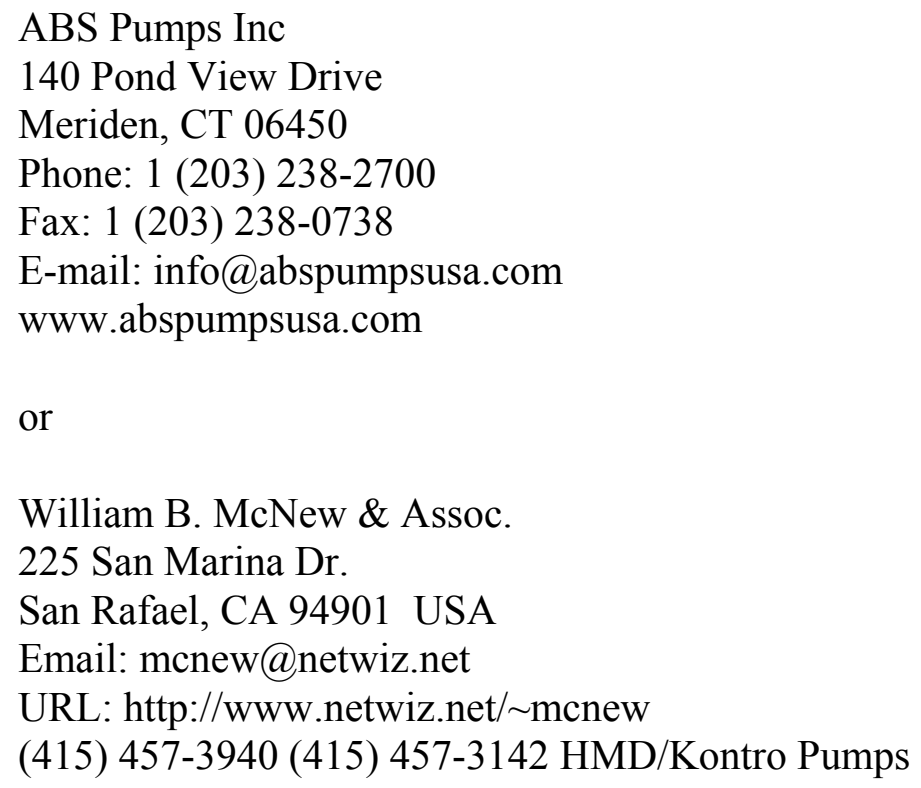

\subsubsection{Steam Generation System Preheater Feedwater Pump(s) Functions}

SGS preheater feedwater pump(s) functions are to take suction directly from the steam drum well and supply feedwater (near the saturation temperature) at a variable flow rate to the preheater. Flow control is maintained by temperature control valve on the inlet to the preheater.

\subsubsection{Steam Generation System Evaporator Feedwater Pump(s) Functions}

SGS evaporator feedwater pump(s) functions are to take suction from the steam drum feedwater mixer (near the saturation temperature) and supply feedwater at a constant flow rate to the evaporator.

\subsubsection{Steam Generation System Preheater Feedwater Pump(s) Sizing}

SGS preheater feedwater pump(s) sizing is based upon two conditions. Initially, the feedwater temperature entering the preheater must be $>230^{\circ} \mathrm{C}\left(>450^{\circ} \mathrm{F}\right)$ to prevent salt freezing in the exchangers. Flow circulation is solely through steam drum to preheater loop with no contribution from the startup feedwater heater or from the turbine extraction feedwater heaters. Once auxiliary steam production commences, feedwater temperatures to preheater can be reduced and will be supplied at temperatures $\geq 150^{\circ} \mathrm{C}\left(\geq 300^{\circ} \mathrm{F}\right)$ in increasing amounts for heating system steam piping and turbine equipment through turbine roll/synchronization. The startup feed water heater handles the supplemental heating load until the extraction feedwater temperature exceeds $150^{\circ} \mathrm{C}\left(300^{\circ} \mathrm{F}\right)$. The range of conditions that the SGS preheater feedwater pump must perform is dependent upon the type of turbine, system startup pressures, temperatures, etc., and will be determined through analysis of the system design load cases. The selection of the pump and its drive depend upon this analysis. 
Once turbine synchronization has been achieved, the blending flow rate will peak and begin to decrease as a function of feedwater temperature and turbine load conditions. When the extraction feedwater heaters assume the feedwater heating load, the startup feedwater heater will selflimit and the SGS preheater feedwater pump can be shut down to reduce parasitic loads. This point in the transition from turbine synchronization to normal operations will be determined through the load case analysis and will determine maximum pump capacity.

\subsubsection{Steam Generation System Evaporator Feedwater Pump(s) Sizing}

SGS evaporator feedwater pump(s) sizing is based upon providing sufficient feedwater flow and mixing to prevent departure from the nucleate boiling regime within the evaporator tubes. Based upon Solar Two experience, this pump will operate at constant rate. The sizing of the SGS evaporator feedwater pump is driven by SGS heat exchanger designer/manufacturer and will be established as part of the SGS system design considering all load conditions.

\subsubsection{Steam Generation System Material Selection}

SGS material selection is presented in Table 3-9.

Table 3-9. SGS Material Selection

\begin{tabular}{lll}
\hline \hline Equipment/Component & \multicolumn{1}{c}{ Materials } & Corrosion Allowance and Remarks \\
\hline Superheater & & $\begin{array}{l}\text { (Two Pass Shell, U-tube Heat ex- } \\
\text { changer, Channel Integral with Tube } \\
\text { Sheet and Removable Cover) }\end{array}$ \\
\hline Tubes & Stainless Steel, ASTM A249 or A213 Gr & $\begin{array}{l}\text { Tubes corrosion allowance: } \\
\text { Type 347: 0.4 mm 15 mils }\end{array}$ \\
& 321 or 347 & $\begin{array}{l}\text { Type 321: TBD (refer to Section 4.3.1.1) } \\
\text { Fouling factor 0.0005 }\end{array}$ \\
& & $\begin{array}{l}\text { Shell Corrosion allowance: } \\
\text { Type 347 0.7mm (25 mils) }\end{array}$ \\
\hline Plate & Stainless Steel Type ASTM 240, Gr 321 TBD \\
& or 347 & Fouling factor 0.0005 \\
\hline Steam Drum & & Corrosion allowance: 0.4 mm (15 mils) \\
\hline \hline
\end{tabular}


Table 3-9. SGS Material Selection (continued)

\begin{tabular}{|c|c|c|}
\hline Equipment/Component & Materials & Corrosion Allowance and Remarks \\
\hline \multicolumn{3}{|l|}{ Evaporator } \\
\hline Tubes & $\begin{array}{l}\text { Low Chrome Alloy, Tubes, Seamless: } \\
\text { 9Cr - 1Mo ASTM A213, T91 }\end{array}$ & $\begin{array}{l}\text { Tubes Corrosion allowance: } 0.4 \mathrm{~mm}(15 \\
\text { mils) } \\
\text { Fouling factor } 0.0005\end{array}$ \\
\hline Plate & $\begin{array}{l}\text { Low Chrome Alloy, Plate } 9 \mathrm{Cr}-1 \mathrm{Mo} \\
\text { ASTM A387, Gr } 91\end{array}$ & $\begin{array}{l}\text { Shell Corrosion allowance: } 0.7 \mathrm{~mm}(25 \\
\text { mils) } \\
\text { Fouling factor } 0.0005\end{array}$ \\
\hline \multicolumn{3}{|l|}{ Preheater } \\
\hline Tubes & Carbon Steel, ASTM 192 & $\begin{array}{l}\text { Tubes Corrosion allowance: } 1.6 \mathrm{~mm} \text { (63 } \\
\text { mils) } \\
\text { Fouling factor } 0.0005\end{array}$ \\
\hline \multirow[t]{2}{*}{ Plate } & Carbon Steel, ASTM A516, Gr 70 & $\begin{array}{l}\text { Shell Corrosion allowance: } 0.4 \text { mm (15 } \\
\text { mils) }\end{array}$ \\
\hline & & Fouling factor 0.0005 \\
\hline \multicolumn{3}{|l|}{ Startup Feedwater heater } \\
\hline Tubes & Carbon Steel, ASTM A556, Gr B2 & $\begin{array}{l}\text { Tubes Corrosion allowance: } 1.6 \mathrm{~mm} \text { (63 } \\
\text { mils) } \\
\text { Fouling factor } 0.0005\end{array}$ \\
\hline Plate & Carbon Steel, ASTM A516, Gr 70 & $\begin{array}{l}\text { Shell Corrosion allowance: } 1.6 \mathrm{~mm} \mathrm{(63} \\
\text { mils) } \\
\text { Fouling factor } 0.0005\end{array}$ \\
\hline \multicolumn{3}{|l|}{ Reheater } \\
\hline Tubes & $\begin{array}{l}\text { Stainless Steel, ASTM A213 or A249 Gr } \\
321 \text { or } 347\end{array}$ & $\begin{array}{l}\text { Tube Corrosion allowance: } \\
\text { Type 347: } 0.4 \mathrm{~mm} \text { (15 mils) } \\
\text { Type } 321: \text { TBD } \\
\text { Fouling factor } 0.0005\end{array}$ \\
\hline Plate & $\begin{array}{l}\text { Stainless Steel, ASTM A240, Gr } 321 \text { or } \\
347\end{array}$ & $\begin{array}{l}\text { Shell corrosion allowance: } \\
\text { Type 347: } 0.4 \mathrm{~mm}(15 \text { mils }) \\
\text { Type 321: TBD } \\
\text { Fouling factor } 0.0005\end{array}$ \\
\hline \multirow[t]{9}{*}{ SGS Circulation Pump } & $\begin{array}{l}316 \text { Stainless Steel impeller, casing } \\
\text { shaft, and bearing retainer }\end{array}$ & Discharge Flanges, refer to Note 1 \\
\hline & $\begin{array}{l}\text { Castings to be ASTM A351, Gr CF } 8 \text { C, } \\
\text { Ferrite content of castings to be less } \\
\text { than } 10 \%\end{array}$ & \\
\hline & Support Frame $316 \mathrm{~L}$ & \\
\hline & Bearing Materials: & \\
\hline & $\begin{array}{l}\text { Journal Sleeve: NPI } 420 \text { Stainless Steel } \\
\text { (good ware) }\end{array}$ & \\
\hline & Bearing: Gray Cast Iron Gr. 40 & \\
\hline & or & \\
\hline & $\begin{array}{l}\text { Journal Sleeve: Stellite } 6 \mathrm{~B} \text { (performed } \\
\text { best, very expensive) }\end{array}$ & \\
\hline & Bearing: Ni-Resist Type I & \\
\hline
\end{tabular}


Table 3-9. SGS Material Selection (continued)

\begin{tabular}{llc}
\hline \hline \multicolumn{1}{c}{ Equipment/Component } & Materials & Corrosion Allowance and Remarks \\
\hline SGS Attemperation Pump & Carbon Steel, ASTM A216, Gr WCB & Discharge Flanges, refer to Note 1 \\
\hline SGS Feedwater Mixer & Carbon Steel, ASTM A216, Gr WCB & \\
\hline $\begin{array}{l}\text { SGS Preheater Feedwater } \\
\text { Pump }\end{array}$ & Carbon Steel, ASTM A216, Gr WCB & \\
\hline
\end{tabular}

SGS Evaporator Feedwater Carbon Steel, ASTM A216, Gr WCB

Pump

Note 1: Pump discharge flange - The pump discharge flange may be either a RJT or Reflange R-Con Connector type. Ring gasket or Hub ring shall be stainless steel, either type 321or 347)

1

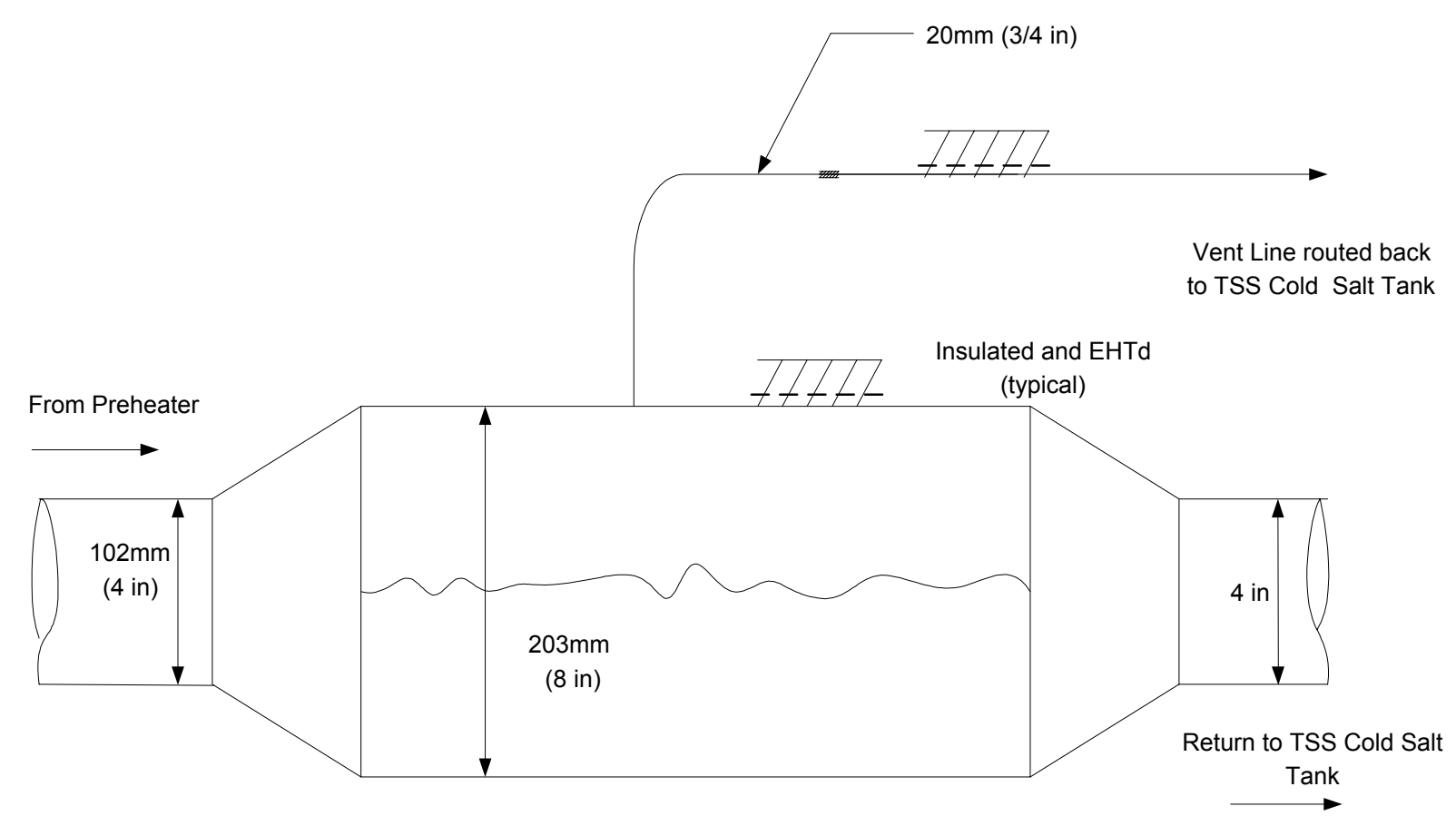

\subsubsection{Steam Generation System Fill Process}

When the SGS exchanger shells are filled with salt, the heat exchanger shells and piping must be purged of air and, similarly, when drained air must be supplied to the exchangers to facilitate draining. A passive high point vent, no valves, on the preheater return line to the TSS cold tank at system high point is required to eliminate trapped air during fill process. The configuration of the passive vent is shown in Figure 3-5.

Fill process is judged complete when the following temperatures are equal to the salt temperature at the SGS attemperation pump discharge:

- Each of the SGS heat exchanger five vents and supply/return header;

Figure 3-5. Configuration of passive vent. 
- The line between the preheater/reheater and the cold salt tank.

Solar Two SGS exchanger filling process required approximately four minutes with the SGS attemperation pump operating at $100 \%$ capacity.

\subsubsection{Steam Generation System Sequence of Operation}

A typical SGS sequence of operation is described below. SGS circulation pump hot salt flow through the superheater is controlled by the SGS circulation pump VSD. The reheater flow is controlled by a TCV on the downstream side of the reheater. An optimized process-piping configuration is depicted on the nitrate salt system PFD, which reduces restart time from the transition from overnight hold to normal operation.

SGS will remain filled with molten salt during overnight hold, operational baseline. Cold salt is circulated through the SGS exchanger train to maintain temperature by the SGS attemperation pump.

The "normally open" (NO) (hot salt supply) and "normally closed" (NC) (recirculation line) isolation valves at the inlet to the superheater should be located as closely as possible to the superheater.

Startup requirements for steam temperature, steam flow rate, and allowable temperature change rates in the heat exchangers will be controlled by varying the SGS circulation pump speed and blending increasing amounts of hot salt while maintaining essentially a fixed flow rate of cold salt.

The typical operational sequence is as follows:

Step 1. SGS attemperation pump cold salt flow is set at a fixed rate through the superheater and reheater; approximately $75 \%$ of rated flow. The cold salt flow rate set point is selected to assure that the pump will not stall or cause oscillations in the attemperated salt temperature at the entrance to the superheater. The temperature set points will be derived from a hydraulic model of the following:

- Four heat exchangers (superheater, evaporator, preheater, and reheater),

- $\quad$ Salt piping system line losses

- Three-dimensional surface fit of the hot salt SGS circulation pump speed, flow, and head characteristics, and

- Three-dimensional surface fit of the SGS attemperation pump flow and head characteristics.

Step 2. SGS circulation pump VSD is accelerated to a point where its head is insufficient to overcome the head developed by the attemperation pump (approximately 30\%). Salt temperature at the superheater inlet is constant at $290^{\circ} \mathrm{C}\left(550^{\circ} \mathrm{F}\right)$. Recirculation bypass protects the SGS circulation pump. 
Step 3. Auxiliary Steam Production - Speed of SGS circulation pump is accelerated so that the attemperated salt temperature rate of increase, measured at the inlet to the superheater, does not exceed either the maximum superheater or reheater temperature change rate criteria. At a superheater inlet temperature of $\mathrm{TBD}^{\circ} \mathrm{C}\left({ }^{\circ} \mathrm{F}\right)$, the sum of the hot salt SGS circulation pump flow rate and cold salt SGS attemperation pump flow rate provides sufficient thermal energy required for auxiliary steam production. The speed of both pumps is held constant until the operator transitions to the next state.

Step 4. Turbine Synchronization - The SGS circulation pump is accelerated to provide a superheater inlet temperature of $\mathrm{TBD}^{\circ} \mathrm{C}\left({ }^{\circ} \mathrm{F}\right)$ at a rate not to exceed the maximum superheater temperature change rate. The combined flow rates of the hot salt SGS circulation pump flow rate and cold salt SGS attemperation pump flow rate provide sufficient thermal energy for turbine synchronization.

Step 5. Normal Operation - The SGS attemperation pump is decelerated at a rate not to exceed the maximum superheater temperature change rate that allows the superheater to reach inlet design temperature of $565^{\circ} \mathrm{C}\left(1050^{\circ} \mathrm{F}\right)$. When the salt temperature reaches $565^{\circ} \mathrm{C}\left(1050^{\circ} \mathrm{F}\right)$, the SGS attemperation pump is shut down.

A typical SGS/EPGS trip and cooldown sequence based upon Solar Two lessons learned is discussed below. Leading up to an SGS/EPGS trip, the following normal temperature gradients through the SGS are:

- $565^{\circ} \mathrm{C}\left(1050^{\circ} \mathrm{F}\right)$ salt at the inlet to the superheater,

- $454^{\circ} \mathrm{C}\left(850^{\circ} \mathrm{F}\right)$ to evaporator inlet, and

- $343^{\circ} \mathrm{C}\left(650^{\circ} \mathrm{F}\right)$ to preheater inlet.

There was no way of restarting the Solar Two SGS without first cooling the heat exchangers to the cold salt temperature, $290^{\circ} \mathrm{C}\left(550^{\circ} \mathrm{F}\right)$, to comply with the heat exchanger temperature rate of change criteria. This same issue will exist for the next plant, but may be obviated by exchanger manufacture allowing a higher temperature ramp rate. This issue needs to be addressed and restart time shortened for the next plant. The SGS/EPGS criteria will state that the SGS/EPGS will restart in TBD (recommended 60 minutes) minutes following a trip. The following Solar Two cooldown sequence is described below and tied to the system PFDs.

Step 1. Close the NO hot salt supply isolation valve to the superheater and open the NC recirculation loop isolation valve. Start the cold salt SGS attemperation pump, establishing flow up to the isolation valve at the inlet to the superheater and back through the recirculation line to the cold salt tank.

Step 2. Start the hot salt pump.

Step 3. Increase the speed of the hot salt pump until the temperature of the mixed salt in the recirculation line equals the temperature of the superheater.

Step 4. Open the main hot salt isolation valve to the superheater, establishing a limited flow rate through the steam generator. 
Step 5. Establish a set point value for the evaporator pressure using the main steam throttle valve to the condenser.

Step 6. Close the recirculation isolation valve.

Step 7. Ramp the superheat temperature downwards at a rate that does not exceed the SGS rate change limitations.

\subsection{Electric Heat Tracing System}

\subsubsection{System Description}

The EHTS is a critical process temperature control system for thermally conditioning the systems before salt flow and steam flow and providing salt freeze protection to all systems.

The EHTS interfaces with the RS, TSS, SGS, and EPGS and is comprised metal-sheathed resistance heating element cable, temperature sensors, and controllers.

Based upon Solar Two experience, the EHTS will be a fully integrated system with the overall control residing in MCS as part of the DCS. Its functions will be directly linked with other process control functions so that system thermal conditioning prior to flowing molten salt is fully automated. The EHTS includes all nitrate salt freeze protection systems, nitrate salt thermal piping, valve and line device conditioning, equipment thermal conditioning, and long-term temperature maintenance of the TSS in the event of a long-term hold and maintenance shut down.

\subsubsection{Scope of Supply}

The EHTS material for equipment, in line component, piping, valves, etc., will be procured as an EHT system that encompasses the physical design, heat transfer calculations/analysis, fabrication, installation, and testing (component and system level acceptance testing). Scope will encompass all materials and hardware comprising the system, including the heat tracing cable sets, splice kits with an interface junction box, temperature sensors/temperature transmitters with associated junction boxes, and all installation hardware. Each circuit/zone should be supported by an approved design for:

- Use in designing and sizing the power distribution and control, and

- Space allocation of equipment and the electrical power tie in points.

Final fabrication, assembly, and installation of each zone will be a field activity performed by the manufacturer to assure that the elements are cut to length to match the actual as-built physical configuration of the equipment and piping systems. This is a schedule-driven decision because factory assembled cable sets that match the as-built configuration cannot be produced at a rate to support construction. The quality and reliability of the field manufactured cable set will match that of factory cable set. 
The scope of design and supply should include circuit solid state contactors; however, installation and rack housings should not be included.

\subsubsection{Electric Heat Tracing System Integration}

The EHTS power distribution, power control center (including installation of the solid-state contractors) and the connection from the temperature sensor elements to the EHTS junction boxes should not be within the scope of the EHTS supply. The EHTS is a critical process control system and, as such, will reside in the MCS on the DCS. The SPT project integrator will be responsible for the overall system design and coordination with other systems to assure that the EHT design meet overall SPT process and operational requirements. Zone definition and location of temperature sensors must be specified by the integrator. Temperature set point are stateand state-transition dependent and must be specified by the integrator.

\subsubsection{Electric Heat Tracing System Design Basis}

\subsubsection{Electric Heat Tracing Control and Set Point Temperatures}

EHT zone definition and the selection of temperature set points is a design integrator responsibility.

EHT system operating modes vary by state and transitions between states. These requirements will be established by a detailed review of the plant operating states and the transitions between the states at the component and line (piping) level. Zone activation/deactivation and temperature set points will vary by states and transition, and the EHT zone design may be impacted. Freeze protection requirements vary. In addition, the EHTS is an integral part of DCS, and will be designed to automatically adjust the temperature set points and activate solid state contactors. Two examples are provided below to emphasize the importance of this task; why it must be handled as part of the process design, and not relegated to a supplier.

The RS system will be drained overnight and the piping EHT zones shut down to minimize parasitics losses. During daily startup in the transition from long-term hold/overnight hold to standby, the riser and downcomer piping must be preheated to a required set point temperature two hours before to flowing molten salt. This should be an automated function. Valve body and inline device EHT zones may have to remain active overnight in order to meet the two-hour limit, however, during a long-term hold, these zones would also be deactivated to reduce parasitics.

In RS system transition from standby to normal operation, certain line segments, e.g., crossover piping, receiver drain lines will change from flowing lines to dead legs, subject to freezing. The limits of the zone and where to place the temperature sensor elements relative to flowing and stagnant sections, and portions subject to convection/eddy flow currents, is important and can only be determined by process review.

The SGS system, including equipment piping, typically will remain filled with molten salt through the overnight hold. The SGS attemperation pump will be periodically bumped to main 
tain equipment system temperatures. Piping and inline device EHT zone will be active and will energize if temperature falls below the required set point. Zone definition is important in that there may be dead legs in parts of the piping system that require active EHT to preclude freezing.

Piping system set point temperatures on the DCS will be set to $260^{\circ} \mathrm{C}\left(500^{\circ} \mathrm{F}\right)$ for both hot and cold salt systems unless there is a thermal conditioning requirement, which limits the temperature rate of increase. The EHTS will operate until the system reaches operating temperature and then de-energize.

Valve and line device set point temperatures on the DCS shall be set to the actual tank salt bulk storage temperature or a maximum operating exposure temperature minus $10^{\circ} \mathrm{C}\left(50^{\circ} \mathrm{F}\right)$ for the particular flow stream, e.g., hot salt from the hot tank to super heater: $565^{\circ} \mathrm{C}\left(1050^{\circ} \mathrm{F}\right)$ minus $10^{\circ} \mathrm{C}\left(50^{\circ} \mathrm{F}\right)$ set point $555^{\circ} \mathrm{C}\left(1000^{\circ} \mathrm{F}\right)$. This will allow the line device to reach the operating temperature without being thermally shocked and allow the EHTS to de-energize once the system has reached the operating temperature.

DCS controller temperature dead band should be selected to limit contactor cycling: \pm 25 to $30^{\circ} \mathrm{C}$ (TBD) \pm 30 to $40^{\circ} \mathrm{F}$.

\subsubsection{System Component Redundancy}

System component redundancy is as follows.

Piping systems - Each piping zone EHT element as a minimum, and as physically possible, should be spared to $150 \%$ (rounding up), e.g., a single cable zone should have three cables installed. The spare cables should not be connected, but coiled and labeled as spare circuits. Piping temperature sensor elements shall be spared to $100 \%$ and shall be connected.

Valves - Installed spare EHT cable sets are not practical on valves, inline devices, and line mounted devices; however, spare EHT cable cut to the exact length of the valve/line device shall be fabricated, tagged for its end use, and stocked in sufficient quantity to allow replacement. Temperature sensor elements on critical valves shall be spared and connected. Refer to Section 4.8 on valve and line device thermal insulation.

\subsubsection{System Component Requirements}

The recommended EHT cable type is mineral insulated (MI) cable with magnesium oxide dielectric, dual-conductor heating elements with a welded Inconel 825 sheath. Two cable diameters are recommended: 5/16 in. (nominal $8 \mathrm{~mm}$ ) for $600 \mathrm{~V}$ service for long piping zones and $3 / 16 \mathrm{in}$. (nominal $4 \mathrm{~mm}$ ) for $300 \mathrm{~V}$ service for valves and line devices. The internal conductor (resistance heating element) resistance will vary depending upon the zone length. Cable power density should be limited to $50 \mathrm{~W} / \mathrm{ft}$ (nominal $164 \mathrm{~W} / \mathrm{m}$ ) to ensure maximum cable life.

Either thermocouple or RTD sensor elements are acceptable; however, the type selected will be standard across the entire facility. 


\subsubsection{Zone Definitions}

Piping System EHT Zones. Piping EHT zone length shall be as long a possible. A piping EHT zone will extend through an inline device zone, but shall not be used to EHT the inline devices.

4 Refer to Figure 3-6.

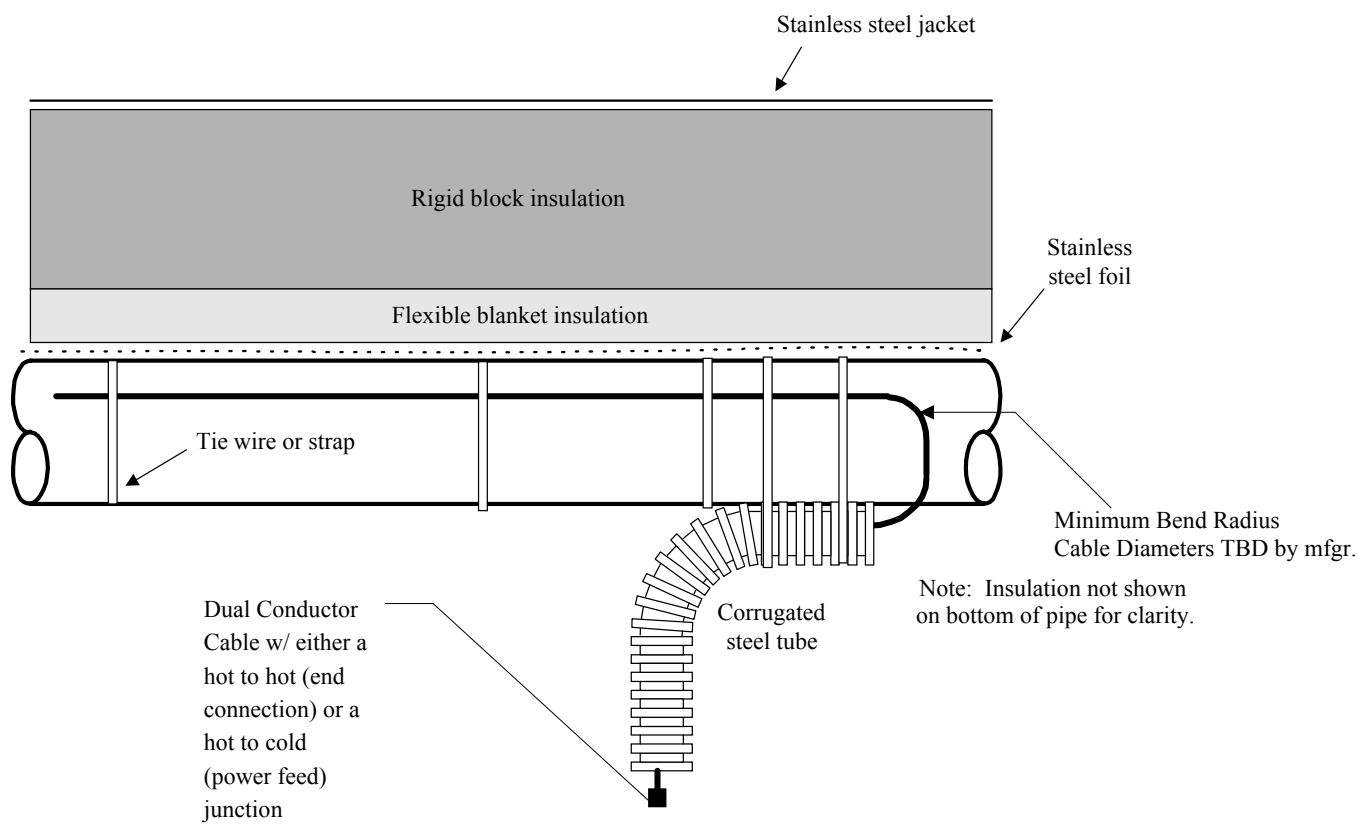

Figure 3-6. Piping System EHT Zones.

Pipe support EHT zones and the insulation systems at both anchor and guide locations require unique dimensioned designs detail with specific installation instructions. Typically, dedicated zones are not required. Daily thermal cycling of the piping systems and the resulting differential thermal expansion, both axially and radially, can result in accelerated wear of the insulation system if not properly specified and installed. The application details for the EHT cables at anchor and guide location must show physical dimensions of all insulation cutouts, banding attachments, and handle EHT and insulation as an integrated installation and not individual elements.

Valve EHT Zones. Valve EHT zones will be independent of the piping EHT zone. Valve zones typically have multiple zones with independent temperature sensors. Zones will be selected based upon the physical configuration of valve or line device with the intent of preventing salt from freezing anywhere in the valve and from exceeding maximum exposure temperatures to valve/line device components. Specifically, valve zones will assure that the valve stem packing is maintained within a temperature range of 260 to $315^{\circ} \mathrm{C}\left(500\right.$ to $\left.600^{\circ} \mathrm{F}\right)$. Refer to Section 4.5.2.

Refer to Figure 3-7 for a typical valve EHT zone definition. The valve body is electrically heat traced to maintain a process temperature while the bonnet is traced with an independent circuit to protect the valve packing from exceeding a limiting packing temperature. 
Check valves do not have extended bonnets. Therefore, if the insulation thickness on the valve and pipe are the same, the unit heat loss for the valve should be essentially the same as for the adjoining pipe. Consequently, treating the pipe and check valve on a contiguous basis is an acceptable design practice.

Each of the piping EHT zone's primary circuits, such as the riser and the downcomer, should use the fewest number of zones possible consistent with the maximum cable length available. Plant availability is improved by the following: (1) reduction in the number of cables, contactors, controllers, and communication lines; (2) reduction in the number of alarms monitored by the operators; and (3) potential operating modes that are not used correctly. The division of a piping circuit into multiple zones decreases the plant availability; the loss of one zone is equivalent to the loss of the complete circuit, and multiple zone components decrease the mean time between failure for the circuit. Each of the piping EHT zone's secondary circuits, such as the discharge line between a pump and a header, should use a separate zone. The zones can then be isolated or activated based on the operating mode.

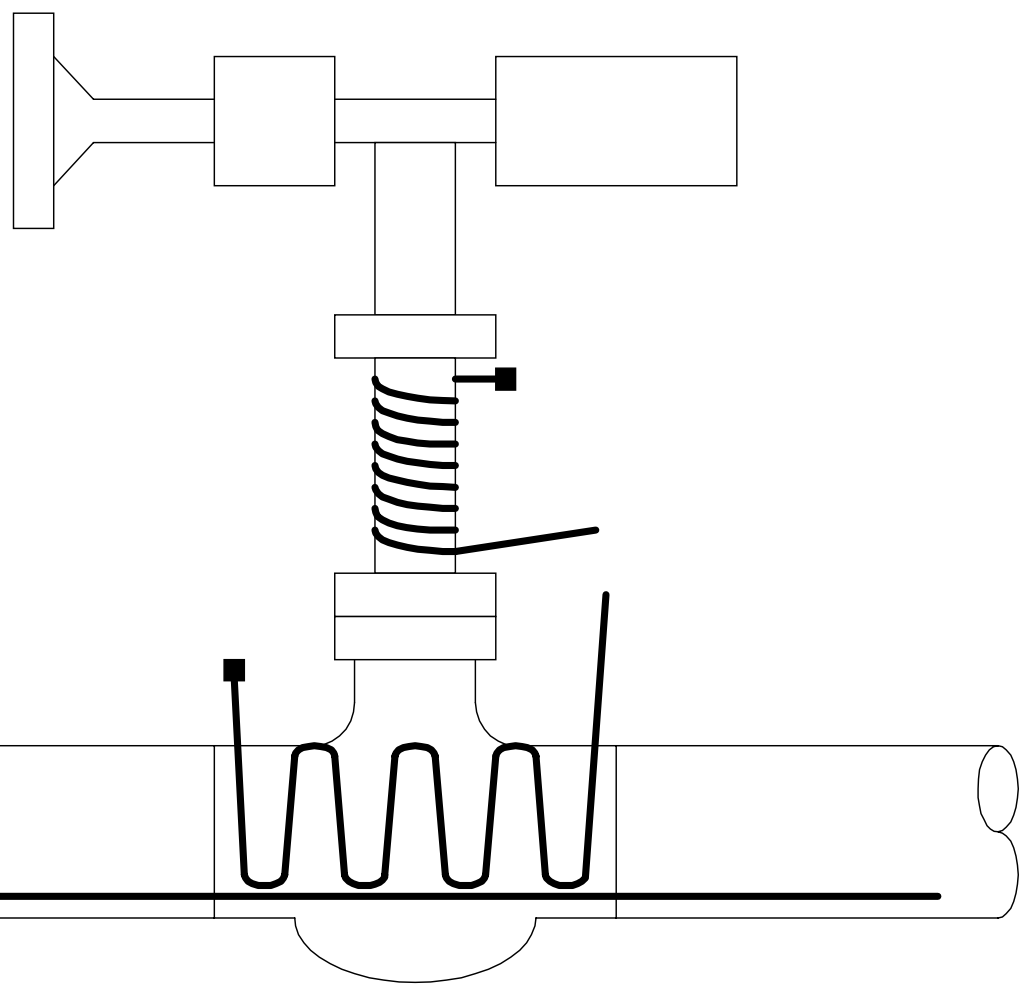

Figure 3-7. Typical Valve EHT Zone Definition.

If different operating modes subject a section of line to different static fluid heights, the boundary between the zones must end above any intermediate liquid levels. For example, from Solar Two experience, recirculated salt from the receiver pumps back to the cold salt tank by means of (1) the pump discharge header, (2) the lower riser-to-downcomer bypass valve, (3) the lower section of the downcomer, and (4) the diversion valve to the cold salt tank. In the recirculation mode, the flow of cold salt caused the heat trace circuit to turn off. Cold salt also rose to a

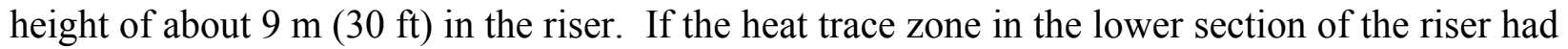


ended below an elevation of $9 \mathrm{~m}(30 \mathrm{ft})$, the stagnant salt in the riser above a height of $9 \mathrm{~m}(30$ $\mathrm{ft})$ would have frozen in a matter of a few hours.

\subsubsection{Temperature Sensor Location and Installation}

Sensor elements dependent upon the type are to be welded or banded to the pipe/line device, and then covered with stainless steel foil to ensure good thermal contact. Two sensor elements shall be provide on each zone and connected to the controller.

\subsubsection{Equipment Thermal Conditioning and Freeze Protection}

Hardware thermal conditioning and freeze protection requirements unique to major equipment elements are discussed below.

\subsubsection{Receiver Inlet and Outlet Vessels}

The vessel shells and heads will be electric heat traced with MI cable with two redundant tracers for vessel thermal conditioning and temperature maintenance during operation. The redundant tracer will not be connected, but will be accessible to connect without having to shut down the receiver. Zones boundaries will be defined based upon liquid level e.g., NLL, high liquid level (HLL), etc., to prevent excessive temperature gradients developing within the vessel. All vessel connections and attachments will be electric heat traced with independent zones similar to piping and line device EHT.

\subsubsection{Pressure Vessel and Tank Appurtenances}

Vents, drains, valves, and instruments wetted by nitrate salt or in contact with nitrate salt ladened vapor will be insulated and electric heat traced. The EHT design and zoning will follow the guidelines described in this section. Any open vent will be exposed to nitrate salt vapor and the extent of the EHT zone will encompass its entire length.

\subsubsection{Receiver Panel Oven Boxes}

Refer to RS Section 3.3.4.3 for EHT and thermal conditioning requirements.

\subsubsection{Hot and Cold Storage Tank Immersion Heater(s)}

Refer to TSS Section 3.4.3.3 for hot and cold storage tank immersion heater(s) requirements.

\subsubsection{Pressure Relief Valves}

All nitrate salt pressure relief valves (PSVs) will be electrically heat traced and insulated. The maximum exposure temperature of the valves is not the same as the springs. The maximum 
spring operating temperature is substantially lower. From Solar Two experience, the springs were over heated and valve springs damaged. PSV EHT design must specifically address the heat transfer effects on valve inlet, valve outlet, valve body, and spring top works. As a minimum, separate zones will be provided for the valve body, inlet piping, and outlet piping. The valve outlet tail/vent line pipe shall be traced over its entire length. Provide a weep hole at the PSV discharge low point to indicate that the valve is leaking.

\subsubsection{Vortex Shedding Flow Meters}

The vortex shedding flow meters reside in fittings, which are the same diameter as the pipe; therefore, the zone can be traced with the piping zone. The unit heat loss from the instrument body is essentially the same as that for the adjacent pipe. However, the instrument has a small boss which houses the vibration sensor, and the boss extends through the pipe insulation. The boss is not insulated due to temperature limits on the piezoelectric sensor. Therefore, the boss acts like a fin and cools the top of the fitting. From Solar Two experience, a loop in the shape of an "S" with a total length of $305 \mathrm{~mm}$ (12 in.) was added to each cable on the $150 \mathrm{~mm}$ (6-in.) flow meter to compensate for the convection losses from the boss. With a unit cable rating of $40 \mathrm{~W} / \mathrm{ft}$ (nominal $130 \mathrm{~W} / \mathrm{m}$ ) and two active cables, the loops increased the heat input to the meter by $80 \mathrm{~W}$ over that which would have been provided by the cables on the adjoining pipe.

\subsubsection{Level Gauges}

Bubblers, air supply lines, and wetted or salt vapor exposed components shall be electrically heat traced and insulated.

\subsubsection{Pressure Transducers}

No EHT is required for NaK capillary transducers since the $\mathrm{NaK}$ mixture melts at $-4^{\circ} \mathrm{C}\left(25^{\circ} \mathrm{F}\right)$ and is operable above $593^{\circ} \mathrm{C}\left(1100^{\circ} \mathrm{F}\right)$. HI TECH XL salt-filled capillaries require EHT. Temperature ranges are TBD. A third option uses a capillary filled with an organic salt, liquid at ambient conditions to well above $650^{\circ} \mathrm{C}\left(1200^{\circ} \mathrm{F}\right)$, is also being considered.

\subsubsection{Vertical Turbine Pump Electrical Heat Tracing}

Vertical turbine pump barrels and discharge housings, including the non-wetted exposed shaft inside the storage tank (ullage clearance volume), the exterior shaft, and the discharge housing will be electrically heat traced. The interior section will not be insulated. The exterior portion will be insulated. Separate zones will be used to trace equipment elements where the thermal/ physical conditions of the system change:

- From no insulation to insulation;

- If physical mass or geometry of the piece of equipment changes significantly. Specifically, the pump discharge flanges, RTJ, or hub type; 
- Interfaces with the VSD that consider equipment protection from potential overheating of VSD;

- When thermal conditioning of the pumps prior to startup is required to avoid thermal overstresses.

The pump barrel that extends into the storage tank needs to be analyzed from a thermal stress perspective. The tank may require a thermal condition system to prevent overstressing vertical turbine pump barrels and supports.

\subsection{Master Control System}

\subsubsection{System Description}

The MCS handles all site process control, monitoring, management, and administrative functions. MCS is comprised of three subsystems; the DCS, HAC, and ADAS. The primary focuses of this Design Basis Document are the DCS and HAC portions of the system. While important, the ADAS will not be discussed, other than to show that it is part of the overall MCS system architecture.

The DCS controls SPT process functions for all systems and equipment and provides reliable redundant coordinated control through all states and transitions in response to operator commands. The DCS consists of the following components:

- Redundant PC network (PCN) Servers (Process Interface),

- Network server (ADAS interface),

- Redundant PLCs,

- Redundant HAC using PC-based technology,

- Data networks,

- Operator consoles,

- PLC remote cabinets with analogue and digital I/O cards,

- Data historians (data logging and acquisition equipment),

- Peripherals, and

- All software.

DCS functions include CS, RS, SGS, TSS, EHTS, EPGS, and BOP process control.

The DCS is an integrated system intended to provide a state-of-the-art HMI.

The DCS is resident of the PCN servers and communicates with the redundant PLCs over the Process Control Network.

The DCS communicates with and controls the heliostats through the HAC and, subsequently, the HCs. The PCN servers and network server communicate with the HAC. Refer to Section 3.2.4 for a discussion on the HAC requirements and functions. HCs are part of the CS. 
DCS peripherals include printers, plotters, scanners, disc storage devices tape drives, CD writers, etc.

\subsubsection{Preliminary System Block Diagram}

Figure 3-8 shows the top-level system hardware, simplified network architecture, and its connectivity. The MCS architecture shown is notional and the actual system configuration will be driven by the state-of-technology at time of design and purchase.

\subsubsection{Scope of Supply}

\subsubsection{Distributed Control System Design Package}

The DCS design package will include all system architecture, interface specifications, and design for the RS, CS, TSS, SGS, EPGS, EHTS, and BOP. The development of hardware and software design and specifications includes logic diagrams, loop diagrams, operational sequences, and mockup HMI screens, and the procurement of the hardware and software. In addition, as the overall system integrator, this package will include technical oversight, startup, and system activation and testing. DCS HMI screens and PLC ladder logic encoding will be developed within this package.

\subsubsection{Distributed Control System Hardware/Software Procurement and Installation Support Package}

A single DCS hardware/software procurement and installation support package will be released, including PCN servers, network servers, PLCs, and remote I/O hardware, to one supplier. This package will include peripherals, operating system, network architecture, standard packagedsoftware, drivers, etc. It also includes support for installation, training, and HMI screen/graphic development. As an option, DCS HMI and PLC ladder logic encoding may be included within this procurement.

\subsubsection{HAC Hardware and Software Procurement Package}

A single HAC hardware and software procurement package will be released including all specialized HAC software encompassing the HAC CS field control, DAPS, SAPS, and BCS. 


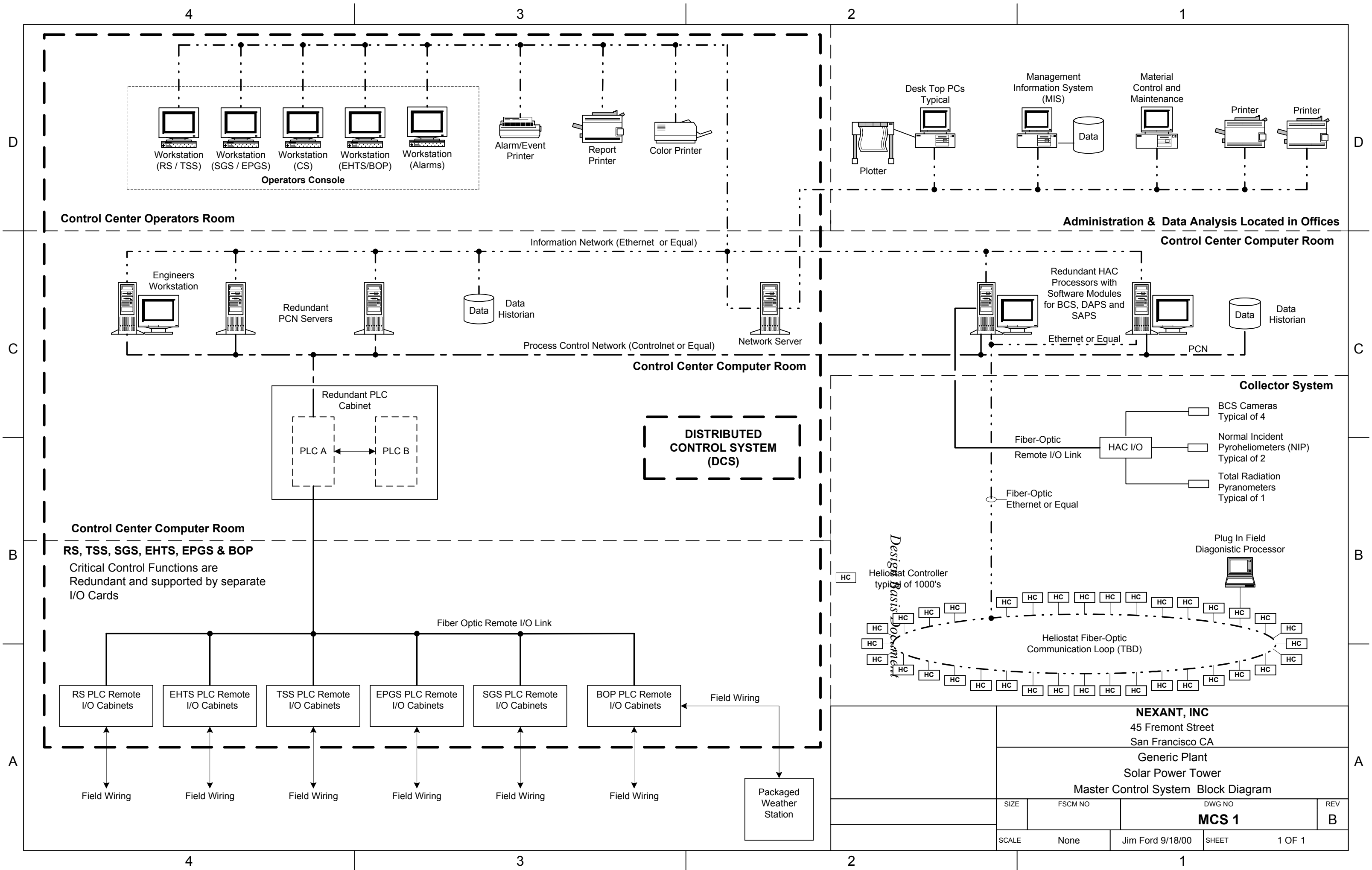

Figure 3-8. Distributed Control System 


\subsubsection{Distributed Control System Hardware Installation Package}

The DCS hardware installation package will be included as part of the site construction package, but will require that the hardware supplier(s) oversee installation, hardware burn-in, software loading, and testing. All network wiring interconnectivity installation will be performed in this package.

\subsubsection{General Distributed Control System Design and Functional Requirements}

General DCS design and functional requirements are as follows:

- Critical process control function will have redundancy from the process controller (PCN Servers/PLCs). Process critical PLC field I/O cards, critical field instruments, and communication paths will also be redundant.

- The PCN servers, PLCs, and HACs hardware will include internal diagnostics to alert the operator to component failures.

- The PCN servers, PLCs, and HACs primary processor (either the "A or B;" refer to the system schematic) will be on hot standby with automatic fail-over to the spare. Hardware will be configured to allow component replacement while the spare continues to function.

- The DCS will be the primary interface between the plant operators and all SPT systems. All graphics and interactions will be through the operator consoles including the HAC graphics and individual heliostat status.

- The DCS requires a data acquisition and recording capability (data historian) for all process instrument data and process variables as a function of time. DCS should be capable of both real time and off line trend and statistical analysis.

- All DCS and HAC computer hardware will be commercial-off-the-shelf, with the exception of the HCs.

- The HAC hardware and data historian will be designed based upon the HAC software primary and secondary functional requirements. Primary functional requirements take precedence in command processing time over the secondary requirements. The primary requirements are:

- Receive and execute commands from the DCS for the CS,

- Provide status to the DCS of the CS (heliostats and HCs),

- Provide a stable, redundant/failsafe platform to run CS heliostat control software,

- Transmit sun position and timing signals to the HCs,

- Transmit Operating Mode Commands to the HCs, and

- Receive Status updates from the HCs. 
- The DAPS, SAPS, and BCS software processing functions are secondary. If the computational complexity of the DAPS, SAPS, or BCS affect the primary HAC functions by degrading processing speed, affecting system stability, or reliability, these functions will be moved to additional processors. Other secondary requirements are:

- Maintain the field status database.

- Compute collector field cleanliness by quadrant based upon the wash log and reflectivity readings.

- Analyze solar data and performance data on a daily basis and provide data to the DCS for generation of reports.

\subsubsection{Communication Protocols}

11 Communication protocols between the DCS and PLCs, DCS and HAC, and PLCs and field I/O will use industry standard protocols with proven performance. It is recommended that a fiber optic based network system be the baseline from the DCS to the each remote field I/O card.

\subsubsection{Administrative and Data Analysis System}

ADAS will have read-only access to the DCS and the data historians. The overall site Materials Management System (MMS) is part of the ADAS and will have read-only access of DCS database for hardware status and component failures data. The MMS must be capable of accommodating and tracking component parts to a large number of individual heliostats. Standard commercially-available maintenance databases may not be adequate.

\subsubsection{Electric Heat Tracing System Zone Temperature Control}

EHTS zone temperature control will be integrated with the field I/O, PLCs, and DCS and not through an EHT supplier provided interface, PC, or temperature controllers.

\subsubsection{Maximum Electronic Hardware Operating Temperatures}

Electronic hardware that operates near nitrate salt containing systems will be exposed to higher than normal ambient temperatures. The maximum temperatures limits that electronic hardware can be exposed to will be exceeded, and therefore hardware cooling provided. Refer to Section 4.7.3. 


\subsection{Major Process to BOP Interfaces}

\subsubsection{General}

There are a substantial number of interfaces between RF, RS, TSS, SGS, EHTS, EPGS and MCS, and the BOP. This section defines special interface requirements unique to the SPT and the BOP, and does not attempt to define normal inter- and intrasystem interfaces, e.g., site, foundations, utilities, power, grounding, etc., unless there are unique issues involved.

Selected BOP system equipment and hardware will operate at different design points during normal operation and during overnight hold. In order to reduce parasitic power consumption, BOP systems design must address the differences in load demand between normal operations and overnight hold operations for compressed air, cooling water, service water, etc. The design analysis will determine if small "jockey"-type compressors, pumps, or cooling tower fan with smaller vessels/receivers could supply the facility overnight hold requirement without operating the main equipment.

Consider placing electrical and electronic equipment, including power distribution panels, EHTS contactor panels, MCCs including VSD cabinets, special instruments transmitters, and MCS remote I/O cabinets inside air-conditioned prefabricated walk-in buildings to protect the equipment and facilitate maintenance. Prefabricated buildings should be considered for the:

- Receiver tower structure just below the receiver deck servicing the receiver, crane, and BCS.

- Receiver tower structure at the SGS deck level servicing the SGS pumps and EHTS contactor panels.

- Receiver tower structure servicing the TSS, RS, and SGS Motors/VSDs, and EHTS systems.

- EPGS equipment and other BOP equipment.

- TSS \& CS at grade servicing TSS immersion heaters, CS, and power distribution area.

- CS field at the locations of the BCS and IR cameras.

- BOP area servicing cooling towers.

\subsubsection{Balance of Plant to Collector System Interface Requirements}

The BOP receiver tower structure mounts and supports BCS target.

\subsubsection{Balance of Plant to Receiver System Interface Requirements}

The BOP provides the tower structure upon which the RS equipment is mounted and supported. There are specific requirements for tower motion and stiffness: 
- Stiffness TBD

- Load TBD

- RSs

- Wind loads TBD

The BOP:

- Provides space and structural support for RS piping, piping expansion loops, and pipe supports.

- Supports and protects RS jib crane.

- Provides an environmentally-conditioned shelter just below the RS deck that is shielded from RS nitrate salt spills/leaks, etc., to house remote MCS/BCS interface hardware.

- Defines the interface plane between the RS equipment and the BOP structure.

- Provides tower access including a combined service freight/personnel elevator.

- Provides spill protection to catch and retain RS leaks and spills.

- Provides a cooling water supply and return for cooling selected receiver instrumentation.

- Provides compressed air to the receiver inlet vessel - ullage pressurization, and to RS outlet vessel bubbler level gage.

The BOP RS tower foundation must be independent from the TSS foundation mats.

\subsubsection{Balance of Plant to Thermal Storage System Interface Requirements}

BOP provides access structures (bridging/cantilevers) tied into the RS support tower structure, which will span/hang over the tops of the TSS hot and cold salt storage tanks. This structure will support the

- RS circulation pump (cold salt tank),

- SGS circulation pump (hot salt tank),

- SGS attemperation pump (cold salt tank), and

- TSS hot tank mixer.

The access structures provide rigid support for the operating equipment. The support includes all piping, pipe supports, and power distribution raceway and equipment. It provides free and 
1 clear access clearance around the pumps for maintenance and operations, recognizing that the

2 equipment will be at temperatures in excess of $540^{\circ} \mathrm{C}\left(1000^{\circ} \mathrm{F}\right)$.

3 The BOP:

- Provides access and egress from the TSS access structures in multiple directions.

- Provides and structurally supports a crane or cranes(s) to remove and install the high temperature vertical turbine pumps from the storage tanks. The crane(s) will be able to lower and raise the pumps to grade elevation. Crane control access should be provided from grade and from the TSS access platform deck.

- Provides compressed air to the TSS bubbler level gages.

- Provides platform space for the VSD control panels, TSS, and remote I/O cabinet(s).

- BOP provides support for elements of the TSS tank air heating system.

The BOP TSS platform provides a means to access the TSS hot and cold tank interior.

\subsubsection{Balance of Plant to Steam Generation System Interface Requirements}

The BOP:

- Supports the SGS heat exchangers and provides clear space for tube bundle extraction.

- Provides space and structural support for SGS valves, insulated piping, piping expansion loops, and pipe supports.

- Provides a monorail crane to extract and insert SGS tube bundles form the SGS exchangers.

- Provides a environmental/windscreen enclosure on the receiver tower structure enclosing all deck levels where SGS equipment is located. This is required to protect personnel during night and day shift equipment maintenance operations.

\subsubsection{Balance of Plant to Electric Heat Tracing System Interface Requirements}

BOP will provide sufficient space in the initial general arrangement/plan development for EHTS panels and power distribution equipment that will not interfere with maintenance and operations access to primary equipment. The space block-outs will be sufficient to accommodate raceway, conduit, and cable runs that do not interfere with access.

\subsubsection{Balance of Plant to Master Control System Interface Requirements}

BOP hardware that may affect the operation of MCS/DCS (emits electronic noise or interference) will be shielded. 
$1 \quad$ 3.8.8 Balance of Plant to Electric Power Generation System Interface Requirements

2 BOP provides a pipeway structure between the SGS and the EPGS for feedwater, main steam, 3 and reheat steam supply and return piping. 
1 4. General Layout, Materials, and Processes

\subsection{Plant Layout}

\subsubsection{Layout for Access and Egress - Personnel Safety}

Personnel access for routine equipment and component inspections, maintenance, and for personnel egress in dealing with high temperature nitrate salt systems will take precedence over design for thermal conservation and heat loss reduction. Initial equipment layouts shall consider the following issues.

Equipment and component handling nitrate salt that can develop leaks, will develop leaks; and therefore, design provisions shall be considered in the initial equipment layout. These will impact the footprint and equipment envelopes.

Elevated equipment that may have personnel access paths underneath equipment shall be provided integral welded sealed drip pans.

Splashguards will be provided where routine horizontal access paths occur.

Egress from elevated structures shall be provided so that personnel can escape in the direction opposite to the equipment and/or component. For example: if a piece of equipment can be accessed from three sides, an egress paths shall be provide from three sides.

\subsubsection{Maintenance Access}

Working areas in and around high temperature system require that generous clearance space be provided around the equipment/components. Ideally, 360-degree access should be provided. The surface temperature and emitted thermal radiation from the equipment/component make working around extremely difficult, and normal maintenance clearances are not sufficient.

Any equipment and component requiring routine inspection and maintenance shall provide permanent provisions for access/egress, including platforms with ladders or stairs.

Initial layouts shall consider the impact of thermal insulation systems and the added clearance dimensional requirements. This includes both the thickness of the insulation and the insulated pipe supports and hangers. Normal plant design clearances are not adequate.

Refer to Section 4.7.1 for a discussion on electrical equipment layout and space allocation. 


\subsection{Mechanical and Electrical Equipment Maintenance Automation}

\subsubsection{Solar Power Tower Mechanical and Electrical Equipment}

All SPT mechanical and electrical equipment specifications will include requirements for selfdiagnostics which will be incorporated into MCS and reported through the DCS. Equipment requiring self diagnostics includes:

- CS heliostat drives.

- HCs.

- All primary and secondary electrical power distribution equipment including switchgear, transformers, motor control centers, etc.

- All mechanical rotating equipment with rotation or moving parts, including pumps, motors, fans, refrigeration units, mechanical mixers, compressors, elevators, cranes, air conditioning, diesel generators, hydraulic systems, etc.

- All unattended mechanical equipment that can develop leaks, including air handling unit coils and buried and surface tanks.

\subsubsection{Component Failure Diagnostics}

Component failure diagnostics may include bearing temperatures, internal equipment temperature, vibration sensors, high-current, ground fault, etc.

\subsection{Material Selection General}

\subsubsection{Material Requirements}

Table 4-1 specifies material requirements for piping in nitrate salt service, and for structural steel. Material specifications for steam, feedwater and other fluid and gas services are not within scope of this design guide. Material specifications for engineered equipment are covered in Section 3.0.

Table 4-1. Material Requirements for Piping in Nitrate Salt Service and Structural Steel

\begin{tabular}{|c|c|c|}
\hline Equipment/Component & Materials & $\begin{array}{l}\text { Corrosion Allowance and Re- } \\
\text { marks }\end{array}$ \\
\hline Nitrate Salt Piping $\leq 750^{\circ} \mathrm{F}\left(400^{\circ} \mathrm{C}\right)$ & & $\begin{array}{l}\text { Corrosion allowance } 0.3 \text { mm (10 } \\
\text { mils) }\end{array}$ \\
\hline Piping & Carbon Steel, ASTM A 106 Grade B & Minimum Wall Schedule 40 \\
\hline Fittings & $\begin{array}{l}\text { Welded: ASTM A234 Grade WPA or } \\
\text { WPB }\end{array}$ & \\
\hline
\end{tabular}


Table 4-1. Material Requirements for Piping in Nitrate Salt Service and Structural Steel (continued)

\begin{tabular}{|c|c|c|}
\hline Equipment/Component & Materials & $\begin{array}{l}\text { Corrosion Allowance } \\
\text { and Remarks }\end{array}$ \\
\hline Flanges & ASTM A105 & \\
\hline \multicolumn{3}{|l|}{ Valves $<$ 2in } \\
\hline$<2$ in & Forged -ASTM A105 and A351 & \\
\hline$>3$ in & Cast Steel , ASTM 216 WCB & \\
\hline Bolts & A193, Gr B7 & \\
\hline
\end{tabular}

\begin{tabular}{|c|c|c|}
\hline $\begin{array}{l}\text { Nitrate Salt Piping }>750^{\circ} \mathrm{F} \\
\left(400^{\circ} \mathrm{C}\right)\end{array}$ & & $\begin{array}{l}\text { Corrosion allowance } \\
\text { Type } 347: 0.7 \mathrm{~mm}(25 \mathrm{mils}) \\
\text { Type } 321: \text { TBD (Note } 1)\end{array}$ \\
\hline Piping & $\begin{array}{l}\text { Stainless Steel, ASTM A } 312 \\
\text { Type } 321 / 347\end{array}$ & Minimum Wall Schedule 40 \\
\hline Fittings & $\begin{array}{l}\text { Stainless Steel } \\
\text { ASTM A } 403 \\
\text { Type } 321 / 347\end{array}$ & \\
\hline Flanges & $\begin{array}{l}\text { Stainless Steel ASTM A182 Gr F321 or } \\
\text { F347 RTJ, Gray Lock Hubs, or approved } \\
\text { equal } \\
\text { Flanges per ASME B } 16.5\end{array}$ & \\
\hline \multicolumn{3}{|l|}{ Valves } \\
\hline$<2$ in & Forged ASTM A $182 \mathrm{Gr} 321$ or 347 & \\
\hline$>3$ in & Casting ASTM A 351 Gr CF8C 347 & \\
\hline Bolts & $\begin{array}{l}\text { ASTM A 193, Gr B8R w/ ASTM A194 Gr } \\
\text { 8R heavy hex nuts }\end{array}$ & \\
\hline
\end{tabular}

Structural Steel

\begin{tabular}{ll}
\hline Shapes & ASTM A 36 \\
\hline Cold Formed Steel Tubing & ASTM A 500 \\
\hline $\begin{array}{l}\text { Steel Pipe (Structural Applica- } \\
\text { tions) }\end{array}$ & ASTM A 53, Gr A or B \\
\hline
\end{tabular}

High Strength Bolts Nuts and ASTM A 325

Washers

Note 1: Corrosion allowance for type 321 stainless is TBD. Intergranular corrosion may be a concern with 321 stainless in nitrate salt services and until some additional test data is generated, a decision on selecting a pipe, forging, and plate corrosion allowance will be deferred.

\subsection{Piping, Fitting, and Pipe Support Requirements}

\subsubsection{Pipe}

\subsubsection{Pipe Connection Nitrate Salt Service}

5 Piping end connections of the following types are suitable for nitrate salt service: butt-welded

6 joints, flanged connections with RTJs, and Grayloc Hubs-type connections. Compression fit 
tings, "Swagelock type," while free of leaks during service at Solar Two, are not recommended for hazardous service. Flat face and raised face flanged connections, as well as socket welded connection, are not suitable for salt service.

\subsubsection{Pipe Schedule}

Minimum American (USA) pipe schedule for pipe sizes $51 \mathrm{~mm}(2$ in.) and greater will be Schedule 40. Minimum schedule for pipe sizes $38.1 \mathrm{~mm}$ (1.5 in.) and less will be Schedule 80. Equivalent European metric pipe sizes and wall schedules may be substituted for the American standard.

Pipe sizes $31.75 \mathrm{~mm}$ (1.25 in.), $63.5 \mathrm{~mm}$ (2.5 in.), $88.9 \mathrm{~mm}$ (3.5 in.), and $127 \mathrm{~mm}$ (5 in.) will not be used.

All pipe will be specified as seamless.

\subsubsection{Flanges}

Flanges in nitrate salt service may be of the following types: RTJ or hub-type manufactured by Reflange, (R-Con), Gray Lock, or equivalent. No other flange types will be used in nitrate salt service. All flange gaskets/rings will be nitrate salt compatible. RTJ gaskets and hub rings will be ASTM 240 Gr 304 for both low temperature and high temperature nitrate salt service.

\subsubsection{Fittings}

Butt weld fittings will be used in nitrate salt service in all pipe size ranges. Socket welded-type fitting shall not be used in nitrate salt service.

\subsubsection{Pipe Supports}

Pipe guides, anchors and hangers, and sliding supports used in nitrate salt systems have unique design issues.

- Hangers, spring hangers, and sliding supports issues are:

- Bolted strap on type supports (U-bolts, pipe clamps) with daily thermal cycling will work loose and slip and should not be used.

- Pipe rolls may be used in conjunction with high density calcium silicate insulation with insulation protection shields in addition to the stainless steel insulation jackets.

- Weld on shoes and tabs with through bolt connections are acceptable for hangers, spring hangers, and sliding support. Minimizing conduction heat loss through slide or tab will require additional insulation to reduce the thermal conduction losses. It may be necessary to EHT a portion of the sliding support to dampen out cold spots on the piping; 
however, the additional EHT may cause local hot spots on the piping that are equally as bad. The caution here is that the support design must be fully integrated with the EHT design and not handled as an afterthought.

- Pipe support, EHT, and insulation work together as an assembly and have to be designed as such. Standard insulation design details and approaches require modification.

- Pipe Anchor design issues are:

- Rigid insulation clamped on pipe anchor designs will fail after repeated daily thermal cycling and should not be used.

- A weld-on anchor tab with bolt through parallel plates with thermal insulation sandwiched between the plates to reduce conducting heat loss to the exterior are acceptable, but may require additional insulation and EHT to prevent localized salt freezing.

\subsubsection{Stud Bolts}

Stud bolts used in nitrate salt service $\geq 400^{\circ} \mathrm{C}\left(\geq 750^{\circ} \mathrm{F}\right)$ or on electrically heat traced pressure containing components will be specified as ASTM A 193, Gr B8R with ASTM A194 Gr 8R heavy hex nuts.

\subsection{Valves}

\subsubsection{Gate Valves and Globe Valves}

Gate valves will be used for isolation, vent, and drain applications. Split body globe valves will be used for throttling/flow control applications. Other valve types (ball, butterfly, etc.) have been evaluated and are not acceptable for molten nitrate salt service. The use of valves in nitrate salt service should be limited to the minimum.

Gate valve seats and disk/wedge will be stellited. Gate valves used in high-temperature nitrate salt service shall have extended bonnets. Bonnet extensions are required for high temperature salt service - refer to discussion below. SGS and RS vents and drains are operating valves and will be provided with remotely-controlled pneumatic operators.

Globe valve disk face and seats will be stellited. Salt corrosion layers may develop on plug and seats of globe valves. Split body valves move the plug away from the seat and therefore the corrosion layer should not prevent the valve from opening or closing.

\subsubsection{Valve Stem Packing Materials}

A significant development effort has been expended by SNL and from Solar Two operations on evaluating valve stem packing materials. Carbon/graphite-containing materials used by manufacturers in standard offerings - bonnet gaskets, seal rings, O-rings - are not acceptable in nitrate 
salt service. There is a single exception: valve stem packing. Note: Molten nitrate salt, an oxidizer, will react with carbon in any form and consume it.

The qualified valve stem packing for nitrate salt service consists of alternating layers of:

- Wire-reinforced graphite braid packing over a fiberglass core (Style 1200-PBI from Garlock Engineering, or Style 387I from John Crane, Inc.), and

- Fiberglass-filled Teflon ${ }^{\circledR}$ washers.

The maximum operating temperature range for this configuration is 260 to $315^{\circ} \mathrm{C}(500$ to $600^{\circ} \mathrm{F}$ ). The lower temperature limit is to prevent salt from freezing and destroying the packing by abrasion. The upper temperature limit is it to prevent the Teflon from failing. The valve stem packing will require periodic replacement regardless of what temperature it operates.

Valve body EHT and insulation design are critical to assure that the temperature ranges are maintained.

\subsubsection{Bonnet Gaskets and Split Body Gaskets}

Bonnet gaskets and split body gaskets will be either metallic ring-type joint or welded sealed spiral wound.

\subsubsection{Extended Bonnet Valves}

Valves that will be used in high temperature nitrate salt service, $\geq 400^{\circ} \mathrm{C}\left(\geq 750^{\circ} \mathrm{F}\right)$, will be specified with extended bonnets so that the valve stem packing is provided with sufficient stand-off distance from the high temperature salt. The bonnet length must be confirmed by test or analysis by the manufacturer so that the stem packing temperature does not exceed $204^{\circ} \mathrm{C}\left(400^{\circ} \mathrm{F}\right)$ without the supplemental EHT.

\subsection{Solar Power Tower and Nitrate Salt Service Instrumentation}

\subsubsection{Flow Instruments}

Vortex shedding flow meters are acceptable in cold salt service at temperatures $\leq 315^{\circ} \mathrm{C}$ $\left(\leq 600^{\circ} \mathrm{F}\right)$ and when adequate piping straight runs are proved upstream and downstream of the instrument.

NaK or HITEC XL salt pressure taps with diaphragms provide a stand-off for the temperature limited transducer. This configuration is acceptable for measuring differential pressure but still requires instrument qualification by SNL for nitrate salt service at required operating temperatures. 


\subsubsection{Temperature Instruments}

Industry standard thermowells with thermocouples will be used for fluid temperature measurements.

RS back of tube temperatures, TSS tank wall and floor temperatures, etc., will be instrumented with thermocouples spot welded directly to the component/equipment. Welding procedures must be developed and qualified for each application.

EHT temperature sensors, either thermocouple or RTD, are acceptable, but must be standardized across the entire project.

Thermocouple extension wire used with nitrate salt containing components, and specifically the RS back of panel thermocouples, must use high-temperature ceramic fiber insulation.

\subsubsection{Pressure Instruments}

Solar Two experience with line mounted pressure instruments (NaK or HITEC XL salt-filled diaphragm pressure instrumentation) was problematic. Various fixes were attempted, but resolution was never achieved.

Oil overheated in the oil-filled diaphragm sensors, affecting the accuracy of the instrument and causing vapor pressure problems.

Impedance transducer inconsistent accuracy required frequent recalibration, which affected control reliability and consistency.

A technical solution using a NaK metal, HITEC salt, or organic salt-filled diaphragm with capillary tube to the transducer/transmitter is available, but development and qualification work must be still completed. Listed below are technical attributes of each.

\subsubsection{NaK}

Requires no EHT since the NaK mixture melts at $-4^{\circ} \mathrm{C}\left(25^{\circ} \mathrm{F}\right)$. The $\mathrm{NaK}$ mixture vapor pressure is in excess of $593^{\circ} \mathrm{C}\left(1100^{\circ} \mathrm{F}\right)$. The diaphragm will be direct mounted with an RTJ WN flange to the salt header without isolation valves. There are safety-related issues with the NaK. If the capillary or diaphragm should rupture, the small quantity of liquid metal will self-ignite/oxidize.

\subsubsection{HITEC KL salt}

Coastal Chemical - composition $15 \%$ by weight $\mathrm{NaNO}_{3}, 43 \% \mathrm{HNO}_{3}$, and $42 \% \mathrm{CaNO}_{3}$ requires EHT and insulation design. Thermal analysis will have to determine the amount of insulation, EHT, and standoff. HITEC XL melts at $130^{\circ} \mathrm{C}\left(266^{\circ} \mathrm{F}\right)$ and has a maximum temperature limit of $480^{\circ} \mathrm{C}\left(900^{\circ} \mathrm{F}\right)$. There are no safety-related issues other than high temperature. The point of contact is: 
Coastal Chemical Co., LLC

3520 Veterans Memorial

Abbeville, LA 70510

Phone: (337) 898-0001

Phone: (800) 535-3862

Facsimile: (337) 892-1185

Internet: http://www.coastalchem.com/contact.html

\subsubsection{Organic salt}

Selection of appropriate organic salt and resolution of other technical issues will be required, and are similar to the $\mathrm{NaK}$ diaphragm/capillary. Initial technical data appears promising and the organic salt should be considered before the $\mathrm{NaK}$ filled system. The organic salt does not have the same safety considerations as the NaK. Point of contact for organic salts which have low freezing points and low vapor pressures at high temperature is:

Solvent Innovation $\mathrm{GmbH}$

AlarichstraBe 14-16

50679 Koln

Germany

Phone: +49-221-99990046

Facsimile: +49-221-2220341

Internet: www.solvant-innovation.de

Refer to Figure 4-1 below for a typical installation. Diaphragm replacement, if required, can easily be performed for the RS/TSS systems overnight shutdowns and for the SGS/TSS with short plant outages. The key issue is commercial availability of the instrument. This will require SNL and industry support.

\subsubsection{Direct Normal Insolation, Total Insolation, and RS Flux Instrumentation}

\subsubsection{Dual Normal Incident Pyrheliometers}

Two Normal Incident Pyrheliometers (NIPs) with a two-axis SMT 3 tracker are required to provide input to the HAC. The NIP is manufactured by Eppley Laboratory. The contact is:

The Eppley Laboratory, Inc. 12 Sheffield Avenue, PO Box 419

Newport, Rhode Island 02840 USA

Phone: 401-847-1020

Facsimile: 401-847-1031

Email: eplab@mail.bbsnet.com 


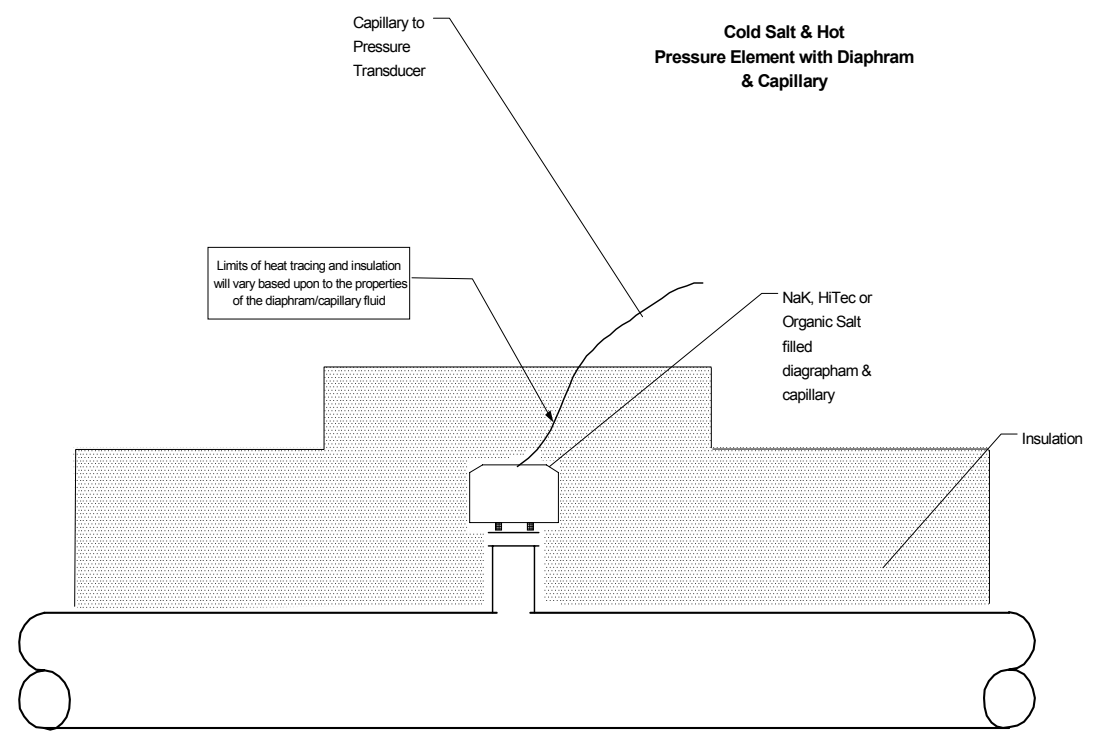

Figure 4-1. Typical Installation of Pressure Transducer

The NIP incorporates a wire-wound thermopile at the base of a tube, the aperture of which bears a ratio to its length of 1 to 10 , subtending an angle of $5^{\circ} 43^{\prime} 30^{\prime \prime}$. The inside of this brass tube is blackened and suitably diaphragmed. The tube is filled with dry air at atmospheric pressure and sealed at the viewing end by an insert carrying a $1 \mathrm{~mm}-(0.039$ in.-) thick Infrasil II window. Two flanges, one at each end of the tube, are provided with a sighting arrangement for aiming the pyrheliometer directly at the sun. Frequent "factory instrument calibration" is required; therefore, operating spares must be considered in the initial procurement.

Automatic Solar Tracker, Model SMT-3, is a two-axis, azimuth/elevation device programmed to align direct beam instruments with the normal incidence of the sun from any position on the earth's surface. Tracking is achieved using a computer program, which calculates the solar position for the time and location and transmits pulses to the drives, which then operate the two stepping motors. Stepping motors move the elevation and azimuth axes to the correct position. After initial installation, the tracker will continue to track the sun and reset during darkness. Periodic resetting of the system clock is required. This software is resident with in the HAC.

The mounting platform upon which the 2-NIPs and 1- Pyranometer are mounted must be easily accessible, level, stable, and isolated from mechanical/electrical equipment vibration. The instruments must view the sun without shading from any other structures, no matter how minor, during all daylight hours throughout the year. "Easily accessible" means that plant operations personnel will be required to make multiple daily inspections for cleanliness and operability. Stair access to an elevated platform is acceptable, whereas ladder access is not.

\subsubsection{Total Radiation Pyranometer}

While the NIP provides accurate measurements, it is subject to tracking misalignment and requires frequent calibration. As such, it may yield suspect readings, which are critical for receiver warm-up/startup. It is recommended that a less accurate, total radiation pyranometer with a ro 
tating shade band be provide to approximate the direct beam radiation. A check value on the direct normal Incident pyrheliometer measurement will be made by taking the difference between the pyranometer total radiation and diffuse radiation measurements.

The pyranometer is comprised of a circular multijunction wire-wound thermopile that has the ability to withstand severe mechanical vibration and shock. Its receiver is coated with Parson's black lacquer (non-wavelength selective absorption). This instrument is supplied with a pair of removable precision-ground and polished hemispheres of Schott optical glass. Both hemispheres are made of clear WG295 glass, which is uniformly transparent to energy between 0.285 to $2.8 \mu \mathrm{m}$. For special applications, other Schott glasses and Infrasil II quartz hemispheres are available. They included a spirit level, adjustable leveling screws, and a desiccator which can be readily inspected. The instrument has a cast bronze body with a white enameled guard disk (shield) and comes with a transit/storage case.

\subsubsection{Dual Normal Incident Pyrheliometers and Total Radiation Pyranometer Software}

Dual NIP and total radiation pyranometer software provided with the instruments will reside in the HAC.

\subsubsection{Photometers}

Refer to page 63 line 24, for RS control. The photometers are industry standard PV cells, collimators, and filters. Silicon photodiode detectors manufactured by International Light, Inc._with the following description are recommended:

- Spectral response: 200-1100 nm

- Field of view: $8^{\circ}$ with hood

- Part No Number: SED003

- Hood Number: HCS410

- Filter: QNDS2

- Cover: T2SCS280

Point of contact is:

International Light Inc.

17 Graf Road

Newburyport, MA 01950-4092

Phone: (508) 4655923

Facsimile (508) 462-0759 


\subsubsection{Level Instruments}

\subsubsection{Nuclear Level Detectors}

Nuclear level detectors are manufactured by TN Technologies, Model 5205 or equivalent, and should be used on all nitrate salt vessels operating above atmospheric pressure - specifically, the RS receiver inlet vessel. Solar Two used two $100 \mathrm{mCi}$ sources with associated detector. The instrument is sensitive to high temperature and must be protected from direct solar insolation.

Point contact is:

TN Technologies

2555 North IH-35

PO Box 800

Round Rock. Texas 78680-0800

Phone: 800.736 .0801

Phone: (512).388-9100

Facsimile: (512).388.9200

Internet: http://www.tn-technologies.com/contact.asp

\subsubsection{Bubbler Level Gauges}

Bubbler level gauges will be used on vessels or tanks operating at atmospherics pressure conditions - specifically, the TSS hot and cold nitrate salt storage tanks and the RS receiver outlet vessel. Solar Two experience indicated that bubbler-type level gages were suitable for steadystate operation; however, erroneous measurements during ullage pressure transients produced level oscillations and erratic flows from receiver pumps.

\subsubsection{Receiver Infra Red Cameras}

Receiver infra red (IR) cameras will be used based upon a Model AGEMA 550 IR camera with 3.6-5.0 micron wave length range with the following requirements:

- Detector : Focal Plane Array

- Nominal Spectral Range: approx. 3.5 to 5 microns

- Operating Temperature Range: at least -10 to $1000^{\circ} \mathrm{C}\left(14\right.$ to $1832^{\circ} \mathrm{F}$ with high-temperature filter

- Spatial resolution: approximately $256 \times 256$ or $320 \times 244$

- Dynamic Range: 12 bit

- Emittance Correction

- Cooling: Stirling cooled

- Video Output: NTSC (or S video)

- Color Viewfinder

- Zoom: 4:1

- Lenses: 
- 1 - Standard (approx 20 deg FOV)

- 1 - approx. $100 \mathrm{~mm}$ or approx. 4 degrees

- Moveable cursor

- Operable via serial remote control including remote filter change capability

- Review stored images from the camera

- Ancillary equipment should include all cables, adapters, carrying cases, batteries, and battery chargers

- Image viewing software PC Windows operating system compatible

- The recommended IR camera can be purchased from the source provide below using a brand name "AGEMA."

FLIR Systems, Inc. (FSI) 16505 S.W. 72nd Ave.

Portland, OR 97224 USA

Tel: $800-G O I N F R A$ (464-6372)

Fax: 978-901-8532

Or call: $978-901-8000$

Internet: www.FLIR.com

\subsection{Electrical Component Requirements}

\subsubsection{General Layout Issues}

\subsubsection{Electrical System Layout}

Generous clearance space between electrical hardware (raceway, conduit, panels, cabinets, junction boxes, etc.) and nitrate salt-containing equipment and components must be provided for both maintenance access to nitrate salt equipment and for protection of the electrical hardware from spills and high local ambient temperatures. OSHA Standard 0.9 to $1.2 \mathrm{~m} \mathrm{(3} \mathrm{to} 4 \mathrm{ft})$ clearances are not sufficient.

\subsubsection{Conduit and Raceway Routing}

Electrical equipment, raceway, and conduit should not be installed or routed underneath salt piping and/or equipment that can develop leaks.

\subsubsection{Splashguards and Shields}

Splashguards and shields must be considered where it is impossible to avoid contact with liquid nitrate salt. Conduit protection in and by itself is not sufficient since molten salt will conduct heat through the conduit wall and destroy the wire and cable insulation. 


\subsubsection{Cable and Raceway Materials}

\subsubsection{Electrical Conduit}

Electrical conduit material must be compatible with nitrate salt service. Rigid metallic conduit and fittings, and extreme high/low temperature flex should be specified. Note that conduit in and by itself will not provide sufficient protection from molten salt spills.

\subsubsection{Cable and Wire}

The space behind the receiver panels, above the receiver to and including the maintenance crane, and directly below the receiver must specify high-temperature wire and cable rated insulation $302^{\circ} \mathrm{F}\left(150^{\circ} \mathrm{C}\right)(\mathrm{TBD})$ as normal part of the design. Conduit and duct bank will provide solar insolation shielding where "heliostat spillage" can focus on conduit/raceway. The conduit by itself does not provide sufficient protection.

\subsubsection{Enclosures, Junction Boxes, Panels, Cabinets, Motors, and Motor Housings}

\subsubsection{Enclosure Type}

Electrical enclosures, junction boxes, panels, and cabinets for CS, RS, TSS, and SGS systems will be specified as NEMA $4 / 4 \mathrm{X}$ with compressible silicon rubber gaskets rated for $204^{\circ} \mathrm{C}$ $\left(400^{\circ} \mathrm{F}\right)$. Enclosures will be painted exterior high gloss white.

\subsubsection{Motor Enclosures}

Motor enclosures will be specified for the intended service as either TEFC or TENV (smaller horsepower rating). Motor external coatings will be evaluated to determine if a similar exterior high gloss white will also reduce absorbed energy.

\subsubsection{Motor Insulation}

Motors used in and around equipment containing molten nitrate salt will be specified with hightemperature motor insulation (Class $\mathrm{H}$ Insulation System rated for $135^{\circ} \mathrm{C}\left(275^{\circ} \mathrm{F}\right)$ ).

\subsubsection{Enclosure Thermal Protection and Cooling}

The electrical gear/electronic component housed within each enclosure will be evaluated to determine the maximum ambient temperature at which each component will operate on a continuous basis. This temperature may lower than the stated maximum temperature. The design ambient temperature near operating nitrate salt-containing equipment around the TSS and SGS at Solar Two exceeded $67^{\circ} \mathrm{C}\left(150^{\circ} \mathrm{F}\right)$ and was significantly higher in the volume behind the RS panels. If walk-in air-conditioned enclosures are not provided under the BOP, supplemental cooling systems may be required to protect the equipment. If enclosure cooling is required, the BOP service water system should be used in conjunction with a standard cooling coil design on a 
SPT-wide basis, rather than using individual electrical manufacture unique systems. A standard system will simplify O\&M requirements.

\subsubsection{Power System Reliability}

Refer to Section 5.2 for requirements for an RS protection trade study. As a minimum, criticalMCS control functions will be protected by a UPS. Secondly, National Fire Protection Association (NFPA) life safety code requirements may dictate that an emergency diesel generator be used to direct drive fire pumps.

\subsection{Equipment and Piping Thermal Insulation}

\subsubsection{Economic Insulation Thickness}

Piping and equipment insulation thicknesses will be determined through economic analysis so that the insulation thickness selected for each application results in the lowest sum of the capital cost of the insulation plus the capital cost of heat loss. The capital cost of the heat loss varies as a function of insulation thickness and be will derived from converting heat loss to an "annualized cost of lost power production" using a levelized capital carrying charge and plant efficiency. The annualized cost of lost power production should be based upon the price the SPT sells energy to the grid. "Each application" means each pipe diameter as a function of temperature and operating time.

In addition, the insulation thickness must be sufficient to prevent the insulation jacket from exceeding a surface temperature of $\left(60^{\circ} \mathrm{C}\left(140^{\circ} \mathrm{F}\right)\right.$ TBD US OSHA $)$ - personnel protection $)$.

Based upon Solar Two experience, calculated heat loss values used to determine insulation thickness should be increased by $30 \%$ for valves and components with complex geometries and by $5 \%$ for piping systems.

\subsubsection{General Insulation System Design}

\subsubsection{Typical Insulation System Cross Section}

The typical insulation system cross section for piping and equipment will be as follows.

First Layer. $304 / 316$ stainless steel foil, $0.08 \mathrm{~mm}$ - (0.003 in.-) thick wrapped and tie wired/ banded over all EHT elements and temperature sensors to prevent the thermal insulation from coming in between the EHT element and the electric heat traced component. If insulation works between tracer resistance heating element and traced component, resistance burn element will result.

Second Layer. Mineral fiber blanket $25 \mathrm{~mm}$ (1 in.) thick, $8 \mathrm{lbs} / \mathrm{ft}^{3}\left(128 \mathrm{~kg} / \mathrm{m}^{3}\right)$ density minimum to provide a flexible compressive insulation layer between stainless steel foil and the third layer of rigid insulation. This layer is required to prevent radial gaps from developing as the piping system or equipment thermally cycles (expands and contracts). 
Third Layer. Multiple alternating layers of preformed or block expanded perlite insulation. Multiple layers are staggered both axially and radially so there is no direct path seam exposed from the innermost layer to outermost layer.

Calcium silicate insulation will be substituted for perlite in situations where the insulation system will be exposed to exterior loading and/or personnel foot traffic to provide compressive strength.

Vertical vessel shells should be insulated with multiple layers of mineral wool blanket in lieu of the expanded perlite block. Horizontal vessels, equipment, and heat exchangers will be insulated with either expanded perlite block or calcium silicate insulation cut to conform the head/vessel/equipment geometry. Multiple staggered layers will be used to prevent any continuous seams from outer to inner layers.

High temperature insulations contract when heated to their service temperature directly opposite to the piping, vessel, or exchanger shells. Expansion joints filled with a compressible mineral fiber are required to accommodate this differential expansion both axially and radially. A staggered joint profile will be used to prevent seams from opening.

Fourth Layer. 304 stainless steel jacket, 0.4 mm- (0.016 in.-) thick without moisture barrier installed and banded with spring expansion clips as required over perlite for weather and mechanical protection. High-temperature mastics may be used in situations where stainless steel jacketing or preformed shapes are not available.

\subsubsection{Adhesives and Mastics}

High temperature refractory adhesives and mastics compatible for the temperature range maximum $565^{\circ} \mathrm{C}\left(1050^{\circ} \mathrm{F}\right)$ must be specified.

\subsubsection{Removable Insulation Housings}

Insulation and the insulation jacketing will be used on equipment, valves, instrumentation, and other tank- or vessel-mounted devices requiring access for periodic maintenance or calibration. These will be designed so that the insulation and jacket can easily being removed and reinstalled as a single unit multiple times. The design approach will consider suitcase-type latches, quick release pins, etc. Fasteners that thread or screw directly into the jacket or insulation are not acceptable. The removable/replaceable insulation housing shall be uniquely designed for the application, including the EHT interface. The housings will be test-fitted with the EHT system in place and demonstrate operation at the operating temperature. The permanent insulation system abutting the removable housing will be designed to accommodate the removable housing and, if necessary, compressible insulation spacers may be used at the interface. 


\subsubsection{Pipe Support, Anchor, and Guide Insulation}

Design approaches for sliding supports, hangers, and anchors must consider daily thermal cycling. Typical insulated stand off designs do not stand up under repeated thermal cycling.

\subsubsection{Flange Insulation}

All flanges and hubs in nitrate salt service will be insulated with removable insulation housings to allow for periodic inspection.

\subsection{Nitrate Salt Handling and Melting}

\subsubsection{Nitrate Salt Handling and Melting Equipment}

The TSS design will plan for and accommodate nitrate salt handling and melting in the hot salt tank either as a permanent plant installation or as a one-time subcontracted service. The handling and melting process design should consider the following issues.

Premixed bulk prilled industrial grade nitrate salt is supplied in one MT "super sack." Substantial area is needed to store the thousands of super sacks. The delivery and off-loading period will span several months.

This is a continuous materials handling process requiring forklifts, front-end loader, hopper, conveyers, staged propane fired process heaters, tanks, pumps, piping EHT, valves, and packaged control system. If NOX off-gas must be collected, neutralized, and disposed of an additional scrubber column, effluent tanks, chemical neutralization pumps, and neutralization chemical storage equipment must be provided.

While the super sacks are sealed, moisture will wick into the nitrate salt, causing the prill to consolidate in to a large block mass. This will require addition steps and a hammer mill to breakup the blocks into conveyer handable sizes.

The melting process is a 24 hour/7-day-per-week operation until it is completed.

Valves, instruments, and other components compatible with nitrate salt service may be provided to the subcontractor on a loan basis since these have long delivery lead times.

The NOX off-gassing process, see below, requires stainless steel components and piping wherever moisture can combine with the NOX to form nitric acid-vents, scrubber column, effluent pumps, etc.

A critical time period in the melting process occurs with the initial tank thermal conditioning and

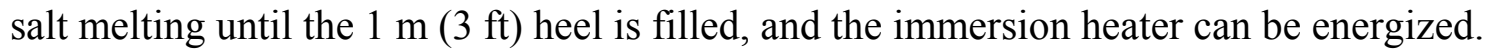

The melting process is similar to petroleum tertiary heavy oil recovery, and a subcontractor experienced with portable fired process heaters from this industrial segment may be capable of 
handling the work. A project cost trade must be developed to determine whether permanent plant or subcontract service is the lowest cost.

\subsubsection{Off-Gassing NOX}

The nitrate salt NOX off-gassing process is discussed below.

Industrial grade nitrate salt may contain trace amounts of $\mathrm{Mg}\left(\mathrm{NO}_{3}\right)$ (Solar Two was $0.05 \%$ by weight) which decomposes during the melting process to $\mathrm{NO}_{2}(\mathrm{NOX})$ and $\mathrm{MgO}$ when the salt temperature exceeds $896^{\circ} \mathrm{F}\left(480^{\circ} \mathrm{C}\right)$. This is a one-time reaction and occurs over relatively long period of time both as the salt is initially being melted and as it resides in the TSS hot tank. On Solar Two, the reaction took approximately two months to complete and the NOX was vented directly to the atmosphere.

Disposal options available are (1) air-dilute the NOX and discharge it into the atmosphere, and (2) scrub the gas stream, neutralize it, and dispose of the effluent. Local, state, regional and/or federal environmental regulations may not permit the direct release of the NOX, making option (2) the only viable option.

As a secondary issue, moisture in the air will cause the to $\mathrm{NOX}$ form nitric acid $\left(\mathrm{HNO}_{3}\right)$ in high enough concentrations to severely corrode system equipment. Therefore, the direct disposal method must discharge the gas stream so that it does not drift through the SPT infrastructure (RS tower structure, control building, etc.).

Salt-melting equipment must be compatible with nitrate salt (oxidizing material) and NOX. Vents, stacks, and components must be selected that are compatible. Vent stack elevation must be selected to assure that the off-gas is directed away from personnel and equipment.

The Solar Two procedures heated the melted salt to $540^{\circ} \mathrm{C}\left(1000^{\circ} \mathrm{F}\right)$ to accelerate the off gassing process. This was done in parallel with the loading process at Solar Two using the immersion heaters to provide supplemental heating. The process took approximately 2.5 months.

\subsubsection{Safety}

Safety is a major concern whether the handling and melting process is performed with permanent plant equipment or by subcontract. If the work is subcontracted, the solicitation must require that the bidder address safety both in initial design, selection of materials, and during operations. There are multiple personnel and equipment hazard issues that must be addressed, including:

- Hazardous high temperature processes that will range from ambient to $540^{\circ} \mathrm{C}\left(1000^{\circ} \mathrm{F}\right)$.

- Nitrate salt is an oxidizer and organic materials (wood, carbon containing components, vehicle tires, wire and cable insulation, etc.) that, when exposed to the molten salt, will burn/selfignite. 
- Off-gassing NOX and nitric acid are personnel hazards. If the NOX is vented, it has to be diluted and directed away from personnel. Even low concentrations of NOX will result in respiratory system distress damaging mucus membranes and lungs. Process equipment and components must be selected that are corrosion-resistant to nitric acid attack. 


\section{Trade Studies}

\subsection{Elimination of the Receiver Inlet Vessel}

Evaluate and determine through a trade study the technical feasibility of eliminating the receiver inlet vessel.

The objective is to simplify RS design by eliminating inlet vessel and high-pressure air system and associated piping, valves, EHT, controls, etc., by relying upon the cold salt pump with its VSD to provide necessary flow control for startup and operation of the receiver. The flow control valves for the north and south receiver flow loops, fill and drain valves and piping, and flow bypass between the riser and downcomer will remain; however, options should be evaluated.

The focus of the study is on RS controls, process, and hydraulics. The study shall assume that one cold nitrate salt pump is reliable and will maintain salt flow through the receiver. This study will evaluate the system controls and system design issues involved in eliminating the inlet vessel independent of the receiver protection issues. Receiver protection is the subject of a separate study in Section 5.2.

The current receiver design baseline incorporates a receiver inlet vessel sized for 60 seconds of resident cold salt storage, which, under the Solar Two design, allowed an emergency diesel generator to come on line to start a spare cold pump to maintain salt flow through the receiver. The Solar Two heliostats were not protected by a UPS and their HCs had volatile memories which required re-initialization of each $\mathrm{HC}$, a 30-minute-plus process. A technical solution was derived based pump sparing due to high cost of replacing/modifying approximately $2000 \mathrm{HC}$. The heliostat field design basis is for non-volatile memories.

\subsection{Receiver Protection}

Provide receiver protection under loss of nitrate salt flow. Evaluate options to protect the entire facility in the event of a power outage with secondary emphasis on protecting the receiver resulting from a loss of salt flow, e.g., cold salt circulation pump failure.

\subsubsection{Primary Objective}

Address the entire facility emergency power requirements and determine what is necessary to satisfy overall site operational and safety requirements. UPS and Emergency Diesel Backup power may be required for fire protection, MCS reliability, critical air conditioning loads, and security. The study shall address code compliance requirements, operational requirements, voltage, services, durations, etc. 


\subsubsection{Secondary Objective}

A secondary objective of the study is receiver protection in the event of a loss of the cold salt pump, loss of power, or loss of salt flow. RS design basis is for one cold salt pump, which will result in a single point of failure. This requires that heliostats move to a defocused position. Only 1 to 2 degrees of movement is required starting from the outer ring and moving inwards. Determine if it is technically feasible to command the heliostats to accomplish this with the specified time duration. After the initial 1 to 2 degrees, the heliostat would be moved to a stowed safe position. The time to do this and how should be included in this study. Also note that the heliostat motor drives are small, approximately $1 / 3 \mathrm{hp}(0.25 \mathrm{~kW})$, and the power distribution system must accommodate the in rush current for motor starting.

\subsubsection{Receiver Protection Requirement Basis}

Following a loss of salt flow, the temperature of a receiver tube will rise rapidly. The tube will suffer permanent damage when the combined thermal and hydraulic stresses equal the yield stress and the tube plastically deforms. A worst case analysis will need to be performed to examine a tube in a region of the highest flux and fluid pressure, i.e., on the north side of the receiver at the equator. A calculation for the time required for plastic deformation will involve the following:

- incident flux,

- radiation and convection losses from the tube surface,

- thermal mass of the tube and salt,

- energy absorbed in salt decomposition reactions,

- compressive tube stresses due to the incident flux,

- hydraulic pressure decay following the loss of salt flow,

- tensile tube stresses due to hydraulic pressure, and

- tube yield stresses as a function of temperature.

The resulting time required for plastic deformation with margin will establish the time basis for which the heliostats must be defocused from the receiver.

\subsubsection{Protection System Reliability}

Protection system reliability shall be optimally 0.99999 . (TBD)

\subsubsection{Receiver Protection Options}

Receiver protection options may include, but are not limited to:

- Pressurized inlet vessel with sufficient volume and driving pressure to ensure 60 seconds of salt flow through the receiver until the heliostats can be defocused using emergency power source, e.g., diesel, UPS. 
- UPS, emergency diesel generator, or a combination.

- Heliostats failsafe mechanism on loss of power or pump.

- Ceramic curtain that drops over or is pulled over the receiver.

- Spare pump with all the valves, piping, and EHT.

\subsection{Elimination of the Receiver Outlet Vessel}

The objective is to simplify the RS design by eliminating the outlet vessel, level control, and throttling valve by relying on pressure drop (line losses) in the downcomer piping system to dissipate the liquid salt static head from the top of the receiver to the hot salt storage tank. The hot salt will fall a distance in excess of $100 \mathrm{~m}(300 \mathrm{ft})$ before it enters the hot salt storage tank.

The focus of the study is upon using piping friction losses, a passive system design, rather that an active throttling valve, to dissipate the static head energy:

$$
\mathrm{h}_{1}=\left(\mathrm{f}^{*}(\mathrm{~L} / \mathrm{D})^{*} \mathrm{v}^{2} / 2 \mathrm{~g},\right. \text { Darcy Equation, }
$$

where

$$
\begin{aligned}
& \mathrm{h}_{1}=\text { head loss }(\mathrm{ft}) \\
& \mathrm{f}=\text { friction factor (dimensionless) } \\
& \mathrm{L}=\text { length }(\mathrm{ft}) \\
& \mathrm{D}=\operatorname{diameter}(\mathrm{ft}) \\
& \mathrm{V}=\operatorname{velocity}(\mathrm{ft} / \mathrm{sec}) \\
& \mathrm{g}=\text { gravitational constant }\left(\mathrm{ft} / \mathrm{sec}^{2}\right)
\end{aligned}
$$

Solar Two experience with valves in nitrate salt service $290^{\circ} \mathrm{C}$ or $565^{\circ} \mathrm{C}\left(550^{\circ} \mathrm{F}\right.$ or $\left.1050^{\circ} \mathrm{F}\right)$ concludes that if valves can be eliminated, long-term maintenance/operating costs are reduced. Nitrate salt valves are problematic - a continuous source of leaks, recurring problems with stem packing failure, jamming, accelerated ware, salt freezing, etc. Do not include evaluation criteria encompassing investigating valve types, stem packing materials, thermal protection options, etc.

This study shall investigate from a physical design perspective low-cost passive solutions to dissipate head using the following guidelines:

- No prefill of the piping system down comer at startup.

- Operate over the entire range of flows conditions from minimum to maximum.

- Allowing a stepped reduction in head so that the salt velocity (impulse load) does not cause excessive piping stresses from changes in line direction or excessive impact loads on pipe supports/anchors. 
- Use innovative design techniques, including stage flow through small line sizes, reducers, elbows, line inserts, multiple expansion loops, etc., to dissipate heat.

- Determine whether the atmospheric vent is a necessary requirement.

- If the atmospheric vent is required, the study must identify the upset conditions that could result in a vent overflow and make recommendations on how to prevent and/or contain the salt.

- The intent is to compare the cost of these options against the capital and operating costs of an outlet vessel with throttling valve. Throttling valve reliability and the impact to plant operating costs for the valve stem packing replacement on six-month or less intervals was the Solar Two experience. Operating cost must be included in the assessment. 


\section{References}

\begin{tabular}{|c|c|c|}
\hline Doc No. & Title and Revision & $\begin{array}{l}\text { Document } \\
\text { Date }\end{array}$ \\
\hline- & $\begin{array}{l}\text { Heat Transfer, Principles of, } 2^{\text {nd }} \text { Ed., Frank Kreith, International } \\
\text { Text Book Co. }\end{array}$ & 1966 \\
\hline- & $\begin{array}{l}\text { Thermal Insulation, John F. Malloy, Van Nostrand Reinhold } \\
\text { Company, New York }\end{array}$ & 1969 \\
\hline Catalog PH87 & Pipe Hangers, Grinnell Corporation, Providence RI & 1987 \\
\hline FSCM A10772 & $\begin{array}{l}\text { Collector Subsystem Requirements, Solar One Heliostats, Rev } \\
\text { E }\end{array}$ & 18 Jan 85 \\
\hline $\begin{array}{l}\text { ASME Tech- } \\
\text { nical Paper }\end{array}$ & $\begin{array}{l}\text { Automatic Control of The Solar Two Receiver, Gregory J, Kolb, } \\
\text { Sandia National Laboratories \& Dan Saluta, formerly of Bechtel } \\
\text { National Inc., Copyright } 1999\end{array}$ & 1999 \\
\hline $\begin{array}{l}\text { ASME Tech- } \\
\text { nical Paper }\end{array}$ & $\begin{array}{l}\text { Methods for reducing Parasitic Energy Consumption Associated } \\
\text { with Use of Molten salt at the solar Two Power Plant, Gregory J } \\
\text { Kolb, Sandia national Laboratories, Proceedings of the } \\
\text { ASES/AIA and ASME (Solar 2000), Copyright } 2000\end{array}$ & 2000 \\
\hline $\begin{array}{l}\text { ASME B\&PV } \\
\text { Code }\end{array}$ & $\begin{array}{l}\text { Code Case N-47-29, Section III (Nuclear Power) of the ASME } \\
\text { B\&PC Code, December } 1990\end{array}$ & 1990 \\
\hline $\begin{array}{l}\text { SAND 86- } \\
8009 \text { UC 62a }\end{array}$ & $\begin{array}{l}\text { A Handbook for Solar Central Receiver Design, Patricia K. Fal- } \\
\text { cone, Sandia National Laboratories Livermore }\end{array}$ & Dec 1986 \\
\hline 30C-R-013 & $\begin{array}{l}\text { Topical Report on the Lessons Learned, Project History, and } \\
\text { Operating Experience, Solar Two Project, Daggett, California }\end{array}$ & 5 Nov 99 \\
\hline Catalogue 106 & McMaster-Carr Supply Company - Catalogue 106 & $\mathrm{~N} / \mathrm{A}$ \\
\hline $\begin{array}{l}\text { Technical Pa- } \\
\text { per No. } 410\end{array}$ & Flow of Fluids (through Valves, Fittings and Pipe) Crane Co. & 1965 \\
\hline $\begin{array}{l}\text { Design Basis, } \\
21948\end{array}$ & $\begin{array}{l}\text { Solar Two Design Basis Document for Solar Two Project, Dag- } \\
\text { gett, California, Rev } 2\end{array}$ & 25 Feb 94 \\
\hline SAND92-7009 & $\begin{array}{l}\text { Wind Load Design Methods for Ground Based Heliostats and } \\
\text { Parabolic Dish Collectors, Sandia National Laboratories Report, } \\
\text { J. A. Peterka and R. G. Derickson }\end{array}$ & Sep 1992 \\
\hline
\end{tabular}




\section{Distribution}

Mr. Donald Aitken

Union of Concerned Scientists

2625 Alcatraz Ave., \#505

Berkeley, CA 94705-2702

Dr. Daniel J. Alpert

Senator Bingaman's Office

SH 703, 2nd \& Constitution

Washington, DC 20510

Mr. Ian Andrews

PacifiCorp

Utah Power Generation Engineering

1407 West North Temple

Salt Lake City, UT 84140-0001

Mr. Doug Bailey

Nevada Power Co.

P.O. Box 230, MS 25

Las Vegas, NV 89151

Daniel L. Barth

Nagle Pumps, Inc.

1249 Center Avenue

Chicago Heights, IL 60411

Mr. Bud Beebe

Sacramento Municipal Utility District 6201 'S' St.

P.O. Box 15830

Sacramento, CA 95852-1830

Jose Benevente Sierra

Avda. del Puerto N 1-6

11006 Cadiz

Spain

Jerry Berquist

Southern California Edison Co.

300 N. Lone Hill Avenue

San Dimas, CA 91773
Manuel J.Blanco Muriel

CIEMAT - PSA

Apartado 22

E-04200 Tabernas (Almeria)

Spain

Dan Brake, P.E.

FPL Energy, Inc.

6952 Preston Avenue

Livermore, CA 94550

Mr. Robert A. Briffett

Los Angeles Dept. of Water and Power

P.O. Box 111, Room 1129

Los Angeles, CA 90051-0100

Gary D. Burch

U. S. Department of Energy EE-11

1000 Independence Avenue SW

Washington, DC 20585

Mr. Barry L. Butler

Science Applications International Corp.

Room 2043, M/S C2J

10260 Campus Point Dr.

San Diego, CA 92121

Mr. John Carstensen

Idaho Power

$1221 \mathrm{~W}$. Idaho

MS CHQ-4

Boise, ID 83702

Mr. Gilbert E. Cohen

Duke Solar

2101 - 115 Westinghouse Blvd.

Raleigh, NC 27604

Walter E. Collier

Boeing Company

499 Boeing Blvd., MC JW-63

P.O. Box 240002

Huntsville, AL 35824-6402 
David L. Dean

Boeing Company

499 Boeing Blvd.

PO Box 240002

Huntsville, AL 35824-6402

John C. Dewey

Pitt-Des Moines, Inc.

9719 Lincoln Village Drive, Suite 301

Sacramento, CA 95827

David Engberg

Pacificorp

825 NE Multnomah

Portland, OR 97232

E. A. Fletcher

University of Minnesota

1111 Church Street, SE

Dept. of Mech. Engr.

Minneapolis, MN 55455

Scott D. Frier

KJC Operating Company

41100 Highway 395

Boron, CA 93516-2109

Bobi Garrett

National Renewable Energy Laboratory

1617 Cole Blvd.

Golden, CO 80401-3393

Mr. Ranji George

South Coast AQMD

21865 Copley Drive

Diamond Bar, CA 91765

Mr. Dave Gorman

Advanced Thermal Systems, Inc.

5031 W. Red Rock Drive

Larkspur, CO 80118
Mr. William R. Gould, Jr.

Nexant

45 Fremont St., 7th Floor

San Francisco, CA 94105-2210

Mr. Tom M. Griffin

Boeing Company

P.O. Box 582808

Tulsa, OK 74158

Ignacio Grimaldi Pastoril

Ghersa

Avda. del Puerto N 1-6

11006 Cadiz

Spain

Pedro Grimaldi Pedrosa

Avda. del Puerto N 1-6

11006 Cadiz

Spain

Mr. Jose Gutierrez

Los Angeles Dept. of Water and Power

111 North Hope Street, Room 648

Los Angeles, CA 90012

Ms. Mary Jane Hale

National Renewable Energy Laboratory

1617 Cole Blvd.

Golden, CO 80401-3393

Larry Hamlin

Southern California Edison Co.

300 N. Lone Hill Avenue

San Dimas, CA 91773

Herb Hayden

Pinnacle West Capital Corporation (APS)

400 N. Fifth Street, MS 8931

Phoenix, AZ 85004

Mats E. Hellstrom

Queue Systems, Inc.

1800 St. Julian Place, Suite 2000

Columbia, SC 29204 
Dr. Arlon Hunt

Lawrence Berkeley Laboratory

University of California

MS 90-2024

One Cyclotron Road

Berkeley, CA 94720

Mr. Gus Hutchison

Solar Kinetics, Inc.

10635 King William Drive

P.O. Box 540636

Dallas, TX 75354-0636

Micel E. Izygon, PhD

I-Net

NASA/Johnson Space Center

Software Technology Branch - MC BT2

NASA Rd. 1

Houston, TX 77058

Mr. Paul Jaster

3M - Solar Optics Program

3M Center, Bldg. 225-2N-06

St. Paul, MN 55144-1000

Mr. Alexander Jenkins

California Energy Commission

Energy Technology Development Div. R\&D

Office

1516 9th Street, MS-43

Sacramento, CA 95814-5512

Peter Johnston

Arizona Public Service

400 N. 5th Street

Phoenix, AZ 85072

Ron Judkoff

National Renewable Energy Laboratory

1617 Cole Boulevard

Golden, CO 80401-3393
Mr. David W. Kearney

Kearney \& Associates

PO Box 2568

Vashon WA 98070

Mr. Bruce Kelly

Nexant

45 Fremont St., 7th Floor

San Francisco, CA 94105-2210

Jim Kern

U. S. Department of Energy EE-11

1000 Independence Ave., SW

Washington, DC 20585

Michael J. Kiley

Boeing Company

6633 Canoga Ave. MC FA-66

P.O. Box 7922

Canoga Park, CA 91309-7922

Kurt Klunder

Klunder Consulting

4498 Larchmont Ct.

Dumfries, VA 22026

R. LeChevalier

Boeing Company

Energy Technology Engineering Center

P.O. Box 1449

Canoga Park, CA 91304

Mr. Mark Lichtwardt

U.S. Bureau of Reclamation

Code D-8230

P.O. Box 205007

Denver, CO 80225

Mr. Bob Litwin

Boeing Company

6633 Canoga Avenue

PO Box 7922 - Mail Code LA38

Canoga Park, CA 91309-7922 
W. Marlatt

Boeing Company

Rocketdyne Division

6633 Canoga Avenue

P.O. Box 7922

Canoga Park, CA 91309-7922

Larry Matthews

New Mexico State University

Box 30001, Dept. 3449

Las Cruces, NM 88003-0001

Michael W. McDowell

Boeing Company

6633 Canoga Ave. MC T038

P.O. Box 7922

Canoga Park, CA 91309-7922

Mr. Mark Mehos

National Renewable Energy Laboratory

1617 Cole Boulevard

Golden, CO 80401-3393

M. Merrigan

Los Alamos National Laboratory

P.O. Box 1663, MS J576

Los Alamos, NM 87545

Jan Miller

Salt River Project

1600 N. Priest St.

Tempe, AZ 85281

Mr. Doug Morris

Electric Power Research Institute

P.O. Box 10412

3412 Hillview Avenue

Palo Alto, CA 94303

Peter G. Mueller

U.S. Department of Energy

Nevada Operations Office

P.O. Box 98518

Las Vegas, NV 89193-8518
Mr. Jay Mulki

Hawaiian Electric Company

P.O. Box 2750

Honolulu, HI 96840-0001

James Nagle

Nagle Pumps, Inc.

1249 Center Avenue

Chicago Heights, IL 60411

Mr. Don Osborne

Sacramento Municipal Utility District

6201 'S' St., P.O. Box 15830

Sacramento, CA 95852-1830

Mr. Ernie Palomino

Salt River Project

P. O. Box 52025

Mail Station ISB664

Phoenix, AZ 85072-2025

Terry Peterson

EPRI

3412 Hillview Avenue

Palo Alto, CA 94304

Lizana K. Pierce

Dept. of Energy/GFO

1617 Cole Blvd.

Golden, CO 80401-3393

Faith Puffer

Tech Reps

5000 Marble NE

Suite 222

Albuquerque, NM 87110

Mr. James E. Rannels

U. S. Department of Energy EE-11

1000 Independence Avenue SW

Washington, DC 20585 
Dale Rogers

Boeing Company

6633 Canoga Avenue

PO Box 7922 - Mail Code LA38

Canoga Park, CA 91309-7922

Manuel Romero Alvarez

CIEMAT - Madrid

Institudo de Energias Renovables

Avda. Complutense, 22

E-28040 Madrid

Spain

Tommy Rueckert

U. S. Department of Energy EE-11

1000 Independence Avenue SW

Washington DC 20585

Mr. D. A. Sanchez

U.S. Department of Energy/AL

P.O. Box 5400

Albuquerque, NM 87115

Mr. Scott Sklar

Stella Group, Ltd.

733 15th Street, NW Suite 700

Washington, D.C. 20005

Glenn Strahs

U. S. Department of Energy EE-11

1000 Independence Avenue, SW

Washington, DC 20585

Steven E. Taylor

Southern California Edison Co.

2131 Walnut Grove Ave.

Rosemead, CA 91770

Mr. Robert Thomas

Advanced Thermal Systems, Inc.

5031 W. Red Rock Drive

Larkspur CO 80118-9053
Tom Tracey

6922 S. Adams Way

Littleton, CO 80122

Dr. Lorin Vant-Hull

University of Houston

Physics Department 5506

4800 Calhoun Road

Houston, TX 77204-5506

Mr. Byron J. Washom

Spencer Management Associates

P.O. Box 724

Diablo, CA 94528-0724

Mr. Tim Wendelin

National Renewable Energy Laboratory

1617 Cole Blvd.

Golden, CO 80401-3393

Mr. David White

Solar Kinetics, Inc.

10635 King William Drive

P.O. Box 540636

Dallas, TX 75354-0636

John White

Queue Systems, Inc.

1800 St. Julian Place, Suite 2000

Columbia, SC 29204

Mr. Bob Wichert

Sacramento Municipal Utility District

6201 'S' St., P.O. Box 15830

Sacramento, CA 95852-1830

Mr. Curtt N. Wilkins

U.S. Department of Energy

1309 Barnes Drive

Arlington, TX 76013

Mr. Frank (Tex) Wilkins

U. S. Department of Energy EE-11

1000 Independence Avenue, SW

Washington, DC 20585 
4 Mr. Alex Zavoico

Nexant

45 Fremont St., 7th Floor

San Francisco, CA 94105-1895

MS 0131 James Chavez, 12121

4 MS 0703 James Pacheco, 6216

MS 0703 Scott Jones, 6216

MS 0703 Craig Tyner, 6216

MS 0703 Hugh Reilly, 6216

MS $0704 \quad$ Marjorie Tatro, 6200

MS 0752 Earl Rush, 6218

MS 1127 Chris Cameron, 6215

MS 1127 Mike Edgar, 6215
MS 1127 Bill Kolb, 6215

MS 1127 Solar Tower Library

MS 1425 Bob Bradshaw, 8722

MS 9004 Dan Dawson, 8746

MS 9014 Scott Faas, 2271

MS 9404 Steve Goods, 8725

1 MS 9018 Central Technical

Files, 8945-1

2 MS 0899 Technical Library,

9616

1 MS 0612 Review and Approval

Desk, 9612 